\title{
4 Ökosysteme, Landnutzung und Biodiversität
}

\section{1 Ökosysteme und planetare Grenzen}

Johann Zaller

Institut für Zoologie,

Department für Integrative Biologie und Biodiversitätsforschung (DIB)

johann.zaller@boku.ac.at

\subsubsection{Grundlegendes zu Ökosystemen}

Ökosysteme setzen sich aus belebten (biotischen) und unbelebten (abiotischen) Komponenten zusammen, die über Ökosystemprozesse miteinander verbunden sind. Hier stehen also Organismen (Pflanzen, Tiere, Mikroorganismen) in Wechselbeziehung mit ihrer Umwelt. Die Wechselbeziehungen zwischen den verschiedenen Komponenten können sich gegenseitig positiv oder negativ beeinflussen (Smith und Smith 2009). Grundsätzlich wird zwischen natürlichen Ökosystemen (z.B. tropische Regenwälder, boreale Wälder, Hochgebirge, Wüsten) und menschlich geprägten Ökosystemen (z.B. Agroökosysteme, Ökosystem Stadt) unterschieden. Global gesehen treten starke Wechselbeziehungen zwischen verschiedenen Ökosystemen auf. Alle Ökosysteme der Biosphäre sind daher mehr oder weniger menschlich beeinflusst.

Die räumliche Abgrenzung von Ökosystemen ist nicht immer leicht. Es kann grundsätzlich zwischen aquatischen (Lebensgemeinschaften im Wasser) und terrestrischen Ökosystemen (Lebensgemeinschaften an Land) unterschieden werden, jedoch gibt es, sowohl regional als auch global gesehen, Wechselbeziehungen zwischen diesen Typen. Beispielsweise ist ein aquatisches Ökosystem (z.B. ein Teich) von einem terrestrischen Ökosystem umgeben. Im Teich lebende Organismen (z.B. Amphibien, Libellen) nutzen auch die Umgebung oder werden durch Nährstoffeinträge aus den umgebenden Landökosystemen beeinflusst.

Auch die zeitliche Abgrenzung eines Ökosystems ist nicht immer eindeutig, da Ökosysteme ständig auf biologische und klimatische Einflüsse reagieren. Ökosystemprozesse sind teilweise sehr träge, und Auswirkungen können erst mit großer zeitlicher Verzögerung sichtbar werden. Beispielsweise wirken sich Sturmereignisse, die ganze Waldbestände vernichtet haben, jahrzehntelang auf Ökosystemprozesse in diesen Wäldern aus. Daraus folgt, dass die Untersuchung von Schädlingskalamitäten oder des Wasserkreislaufs in einem Wald durch vorangegangene Ereignisse beeinflusst sein kann. 


\section{4 Ökosysteme, Landnutzung \& Biodiversität}

Ein Ökosystem wird mithilfe von Naturgesetzen beschrieben, die Aussagen über Stoffund Energieflüsse machen. Die Energiebilanz eines Ökosystems hängt dabei wesentlich von der sogenannten Primärproduktion durch Pflanzen ab. In aquatischen Ökosystemen limitieren Licht und Nährstoffe die Primärproduktion, in terrestrischen Ökosystemen wirken sich besonders Temperatur und Wasserverfügbarkeit auf die Primärproduktion aus. Intakte Ökosysteme sind durch ausgeglichene Kreisläufe von Wasser, Kohlenstoff und Nährstoffen gekennzeichnet. Das Funktionieren der Ökosysteme ist wesentlich von klimatischen Faktoren abhängig, andererseits sind Ökosysteme über Wasser- und Kohlenstoffkreisläufe aber auch wesentliche Komponenten des regionalen und globalen Klimasystems.

Ökosysteme werden durch menschliche Aktivitäten direkt (durch Bergbau, Straßenbau, Landwirtschaft) oder indirekt (durch Treibhausgase, Kontamination mit Chemikalien, Plastik, Nanopartikeln, Lichtverschmutzung, Lärmverschmutzung, Freisetzung gentechnisch veränderter Organismen) beeinflusst. Da für die komplexen Interaktionen innerhalb eines Ökosystems viele physikalische, chemische und biologische Prozesse eine Rolle spielen, müssen in ökologische Studien verschiedene Wissenschaftsgebiete miteinbezogen werden (z.B. Pflanzenwissenschaften, Zoologie, Mikrobiologie, Chemie, Klimatologie, und sollen auch sozioökonomische Aspekte berücksichtigt werden, die Sozial- und Wirtschaftswissenschaften).

\subsection{2 Ökosysteme und nachhaltige Entwicklung}

Mit der Publikation des Club of Rome zu den Grenzen des Wachstums (Meadows et al. 1972) ist vielen Menschen klar geworden, dass die Ressourcen unseres Planeten nicht unbegrenzt zur Verfügung stehen. Obwohl daraufhin zahlreiche politische Rahmenbedingungen geschaffen wurden, hat sich das vorherrschende kapitalistische Wirtschaftssystem erst sehr wenig auf die Begrenztheit der natürlichen Ressourcen eingestellt (Meadows und Randers 2013). Ein wichtiger Aspekt, der bei der Betrachtung der Grenzen des Wachstums fehlte, war die Berücksichtigung der Auswirkungen der menschlichen Aktivitäten auf die Biodiversität und die verschiedenen Funktionen eines Ökosystems. Diese zu evaluieren war der Auftrag des sogenannten Millennium Ecosystem Assessments (MA) (2005), wo über 1.300 Wissenschaftlerinnen und Wissenschaftler aus 95 Ländern Informationen zum Zustand und zu den Entwicklungstrends der Ökosysteme auf der Erde zusammengetragen haben. In dem Bericht werden der Zustand und die Entwicklung der Ökosysteme in den letzten 50 Jahren dargestellt und Szenarien für mögliche Entwicklungen bis zum Jahr 2050 diskutiert. Ein Fokus liegt dabei insbesondere auf sogenannten Ökosystemdienstleistungen und deren Einfluss auf das menschliche Wohlbefinden. Unter Ökosystemdienstleistungen 
versteht man Güter und Leistungen, die dem Menschen durch Ökosysteme bereitgestellt werden, beispielsweise Holz, Nahrung, saubere Luft und Trinkwasser, oder die Regulationsleistung bei Klima und Naturgefahren (Beck et al. 2006). Das besorgniserregende Hauptresultat des MA war, dass sich $60 \%$ oder 15 von 24 untersuchten Ökosystemdienstleistungen in einem Zustand fortgeschrittener und anhaltender Zerstörung befinden.

Mit der Agenda 2030 der Vereinten Nationen (UN 2015) greift man die Problematik für Ökosysteme anhand mehrerer SDGs direkt und indirekt auf. Aquatische Ökosysteme bzw. deren Interaktionen mit benachbarten terrestrischen Ökosystemen werden im SDG 6 (Verfügbarkeit und nachhaltige Bewirtschaftung von Wasser und Sanitärversorgung für alle gewährleisten) und im SDG 14 (Ozeane, Meere und Meeresressourcen im Sinne nachhaltiger Entwicklung erhalten und nachhaltig nutzen) angesprochen. Stark von Menschen geprägte urbane Ökosysteme behandelt SDG 11 (Städte und Siedlungen inklusiv, sicher, widerstandsfähig und nachhaltig gestalten), während SDG 13 (umgehend Maßnahmen zur Bekämpfung des Klimawandels und seiner Auswirkungen ergreifen) im Grunde das Zusammenspiel aller Ökosysteme auf der Erde betrifft. In erster Linie auf terrestrische Ökosysteme fokussiert SDG 15 (Landökosysteme schützen, wiederherstellen und ihre nachhaltige Nutzung fördern).

Während die SDGs international von den Staaten ratifizierte Zielsetzungen für die nachhaltige Entwicklung darstellen, liefert das „Konzept der planetaren Grenzen“ Informationen über den derzeitigen Stand unserer Ressourcennutzung und möglicher Nutzungsspielräume bei Verfolgung der SDGs. Dieses Konzept ist ein wichtiges Instrument bei der Transformation unserer Gesellschaft in Richtung nachhaltigerer Ressourcennutzung. Es zählt daher zu den grundlegenden Kompetenzen, die im UBRMStudium vermittelt werden sollen, und ist Grundlage mehrerer Lehrveranstaltungen.

\subsubsection{Das Konzept der planetaren Grenzen}

Das Konzept der planetaren Grenzen ist eine Weiterentwicklung der Grenzen des Wachstums, kombiniert mit den Erkenntnissen des im vorangegangenen Abschnitt beschriebenen MA. Im Prinzip handelt es sich dabei um eine wissenschaftlich fundierte Analyse des Risikos menschlicher Aktivitäten für das Funktionieren aquatischer und terrestrischer Ökosysteme und deren Interaktionen im Klimasystem. Die definierten planetaren Grenzen sollen die ökologischen Belastungsgrenzen unseres Planeten aufzeigen und einen „sicheren Handlungsspielraum“ für menschliche Aktivitäten auf der Erde festlegen (Rockström et al. 2009). Im Jahr 2015 wurde eine aktualisierte und erweiterte Analyse des Konzepts veröffentlicht (Steffen et al. 2015). Bestimmte 


\section{4 Ökosysteme, Landnutzung \& Biodiversität}

Schwellenwerte dürfen dabei nicht über- oder unterschritten werden, um die Resilienz der Erde (d.h. deren Fähigkeit, Störungen auszugleichen) nicht zu gefährden und einen für Menschen bewohnbaren Lebensraum sicherzustellen.

Bis dato wurden planetare Grenzen für neun Themenbereiche definiert, deren Einhaltung unabdingbar für den Fortbestand der menschlichen Spezies sind. Diese planetaren Grenzen werden in mehrere Stufen kategorisiert und mit entsprechenden Farbcodes versehen:

- Grüner Bereich - sicherer Handlungsspielraum: Nach derzeitigem Wissensstand besteht nur eine sehr geringe Wahrscheinlichkeit, dass die Widerstandsfähigkeit des Erdsystems überlastet wird.

- Gelber Bereich - Zone der Unsicherheit: Dabei können entweder die Grenzwerte aufgrund der komplexen Zusammenhänge nicht exakt bestimmt werden, oder es besteht noch Zeit zum Gegensteuern. Mitberücksichtigt wird hier auch die Trägheit bestimmter Erdsystemprozesse (z.B. des Klimasystems).

- Roter Bereich - Hochrisikozone: Hier besteht eine hohe Wahrscheinlichkeit für die Beeinträchtigung des Erdsystems.

- Grauer Bereich - keine Einschätzung. Wegen fehlender Daten ist keine Beurteilung möglich.

Von den definierten Teilbereichen werden zwei als fundamental wichtig für das Erdsystem angesehen: der Klimawandel und die Integrität der Biosphäre. Das Klimasystem bildet die Voraussetzung dafür, dass unsere Erde hinsichtlich Temperatur und Strahlung für Menschen bewohnbar bleibt. Die Biosphäre ist einerseits Teil des Klimasystems, reguliert anderseits aber auch Material- und Nährstoffkreisläufe und beherbergt Biodiversität.

Für zwei Bereiche, die „Integrität der Biosphäre“ (genetische Diversität) und „biogeochemische Kreisläufe" (Phosphor und Stickstoff), sind die planetaren Grenzen bereits überschritten (rote Zone). In der Zone der Unsicherheit werden die Landnutzungsänderungen und der Klimawandel gelistet (gelbe Zone). Für die Bereiche „atmosphärische Aerosolbelastung“, „Einbringung neuartiger Entitäten“ und „Zustand der funktionellen Diversität" in Ökosystemen ist wegen ungenügender Daten keine Einschätzung möglich (graue Zone). Lediglich in den Dimensionen „Versauerung der Ozeane“, „Süßwasserverbrauch“ und „stratosphärischer Ozonabbau“ sind die planetaren Grenzen noch nicht überschritten (grüne Zone).

Tabelle 4.1.1 gibt einen Überblick über die identifizierten Kontrollvariablen der planetaren Grenzen und die Parameter zu deren Formulierung. 
Tabelle 4.1.1: Plantare Grenzen, deren Messgrößen und Grenzwerte (nach Steffen et al. 2015)

\begin{tabular}{|c|c|c|c|c|}
\hline \multicolumn{2}{|c|}{ Planetare Grenze } & Messgröße & Grenzwert & Aktueller Wert \\
\hline \multicolumn{2}{|l|}{1 Klimawandel } & $\begin{array}{l}\mathrm{CO}_{2} \text {-Konzentration in der Atmosphäre } \\
\text { (ppm) oder Strahlungsantrieb }\left(\mathrm{W} \mathrm{m}^{-2}\right)\end{array}$ & $\begin{array}{l}\text { Max. } 350 \mathrm{ppm} \\
\text { Max. }+1,0 \mathrm{~W} \mathrm{~m}^{-2}\end{array}$ & $\begin{array}{l}405 \mathrm{ppm} \\
3,06 \mathrm{~W} \mathrm{~m}^{-2}\end{array}$ \\
\hline \multicolumn{2}{|c|}{2 Versauerung der Ozeane } & $\begin{array}{l}\text { Globale Aragonit-Sättigung } \\
\text { im Oberflächenwasser } \\
\text { (Omega-Einheiten) }\end{array}$ & $\begin{array}{l}\text { Min. } 2,75 \text { ( } 80 \% \text { des } \\
\text { vorindustriellen } \\
\text { Wertes) }\end{array}$ & $\begin{array}{l}3,03 \text { ( } 88 \% \text { des } \\
\text { vorindustriellen } \\
\text { Wertes) }\end{array}$ \\
\hline \multicolumn{2}{|c|}{3 Stratosphärischer Ozonabbau } & $\begin{array}{l}\text { Stratosphärische } \mathrm{O}_{3} \text {-Konzentration } \\
\text { (Dobson units) }\end{array}$ & Min. 275 DU & 220-450 DU \\
\hline \multicolumn{2}{|l|}{$\begin{array}{l}4 \text { Atmosphärische } \\
\text { Aerosolbelastung }\end{array}$} & $\begin{array}{l}\text { Aerosol-Optische Dicke } \\
\text { (ohne Einheit) }\end{array}$ & $\begin{array}{l}\text { Kein globaler Grenz- } \\
\text { wert definiert; Süd- } \\
\text { asien: max. } 0,25\end{array}$ & $\begin{array}{l}\text { Südasien: } \\
0,3-0,4\end{array}$ \\
\hline \multirow{3}{*}{$\begin{array}{l}5 \text { Biogeo- } \\
\text { chemische } \\
\text { Kreisläufe }\end{array}$} & \multirow{2}{*}{$\begin{array}{l}\text { Phosphor- } \\
\text { kreislauf }\end{array}$} & Global: P-Eintrag in Ozeane (Tg Jahr $\left.{ }^{-1}\right)$ & Max. $11 \mathrm{Tg} \mathrm{Jahr}^{-1}$ & $22 \mathrm{Tg} \mathrm{Jahr}^{-1}$ \\
\hline & & $\begin{array}{l}\text { Regional: P-Eintrag in Süßwasser- } \\
\left.\text { systeme ( } \operatorname{Tg~Jahr} r^{-1}\right)\end{array}$ & Max. 6,2 Tg Jahr-1 & $14 \mathrm{Tg} \mathrm{Jahr}^{-1}$ \\
\hline & $\begin{array}{l}\text { Stickstoff- } \\
\text { kreislauf }\end{array}$ & $\begin{array}{l}\text { Industrielle und beabsichtigte biolog. } \\
\text { Bindung von Stickstoff }\left(\mathrm{Tg} \mathrm{Jahr}^{-1}\right)\end{array}$ & Max. $62 \mathrm{Tg} \mathrm{Jahr}^{-1}$ & $\begin{array}{l}\text { 150-180 Tg } \\
\text { Jahr }^{-1}\end{array}$ \\
\hline \multicolumn{2}{|l|}{$\begin{array}{l}6 \text { Süßwasser- } \\
\text { verbrauch }\end{array}$} & $\begin{array}{l}\text { Globaler Verbrauch von Oberflächen- } \\
\text { und Grundwasser }\left(\mathrm{km}^{3} \mathrm{Jahr}^{-1}\right)\end{array}$ & $\begin{array}{l}\text { Max. } 4.000 \mathrm{~km}^{3} \\
\text { Jahr-1 }^{-1}\end{array}$ & $\begin{array}{l}2.600 \mathrm{~km}^{3} \\
\mathrm{Jahr}^{-1}\end{array}$ \\
\hline \multicolumn{2}{|c|}{7 Landnutzungsänderung } & $\begin{array}{l}\text { Anteil der ursprünglichen } \\
\text { Waldfläche }\end{array}$ & Min. $75 \%$ & $62 \%$ \\
\hline \multirow[t]{2}{*}{$\begin{array}{l}8 \text { Integrität der } \\
\text { Biosphäre }\end{array}$} & $\begin{array}{l}\text { Genetische } \\
\text { Diversität }\end{array}$ & Aussterberate (E/MSY) & Max. $10 \mathrm{E} / \mathrm{MSY}$ & $\begin{array}{l}100-1000 \\
\text { E/MSY }\end{array}$ \\
\hline & $\begin{array}{l}\text { Funktionelle } \\
\text { Diversität }\end{array}$ & Biodiversitäts-Intaktheits-Index (BII) & Min. $90 \%$ & $\begin{array}{l}84 \% \text { für das } \\
\text { südliche Afrika }\end{array}$ \\
\hline \multicolumn{5}{|c|}{$\begin{array}{l}9 \text { Einbringung neu- Bisher keine Kontrollvariable oder ein Grenzwert definiert } \\
\text { artiger Entitäten }\end{array}$} \\
\hline
\end{tabular}

Farben bezeichnen den Zustand der jeweiligen Parameter: Grün - sicherer Handlungsspielraum, Gelb - Unsicherheit, Rot - Grenze bereits überschritten. Die planetarische Grenze selbst liegt am Schnittpunkt der grünen und gelben Zone. Angaben in Teragramm pro Jahr ( $\left(\mathrm{g}\right.$ Jahr $\left.{ }^{-1}\right)$, Watt pro Quadratmeter (W m-2), part per million (ppm), Anzahl der Arten, die in einer Million Species-Jahren aussterben (E/MSY; ein Species-Jahr ist ein Jahr, multipliziert mit der Zahl der aktuell in diesem Jahr lebenden Arten)

Die Bedeutung von Grenzwerten und Messgrößen wird im Anschluss kurz erläutert.

\subsubsection{Klimawandel}

Das Klimasystem umfasst im Wesentlichen die Energiebilanz zwischen der Sonne und dem Erdsystem. Die planetare Grenze „Klimawandel“ zielt darauf ab, das Risiko klimatisch induzierter und potenziell irreversibler Änderungen des Erdsystems zu minimieren. Die Grenzsetzung berücksichtigt Störungen in regionalen Klimasystemen oder Einflüsse auf wichtige Klimadynamikmuster (z.B. Meeresströmungen, Anstieg des Meeresspiegels). Dabei werden zwei Grenzen definiert: die atmosphärische $\mathrm{CO}_{2}$-Konzentration (die maßgeblich für den Treibhauseffekt ist) und der globale Strahlungs- 


\section{4 Ökosysteme, Landnutzung \& Biodiversität}

antrieb (dazu zählen jene Faktoren, die die Strahlungsbilanz der Erde beeinflussen, z.B. Treibhausgase, Aerosole, Wolken, Strahlungsreflexionen von der Erdoberfläche).

Status: Sowohl der atmosphärische $\mathrm{CO}_{2}$-Gehalt, als auch der Strahlungsantrieb haben die planetaren Grenzen bereits überschritten.

\subsubsection{Versauerung der Ozeane}

Die Versauerung der Ozeane ist eng an den Klimawandel gekoppelt, da die Ozeane sowohl durch direkte Lösung von atmosphärischem $\mathrm{CO}_{2}$ im Wasser als auch durch Aufnahme von Kohlenstoff durch Wasserorganismen als Kohlenstoffsenke dienen. Eine Zunahme des $\mathrm{CO}_{2}$-Gehalts in den Ozeanen führt zu einer Versauerung des Meerwassers. Dadurch löst sich das Kalziumkarbonat aus den Schalen und/oder Skelettstrukturen zahlreicher Meeresorganismen (z.B. Korallen oder Weichtiere), wodurch marine Organismen und ihr Beitrag für das Erdsystem verloren gehen.

Status: Die Versauerung der Ozeane ist noch in der sicheren Zone, aber bereits nahe an der planetaren Grenze.

\subsubsection{Stratosphärischer Ozonabbau}

Ozon in der Stratosphäre (ca. $40 \mathrm{~km}$ dicke Zone oberhalb der erdnahen Wetterschicht) schützt uns vor der schädlichen ultravioletten Strahlung der Sonne. Menschengemachte Substanzen (v.a. Fluorchlorkohlenwasserstoffe, FCKWs) und natürliche Phänomene (polare, sehr kalte Stratosphärenwolken) führen zu einem Ozonabbau. Die Stärke der Ozonschicht wird in DU (Dobson units) gemessen - 100 DU entsprechen einer Ozonschichtdicke von $1 \mathrm{~mm}$ bei Standardtemperatur und Standardluftdruck. Bei einem Wert von unter 220 DU wird von einem „Ozonloch“ gesprochen.

Status: Durch das Verbot von FCKW-Gasen in einem völkerrechtlich verbindlichen Vertrag des Umweltrechts (Montreal-Protokoll) erholt sich die Ozonschicht seit 1989 stetig. Dies ist ein wichtiges Beispiel dafür, dass nach einer einstmaligen regionalen Überschreitung am Südpol durch menschliche Bemühungen eine Rückkehr in den sicheren Handlungsspielraum möglich ist.

\subsubsection{Atmosphärische Aerosolbelastung}

Aerosole, d.h. flüssige oder feste Schwebeteilchen in der Atmosphäre (z.B. Schwefeldioxid, Rauchpartikel, Meersalz, Pollen), können sowohl Auswirkungen auf das Klimasystem als auch auf die menschliche Gesundheit haben. Aerosole beeinflussen die Wolkenbildung und den Treibhauseffekt, sind jedoch auch Ursache für die Entstehung sauren Regens. Auch sind sie häufig nicht regional gebunden, sondern werden über 
große Entfernungen von der Entstehungs- zur Wirkungsstätte weitergeleitet. Als Parameter zur Messung der Aerosolbelastung wird die Aerosol-Optische Dicke (AOD) verwendet, die die Abschwächung der Sonnenstrahlung beim Durchlaufen der Atmosphäre durch Partikel angibt.

Status: Es gibt regional starke Belastungen, aber eine planetare Grenze kann aufgrund der spezifischen Auswirkungen nicht ermittelt werden.

\subsubsection{Biogeochemische Kreisläufe}

Die Elemente Phosphor und Stickstoff sind weltweit als Dünger in der Landwirtschaft und in industriellen Prozessen in Verwendung. Beim Phosphor wird der Eintrag in die Weltmeere als hauptsächliches Kriterium für die Definition einer planetaren Grenze gesetzt. Mit ihr soll die Wahrscheinlichkeit für das Auftreten einer Sauerstoffverarmung der Ozeane und damit eines Massenaussterbens von Meereslebewesen verringert werden. Der Stickstoffkreislauf wird durch zahlreiche anthropogene Prozesse beeinflusst. Atmosphärischer Stickstoff wird sowohl bei der Herstellung synthetischer Stickstoffdünger als auch durch den Anbau von Leguminosen gebunden. Durch die Verbrennung von fossilen Brennstoffen und von Biomasse gelangt Stickstoff in die Atmosphäre. Wichtige Komponenten im Stickstoffkreislauf sind auch Lachgas $\left(\mathrm{N}_{2} \mathrm{O}\right)$, das als starkes Treibhausgas natürlicherweise aus Böden in die Atmosphäre freigesetzt wird, und Nitrat $\left(\mathrm{NO}_{3}{ }^{-}\right)$, das in Dünger enthalten ist und in Gewässer oder ins Grundwasser ausgewaschen wird und dort zur Überdüngung (Eutrophierung) und zu Problemen für die menschliche Gesundheit führen kann.

Status: Phosphor- und Stickstoffkreisläufe befinden sich in der Hochrisikozone, da die definierten planetaren Grenzen bereits um das Doppelte überschritten wurden.

\subsubsection{Wasserverbrauch}

Der Wasserhaushalt ist zentral für die Biodiversität und die Funktion von Ökosystemen, beeinflusst die Ernährungssicherheit für die Menschen und ist essenziell im globalen Klimasystem. Dabei wird differenziert zwischen im Boden gespeichertem Wasser (sogenanntem grünem Wasser) sowie Oberflächen- und Grundwasser (sogenanntem blauem Wasser). Beide Arten von Wasser sind über den Wasserkreislauf eng verknüpft. Die planetaren Grenzen zum Frischwasserverbrauch wurden so gesetzt, dass für den Erhalt der Bodenfeuchtigkeit und die Aufnahme von Niederschlag ausreichend grünes Wasser vorhanden ist, gleichzeitig zum Erhalt der aquatischen Ökosysteme aber auch genügend blaues Wasser.

Status: Trotz temporärer und regionaler Überschreitungen dieser Grenzen wird derzeit ein Überschreiten der planetaren Grenze nicht erwartet. 


\section{4 Ökosysteme, Landnutzung \& Biodiversität}

\subsubsection{Landnutzungsänderung}

Diese Grenze bezieht sich auf den weltweiten Anteil der waldbedeckten Fläche in tropischen, gemäßigten und kaltgemäßigten Klimazonen. Wälder haben eine wichtige Rolle im Energie- und Wasserhaushalt der Erde und beeinflussen damit das Klimasystem, z.B. durch Verdunstungseffekte tropischer Regenwälder oder Rückstrahleffekte borealer Nadelwälder (Nadelwälder in kaltgemäßigten Klimazonen). Der Fokus liegt auf Landnutzungsänderungen, die nicht nur regionale Auswirkungen haben, sondern auch überregional oder sogar global das Klima verändern. Konkret wird die Grenze bei $85 \%$ Bedeckungsanteil für tropische und boreale Wälder sowie bei $50 \%$ Bedeckungsanteil für Wälder in gemäßigten Breiten gesetzt. Zusätzlich zu den regionalen Grenzen wird der globale Mittelwert der Waldarten als Grenze herangezogen und mit 75\% festgelegt (als Anteil der vorindustriellen globalen Waldfläche).

Status: Der globale Waldbedeckungsgrad liegt bei 62\% und hat damit den definierten planetaren Grenzwert überschritten (Zone der Unsicherheit).

\subsubsection{Integrität der Biosphäre}

Die Integrität der Biosphäre wird wesentlich durch die Biodiversität bestimmt. Große Änderungen in der biologischen Vielfalt können schwerwiegende Einflüsse auf die Erdsystemfunktionen haben. Die Biodiversität wird unterteilt in genetische und funktionelle Diversität. Genetische Diversität umfasst die Vielfalt des gesamten Genpools. Je mehr genetisch verschiedene Arten vorhanden sind, desto höher ist die Chance für Lebewesen, sich an abrupte oder graduelle abiotische Änderungen anzupassen. Funktionelle Diversität umfasst die Vielfalt und den Umfang der funktionellen Eigenschaften von Organismen in einem Ökosystem (z.B. Verhältnis von Primärproduzenten, Konsumenten, Destruenten) und beschreibt damit die Funktionsfähigkeit der Biosphäre. Als Basis für die Grenzziehungen dient die Situation vor Beginn der industriellen Revolution im späten 18. Jahrhundert.

Status: Während sich die genetische Diversität bereits in der Hochrisikozone befindet, können die Folgen für die Funktion der Ökosysteme inklusive möglicher Kipppunkte nicht beurteilt werden.

\subsubsection{Einbringung neuartiger Entitäten}

Diese planetare Grenze fasst unterschiedliche Einflussfaktoren zu einer sehr heterogenen Gruppe zusammen. Dazu zählen von Menschen künstlich hergestellte Substanzen, aber auch natürliche Elemente, die durch menschliche Aktivitäten weiter 
verbreitet werden. Beispiele dafür sind radioaktive Elemente, Schwermetalle, Nanomaterialien, Mikroplastik, organische und anorganische Chemikalien sowie auch gentechnisch veränderte Organismen. All diesen Entitäten wird das Potenzial zugeschrieben, weltweit geophysische oder biologische Effekte zu beeinflussen, die menschliche Gesundheit zu gefährden und im Wechselspiel mit anderen planetaren Grenzen zu stehen. Aufgenommen wurden hier vorwiegend Substanzen und/oder Lebewesen, die große Beständigkeit (Persistenz) aufweisen, sehr mobil sind, global leicht verbreitet werden können und dadurch Ökosysteme in verschiedenen Regionen beeinflussen.

Status: Es gibt weltweit keine systematischen Erhebungen zum Ausmaß und zur Verbreitung dieser Substanzen. Deshalb kann keine seriöse Einschätzung etwaiger planetarer Grenzen gemacht werden.

\subsubsection{Basis für politische und gesellschaftliche Transformation}

Das Konzept der planetaren Grenzen zeigt zahlreiche Handlungsoptionen auf, ohne konkrete Maßnahmen zur politischen Umsetzung zu definieren. Es bezog sich ursprünglich ausschließlich auf globale Maßstäbe und berücksichtigte nicht, dass einige Prozesse eine große zeitliche und räumliche Heterogenität aufweisen. Das aktualisierte Konzept bezieht nun auch regionale Auswirkungen ein und ermöglicht damit die Beurteilung auf gesellschaftlich adäquaten Einheiten (z.B. Gemeinden, Regionen, Länder).

Im Gegensatz zu den SDGs beschränkt sich das Konzept der planetaren Grenzen auf rein naturwissenschaftliche Einschätzungen, ohne sozioökonomische oder politische Empfehlungen zu formulieren. Auch rein soziologische oder historische Entwicklungen finden wenig Berücksichtigung, was wahrscheinlich der Komplexität dieser Interaktionen geschuldet ist. Dennoch kann das Rahmenwerk einen wertvollen Beitrag dazu leisten, Entscheidungsträgerinnen und -trägern Optionen für eine ökologisch nachhaltige gesellschaftliche Entwicklung aufzuzeigen.

Die aufgezählten planetaren Grenzen können dabei nicht isoliert voneinander betrachtet werden. Am Beispiel der chemischen Verschmutzung sollen Interaktionen mit anderen Kontrollvariablen der planetaren Grenzen illustriert werden (siehe Fallbeispiel 4.1.1).

Fallbeispiel 4.1.1 zeigt auf, dass politische Entscheidungsträgerinnen und -träger durchaus auf wissenschaftliche Befunde in Zusammenhang mit den planetaren Grenzen reagiert haben. Bei den Zwei-Grad-Klimaschutzbemühungen des Pariser Klimaabkommens wurde die Einhaltung planetarer Grenzen von der internationalen Klimapolitik bereits als Ziel übernommen. Auch das Hauptgutachten des Wissenschaftlichen Beirats der Deutschen Bundesregierung Globale Umweltveränderungen (WBGU) basiert im Wesentlichen auf dem Konzept der planetaren Grenzen. 
In unserer Umwelt sind wir mit einer Vielzahl von synthetischen, also von Menschen hergestellten Chemikalien konfrontiert. Eine Sonderrolle nehmen dabei die Pflanzenschutzmittel (Pestizide) ein. Sie werden in der konventionellen Landwirtschaft verwendet und in einem Ausmaß wie keine andere Stoffgruppe offen in die Umwelt ausgebracht. Pestizide, zu denen Herbizide, Bakterizide, Fungizide, Insektizide, Akarizide oder andere Untergruppen gehören, werden zwar in erster Linie gegen landwirtschaftliche Schaderreger eingesetzt, beeinflussen unbeabsichtigt aber auch sogenannte Nichtzielorganismen, die in Agroökosystemen oder in deren Nachbarschaft leben.

Je nach Anwendungstechnik (Feldspritze, Flugzeug, Helikopter) können Pestizide auch in benachbarte Areale abdriften oder ausgeschwemmt werden. Die Exposition der Umwelt gegenüber Pflanzenschutzmitteln und ihren Wirkstoffen ist somit nicht nur auf die tatsächlich behandelte Fläche begrenzt, sondern betrifft letztendlich die gesamte Biosphäre. Neben diesen räumlichen Aspekten sind auch zeitliche zu berücksichtigen. Viele Pestizide werden nämlich nicht sofort abgebaut, sondern verbleiben zum Teil längerfristig in der Umwelt, sodass regelmäßig Rückstände von Pestiziden in Böden oder Gewässern gefunden werden, deren Anwendung bereits seit Jahrzehnten verboten wurde. Zu den umstrittensten derzeit verwendeten Pestiziden gehören Insektizide mit der Wirkstoffgruppe der Neonikotinoide und Herbizide mit dem Wirkstoff Glyphosat. Neonikotinoide sind systemische Insektizide, die überwiegend zur Saatgutbeizung eingesetzt werden. Da das Saatgut im Boden abgelegt wird, wurde lange keine Gefahr für Honigbienen und andere Insektenbestäuber gesehen. Inzwischen konnte jedoch ein Zusammenhang mit der massiven Schädigung von Honigbienen hergestellt werden. Bei der Aussaat von mit Neonikotinoiden gebeiztem Saatgut wurde pestizidhaltiger Staub kilometerweit verbreitet, was die Bienenvölker im Umkreis vernichtet hat (Pistorius et al. 2009). Mittlerweile haben zahlreiche Studien auch andere nichtletale Auswirkungen auf Wildbienen, Bodenorganismen und aquatische Insekten belegt. Neonikotinoide werden auch für den Rückgang an Feldvögeln verantwortlich gemacht, da Insekten eine wichtige Nahrungsquelle für Vögel darstellen und Neonikotinoide andererseits auch das Nervensystem von Vögeln beeinträchtigen (Hallmann et al. 2014). Politisch wurde seitens der Europäischen Kommission darauf reagiert und auf Basis aller vorliegenden Informationen im Mai 2018 die Anwendung von drei Neonikotinoiden im Freiland untersagt. Auch soll die Möglichkeit der Pestizidabdrift bei der Bewertung möglicher Umweltrisiken im Rahmen der Pestizidzulassung berücksichtigt werden.

Herbizide mit dem Wirkstoff Glyphosat zählen zu den am häufigsten eingesetzten Pestiziden. Die Aufwandmengen sind allein zwischen 1996 und 2014 weltweit um das 15-Fache angestiegen (Benbrook 2016). Glaubte man lange, dass der Wirkstoff spezifisch nur Pflanzen beeinträchtigt, mehren sich mittlerweile Befunde über vielfältige Auswirkungen auf Nichtzielorganismen (von aquatischen Algen und Bodenorganismen über Mikroorganismen im Darm von Honigbienen oder im Pansen von Rindern bis hin zu chronischen Krankheiten beim Menschen). Durch den Einsatz von Pestiziden werden blühende Beikräuter auf dem Feld vernichtet und so vielen Insekten Nahrung und Lebensraum entzogen, was zu einem Rückgang an Insekten führt (Sánchez-Bayo und Wyckhuys 2019). Der Rückgang an Insekten und pflanzlicher Biodiversität schlägt sich letztlich auch im Rückgang an Feldvögeln nieder (Hallmann et al. 2017). Dass die Organismen, die mit Pestiziden kontrolliert werden sollen, resistent gegenüber den eingesetzten Wirkstoffen werden können, ist ein weiteres Beispiel für die wechselseitige Beeinflussung zwischen der Integrität der Biosphäre und der Einbringung neuartiger Entitäten. Eine adäquate politische Reaktion auf diese Befunde steht noch aus.

Die Beispiele zeigen, dass die Wechselwirkungen zwischen der Einbringung neuartiger Entitäten und der Integrität der Biosphäre nicht nur rein naturwissenschaftlich abgehandelt werden können. Nur ein transdisziplinärer Ansatz kann der Komplexität dieser Wechselwirkungen gerecht werden. 
Wertvoll ist das Konzept auch, weil es Lücken in unserer Einschätzung menschlichen Handelns aufzeigt. Analysiert man einige der planetaren Grenzen näher, zeigt sich, dass eine kritische und wissenschaftliche Reflexion bereits begangener Fehler ausblieb, bevor neue Technologien etabliert wurden. Die Beispiele der neuartigen Entitäten und der atmosphärischen Aerosolbelastung legen nahe, die Ausbringung dieser Substanzen durch die Menschheit als Experimente auf globalem Maßstab zu betrachten, ohne dass eine Kontrollvariante vorgesehen wäre oder dass deren Ausgang auch nur annähernd abgeschätzt werden kann. Würde ein derartiger Forschungsansatz zur Förderung eingereicht werden, würde man ihn ziemlich sicher wegen unwissenschaftlicher Vorgangsweise und unverantwortlichen Handelns ablehnen.

Weil wissenschaftliche Erkenntnis nie einen Anspruch auf Vollständigkeit erheben kann, ist die verstärkte Beachtung des Vorsorgeprinzips geboten, d.h. die Vermeidung und Verringerung ökologisch bedenklicher Belastungen, auch dann, wenn die Wissensbasis noch unvollständig ist. Das UBRM-Studium sensibilisiert für diese komplexen Zusammenhänge, u.a. auch aufgrund der sehr breiten und transdisziplinären Struktur.

\section{Literatur}

Beck, S., Born, W., Dziock, S., Görg, C., Hansjürgens, B., Henle, K., Jax, K., Köck, W., Neßhöver, C., Rauschmayer, F., Ring, I., Schimdt-Loske, K., Unnerstall, H. und Wittmer, H. (2006): Die Relevanz des Millennium Ecosystem Assessment für Deutschland. Leipzig: UFZ - Umweltforschungszentrum Leipzig-Halle. Verfügbar in: https://www.ufz.de/index.php?de=36795\#2006 [Abfrage am 20.7.2019].

Benbrook, C. M. (2016): Trends in glyphosate herbicide use in the United States and globally. Environmental Sciences Europe, 28, 1-15. https://doi.org/10.1186/s12302-016-0070-0.

Hallmann, C. A., Foppen, R. P. B., van Turnhout, C. A. M., de Kroon, H., and Jongejans, E. (2014): Declines in insectivorous birds are associated with high neonicotinoid concentrations. Nature, 511, 341-343. https://doi.org/10.1038/nature13531.

Hallmann, C. A., Sorg, M., Jongejans, E., Siepel, H., Hofland, N., Schwan, H., Stenmans, W., Müller, A., Sumser, H., Hörren, T., Goulson, D., and de Kroon, H. (2017): More than 75 percent decline over 27 years in total flying insect biomass in protected areas. PLOS ONE, 12, 10, e0185809. https://doi.org/10.1371/journal.pone.0185809

Meadows, D. L. and Randers, J. (2013): Limits to Growth: The 30 Year Update. London: Chelsea Green Publishing.

Meadows, D. H., Meadows, D. L., Randers, and Behrens W. W. III (1972): The Limits to Growth. Washington, DC: Potomac Associates Universe Books.

MA (Millennium Ecosystem Assessment) (2005): Ecosystems and Human Well-Being: Current State and Trends. Washington, DC, USA: Island Press. Available at: http://www.millenniumassessment.org/ [accessed 20.7.2019].

Pistorius, J., Bischoff, G. und Heimbach, U. (2009): Bienenvergiftung durch Wirkstoffabrieb von Saatgutbehandlungsmitteln während der Maisaussaat im Frühjahr 2008. Journal für Kulturpflanzen, 61, 1, 9-14.

Rockström, J., Steffen, W., Noone, K., Persson, Å., Chapin, F. S. III, Lambin, E., Lenton, T. M., Scheffer, M., Folke, C., Schellnhuber, H., Nykvist, B., De Wit, C. A., Hughes, T., van der Leeuw, S., Rodhe, H., Sörlin, S., Snyder, P. K., Costanza, R., Svedin, U., Falkenmark, M., Karlberg, L., Corell, R. W., Fabry, V. J., Hansen, J., Walker, B., Liverman, D., Richardson, K., Crutzen, P., and Foley, J. (2009): 


\section{4 Ökosysteme, Landnutzung \& Biodiversität}

Planetary boundaries: Exploring the safe operating space for humanity. Ecology and Society, 14, 2, 32. http://www.ecologyandsociety.org/vol14/iss2/art32/.

Sánchez-Bayo F. and Wyckhuys, K. A. G. (2019): Worldwide decline of the entomofauna: A review of its drivers. Biological Conservation, 232, 8-27. https://doi.org/10.1016/j.biocon.2019.01.020.

Smith, T. M. und Smith, R. L. (2009): Ökologie. 6. Auflage. München: Pearson Studium.

Steffen, W., Richardson, K., Rockström, J., Cornell, S. E., Fetzer, I., Bennett, E. M., Biggs, R., Carpenter, S. R., de Vries, W., de Wit, C. A., Folke, C., Gerten, D., Heinke, J., Mace, G. M., Persson, L. M. Ramanathan, V., Reyers, B., and Sörlin, S. (2015): Planetary boundaries: Guiding human development on a changing planet. Science, 347, 6223. https://doi.org/10.1126/science.1259855.

UN (United Nations) (2015): Transforming our World: The 2030 Agenda for Sustainable Development. A/RES/70/1. New York. Available at:

https://sustainabledevelopment.un.org/post2015/transformingourworld/publication [accessed 6.5.2019].

Zaller, J. G. (2018): Unser täglich Gift. Pestizide - die unterschätzte Gefahr. Wien: Deuticke Verlag. 


\subsection{Klimawandel und atmosphärische Prozesse}

Harald Rieder, Herbert Formayer und Josef Eitzinger

Institut für Meteorologie,

Department für Wasser-Atmosphäre-Umwelt (WAU)

harald.rieder@boku.ac.at, herbert.formayer@boku.ac.at, josef.eitzinger@boku.ac.at

\subsubsection{Begriffsklärung: Wetter und Klima}

Menschen interessieren sich seit jeher für das aktuelle und zukünftige Wetter, da dieses in die Planung vieler beruflicher und privater Aktivitäten einfließt. Unter Wetter versteht man in der Meteorologie den Zustand der Atmosphäre zu einer bestimmten Zeit an einem bestimmten Ort. Betrachtet man das mittlere Verhalten von Wetterphänomenen sowie statistische Abweichungen davon auf unterschiedlichen Zeitskalen, so spricht man von Klima. Der Zustand der Atmosphäre (und somit auch das Klima eines Planeten) ist maßgeblich durch ihre chemische Zusammensetzung sowie astronomische Faktoren (z.B. Sonnennähe) bestimmt. Bedingt durch die Periodizität astronomischer Abläufe, durch Kontinentalverschiebungen und Vulkanausbrüche hat sich das Klima unseres Planeten Erde stets gewandelt und zwischen Warm- und Kaltzeiten bewegt. In der jüngeren Vergangenheit ist der anthropogene Einfluss als entscheidender Faktor hinzugekommen. Er beeinflusst den Energiehaushalt und somit das Klima maßgeblich (durch Landnutzungsänderungen, aber v.a. durch die Verbrennung fossiler Energieträger und die damit verbundenen Treibhausgasemissionen).

\subsubsection{Chemische Zusammensetzung der Erdatmosphäre}

Die chemische Zusammensetzung der Erdatmosphäre unterscheidet sich maßgeblich von jener anderer Planeten unseres Sonnensystems. Die Hauptkomponenten der trockenen Erdatmosphäre sind Stickstoff $\left(\mathrm{N}_{2}, 78,1 \%\right)$, Sauerstoff $\left(\mathrm{O}_{2}, 20,9 \%\right)$ und Argon (Ar, 0,93\%) (Kraus 2004). Der verbleibende Rest (0,07\%) erscheint zunächst unbedeutend. Viele dieser sogenannten Spurengase sind jedoch für den Energiehaushalt, die Vertikalstruktur der Atmosphäre und die Luftchemie von größter Bedeutung. Kohlendioxid $\left(\mathrm{CO}_{2}\right.$, ca. $\left.0,04 \%\right)$ beispielsweise ist ein potentes Treibhausgas, d.h., es steuert gemeinsam mit anderen Spurengasen (Methan $\left[\mathrm{CH}_{4}\right]$, Ozon $\left[\mathrm{O}_{3}\right]$, Wasserdampf $\left[\mathrm{H}_{2} \mathrm{O}\right]$ etc.) durch Absorption thermischer Strahlung die Energiebilanz unseres Planeten (Kraus 2004). Dieser natürliche Treibhauseffekt hält die Temperatur im globalen Mittel bei durchschnittlich ca. $+15^{\circ} \mathrm{C}$. Ohne ihn wäre es mit durchschnittlich ca. $-18^{\circ} \mathrm{C}$ wesentlich kälter (Ahrens 2001). Spurengase sind somit von besonderer Bedeutung für das Aufrechterhalten von klimatischen Bedingungen, unter denen sich das Leben auf der Erde in gewohnter Weise entfalten kann. 


\section{4 Ökosysteme, Landnutzung \& Biodiversität}

Ein weiteres bedeutendes Spurengas ist der atmosphärische Wasserdampf, dessen Konzentration räumlich und zeitlich stark variieren kann. In den warmen, bodennahen Luftschichten der Tropen kann sie bis zu 4\% erreichen, in den kalten Polarregionen beträgt sie nur einen Bruchteil eines Prozents (Ahrens 2001). Während die meisten atmosphärischen Gase unsichtbar sind, manifestieren sich die Kondensationsprodukte des Wasserdampfs in Form von Wolken. Die Zugbahnen der Wolken veranschaulichen atmosphärische Bewegungen (Kraus 2004).

Bei atmosphärischen Spurengasen unterscheidet man zwischen variablen und permanenten Gasen. $\mathrm{CH}_{4}$ und $\mathrm{CO}_{2}$ zählen zu den permanenten, global gut gemischten Treibhausgasen. Wasserdampf, $\mathrm{O}_{3}$ oder Stickoxide $\left(\mathrm{NO}_{\mathrm{x}}\right)$ sind raum-zeitlich variabel. Ihre Konzentration hängt maßgeblich von den atmosphärischen Bedingungen sowie vom Vorliegen natürlicher oder anthropogener Quellen oder Senken ab.

Die chemische Zusammensetzung der Atmosphäre bestimmt auch ihren vertikalen Aufbau. Die Meteorologie und Klimatologie betrachtet zumeist den Bereich zwischen der Erdoberfläche und einer Höhe von ca. $11 \mathrm{~km}$, die sogenannte Troposphäre. In dieser Atmosphärenschicht läuft das globale Wettergeschehen ab. Mit zunehmender Höhe sinkt die Temperatur in der Troposphäre stetig und erreicht ihr Minimum an der sogenannten Tropopause. Unter den dort herrschenden Bedingungen kondensiert der Wasserdampf fast vollständig. Dies erklärt die trockenen Bedingungen in der Stratosphäre, die über der Troposphäre anschließt. Aufgrund der Absorption von ultravioletter Strahlung durch die Ozonschicht steigt die Temperatur in der Stratosphäre mit zunehmender Höhe an. Die seit den 1980er-Jahren beobachtete Ausbildung des antarktischen Ozonlochs, bedingt durch die anthropogene Emission von Fluorchlorkohlenwasserstoffen (FCKWs), verdeutlicht anschaulich den Einfluss des Menschen auf die Zusammensetzung der Atmosphäre und zeigt, welch große Umweltveränderungen durch geringe Mengen an Spurengasen ausgelöst werden können.

\subsubsection{Strahlungs- und Energiehaushalt}

Physikalisch bedeutet der Ausstoß von Treibhausgasen durch menschliche Aktivität v.a. eine Veränderung der atmosphärischen Konzentration der Gase (sowie der Konzentration im ozeanischen Speicher) und somit eine Veränderung im Strahlungs- und Energiehaushalt (Wild et al. 2015). Welcher Anteil der einfallenden, direkten und diffusen (gestreuten) solaren Strahlung an der Erdoberfläche reflektiert wird, hängt maßgeblich von den Oberflächeneigenschaften ab. Der Reflexionsgrad einer Oberfläche wird als „Albedo“ bezeichnet. Diese Größe wirkt klimadifferenzierend, d.h., Regionen mit unterschiedlicher Albedo erwärmen sich bei gleichem Strahlungsangebot unterschiedlich (Chmielewski et al. 1998). Erdoberfläche und Erdatmosphäre 
emittieren entsprechend ihrer Temperatur im langwelligen Bereich des elektromagnetischen Spektrums. $\mathrm{CO}_{2}$ sowie eine Reihe anderer Spurengase absorbieren genau in diesem Wellenlängenbereich selektiv: Ein Großteil der emittierten thermischen Strahlung wird absorbiert, während die einfallende solare Strahlung im kürzeren Wellenlängenbereich ungehindert zur Oberfläche vordringen kann.

Die Summe der eingehenden und ausgehenden Strahlungsflüsse bildet die Strahlungsbilanz. Die auf Atmosphäre und Erdoberfläche eingehenden und die von ihnen ausgehenden Strahlungsflüsse sind nicht gleich groß. Die Strahlungsbilanz ist daher nicht ausgeglichen. Ausgeglichen wird sie über turbulente (fühlbare bzw. latente) Wärmeflüsse. Der fühlbare Wärmestrom hängt von der Temperaturdifferenz zwischen Erdoberfläche und Atmosphäre sowie von der Windgeschwindigkeit ab. Der latente Wärmestrom beschreibt den Energiefluss, welcher bei der Kondensation von Wasserdampf entsteht (Ahrens 2001). Beide sind in Richtung Atmosphäre gerichtet. Der latente Wärmestrom illustriert auch die enge Verzahnung des Energie- und Wasserhaushalts unseres Planeten. Der sich aus dem Saldo der Strahlungsbilanz und aus fühlbarer bzw. latenter Wärme ergebende Bodenwärmestrom wirkt als Puffer und modifiziert so die Energieflüsse (Chmielewski et al. 1998).

\subsubsection{Klima im Wandel}

Der Mensch hat über die letzten Jahrhunderte durch sein Handeln zunehmend in den Energiehaushalt der Erde eingegriffen. Eine wesentliche Rolle spielen v.a. Veränderungen der Albedo durch Landnutzung sowie Emissionen durch die Verbrennung fossiler Rohstoffe. Der Weltklimarat (IPCC) hält in seinem fünften Sachstandsbericht (IPCC 2013) viele bedeutende Fakten zum Einfluss des Menschen auf das Klimasystem fest. Zu den bedeutendsten Aussagen zählt, dass die Erwärmung des Klimasystems unzweifelhaft festgestellt werden kann, sowie die Tatsache, dass viele der seit den 1950er-Jahren beobachteten Veränderungen zuvor über Jahrzehnte bis Jahrtausende nicht aufgetreten sind. Jedes der letzten drei Jahrzehnte (1980-2009) war an der Erdoberfläche sukzessive wärmer als alle vorangegangenen Jahrzehnte seit 1850. Der Bericht zeigt einen klaren Zusammenhang zwischen Klimaveränderungen einerseits und der Emission und Konzentration von Treibhausgasen andererseits auf. Der Beitrag des Menschen ist in Bezug zu historischen Veränderungen zu sehen.

Auf geologischen Zeitskalen (Millionen von Jahren) kam es immer wieder zu klimatischen Schwankungen. Auslöser für kurzzeitige Schwankungen sind v.a. Veränderungen in der Sonnenaktivität sowie Vulkanausbrüche, während auf langen Zeitskalen Kontinentalverschiebungen und Veränderungen der Erdumlaufbahn dominieren (Chmielewski et al. 1998). Derzeit befinden wir uns in einem Eiszeitalter, d.h., große 


\section{4 Ökosysteme, Landnutzung \& Biodiversität}

Flächen der Erde ( $-10 \%)$ sind permanent mit Eis oder Schnee bedeckt. Während eines Eiszeitalters ist das Klimasystem besonders empfindlich und schwankt zwischen Kaltzeiten (Glaziale) und Warmzeiten (Interglaziale). Bereits geringe Schwankungen des Energieeintrages, die z.B. durch Veränderungen der Erdbahngeometrie, die sogenannten Milankovitch-Zyklen (Milankovitch 1941), ausgelöst werden, führen zu starken Schwankungen der globalen Mitteltemperatur (Malberg 2007).

Die derzeitige Warmzeit (Holozän) begann vor ca. 11.000 Jahren. Seither ist das Klima der Erde relativ konstant geblieben. Die globale Mitteltemperatur schwankte in diesem Zeitraum um weniger als ein Grad. Aufgrund der Milankovitch-Zyklen wurde das Klimaoptimum vor 7.000 bis 4.000 Jahren erreicht. Derzeit bewegen wir uns langsam auf eine neue Kaltzeit zu. In einigen Tausend Jahren könnte wieder eine massive Vereisung und eine starke Abkühlung einsetzen.

\subsubsection{Anthropogener Klimawandel und Klimafolgen}

Der Mensch greift seit Beginn der industriellen Revolution im 18. Jahrhundert massiv in das Klimageschehen ein (Freisetzung von Treibhausgasen, v.a. $\mathrm{CO}_{2}$, durch die Verbrennung fossiler Brennstoffe). Der Strahlungseintrag durch menschliche Aktivitäten ist verglichen mit der Zeit vor der industriellen Revolution um ca. 2,5 W/m² gestiegen (IPCC 2013).

Laut dem Sonderbericht zum 1,5-Grad-Ziel des Weltklimarates (IPCC 2018) liegt die globale Mitteltemperatur bereits ein Grad über dem vorindustriellen Niveau. Besonders die rasche Erwärmung in den letzten Jahrzehnten kann nur durch menschliche Aktivitäten erklärt werden. In Europa und den USA ist es inzwischen gelungen, $\mathrm{CO}_{2}$-Emissionen einigermaßen zu stabilisieren. Die starke wirtschaftliche Entwicklung in Asien und in anderen Entwicklungs- und Schwellenländern, auch bedingt durch die westliche Nachfrage nach Gütern, lässt die globalen Treibhausgasemissionen jedoch weiter ansteigen. Aufgrund der starken Auswirkungen der menschlichen Aktivitäten auf das Klima spricht man heute bereits vom Anthropozän, also vom Erdzeitalter, das von menschlichen Aktivitäten geprägt wird (Crutzen 2002).

Der Weltklimarat bezieht sich in seinen Abschätzungen zukünftiger Veränderungen im Klimasystem auf die sogenannten repräsentativen Konzentrationspfade (Representative Concentration Pathways, RCPs). Die RCPs beschreiben vier unterschiedliche Pfade bezüglich der Entwicklung von Emissionen und Konzentrationen von Treibhausgasen sowie von Luftschadstoffemissionen und Landnutzung bis ins Jahr 2100 (IPCC 2013). Die RCPs spannen sich von einem strengen Minderungsszenario (RCP2.6) bis zu einem Szenario mit sehr hohen Emissionen (RCP8.5). Für alle Emissionsszenarien wird ein Temperaturanstieg an der Erdoberfläche im Verlauf des 21. Jahrhunderts 
projiziert. Des Weiteren wird angenommen, dass Hitzewellen wahrscheinlich häufiger auftreten und länger andauern werden.

Durch den anthropogenen Klimawandel wird neben der Temperatur auch eine Reihe anderer meteorologischer Variablen maßgeblich beeinflusst. Verbunden mit den potenziellen Auswirkungen auf die Landwirtschaft sind v.a. Veränderungen in den Niederschlagsverhältnissen von großer Bedeutung. Viele Studien zeigen, dass sich Veränderungen in einzelnen Klimavariablen regional sehr unterschiedlich auswirken. Neben Änderungen in den mittleren Verhältnissen ist v.a. mit häufiger auftretenden und stärkeren Extremereignissen zu rechnen (IPCC 2013). Bezüglich der auftretenden Temperaturwerte sind vermehrt warme und weniger kalte Extreme zu erwarten. Da eine wärmere Atmosphäre mehr Wasserdampf aufnehmen kann, ist mit intensiveren Niederschlägen zu rechnen.

Im Allgemeinen ist der langfristige Klimawandel im alltäglichen Leben nicht wahrnehmbar. Es gibt jährliche Schwankungen sowie das Aufeinanderfolgen von einigen zu nassen oder zu trockenen bzw. zu kühlen oder zu warmen Saisonen. In Österreich beträgt der Unterschied der saisonalen Mitteltemperatur zwischen einem sehr kalten und einem sehr heißen Sommer ca. $5^{\circ} \mathrm{C}$ (im Winter ca. $9^{\circ} \mathrm{C}$ ) (Datenbasis: SPARTACUS, ZAMG (Hiebl und Frei 2016)). Der beobachtete Anstieg der saisonalen Mitteltemperatur durch den Klimawandel reicht von 0,2 bis $0,4^{\circ} \mathrm{C}$ pro Jahrzehnt und liegt somit unter der Wahrnehmungsgrenze. Die jährlichen Niederschlagsschwankungen an einem Ort sind noch größer, d.h., Veränderungen durch den Klimawandel sind noch weniger direkt spürbar.

Trotz Klimawandel wird es auch in Zukunft immer wieder kühle oder verregnete Sommer geben bzw. langanhaltende kalte Winter mit Temperaturen unter $-10{ }^{\circ} \mathrm{C}$. Auch mehrere Jahre hintereinander mit ungewöhnlich kühlen Temperaturen in einer Jahreszeit sind möglich, da die natürlichen dekadischen Schwankungen in unseren Breiten in einer Größenordnung liegen, welche den Klimawandel von mehreren Jahrzehnten kompensieren kann. Dennoch schreitet der globale Klimawandel stetig voran. Die reale Witterung ist immer eine Überlagerung von natürlichen Schwankungen, dem globalen Klima und dessen Wandel. So wie dekadische Schwankungen den Klimawandel teilweise kompensieren können, führen sie bei einer positiven Überlagerung zu weiteren Extremereignissen und potenziell auch zu Ausprägungen der Witterung, die bisher nicht zu beobachten waren.

In Österreich manifestiert sich der Klimawandel bisher primär in einem Temperaturanstieg. Seit dem Höhepunkt der „Kleinen Eiszeit“ in der zweiten Hälfte des 19. Jahrhunderts stieg die Jahresmitteltemperatur um mehr als $2{ }^{\circ} \mathrm{C}$ an. Die zunehmende Erwärmung in der ersten Hälfte des 20. Jahrhunderts hatte überwiegend natürliche 


\section{4 Ökosysteme, Landnutzung \& Biodiversität}

Ursachen und wurde teilweise auch als Rückkehr zur Normalität nach der „Kleinen Eiszeit" betrachtet. Die deutliche Erwärmung in den letzten vier Jahrzehnten kann jedoch nur durch den menschlichen Eingriff ins Klimasystem erklärt werden. Derzeit ist die Erwärmung besonders stark im Frühjahr und Sommer zu spüren, wo in den letzten 40 Jahren eine saisonale Temperaturzunahme um ca. $2{ }^{\circ} \mathrm{C}$ (siehe Abbildung 4.2.1) beobachtet wurde. Dies hat große Auswirkungen auf die Land- und Forstwirtschaft sowie auf alpine Gletscher.

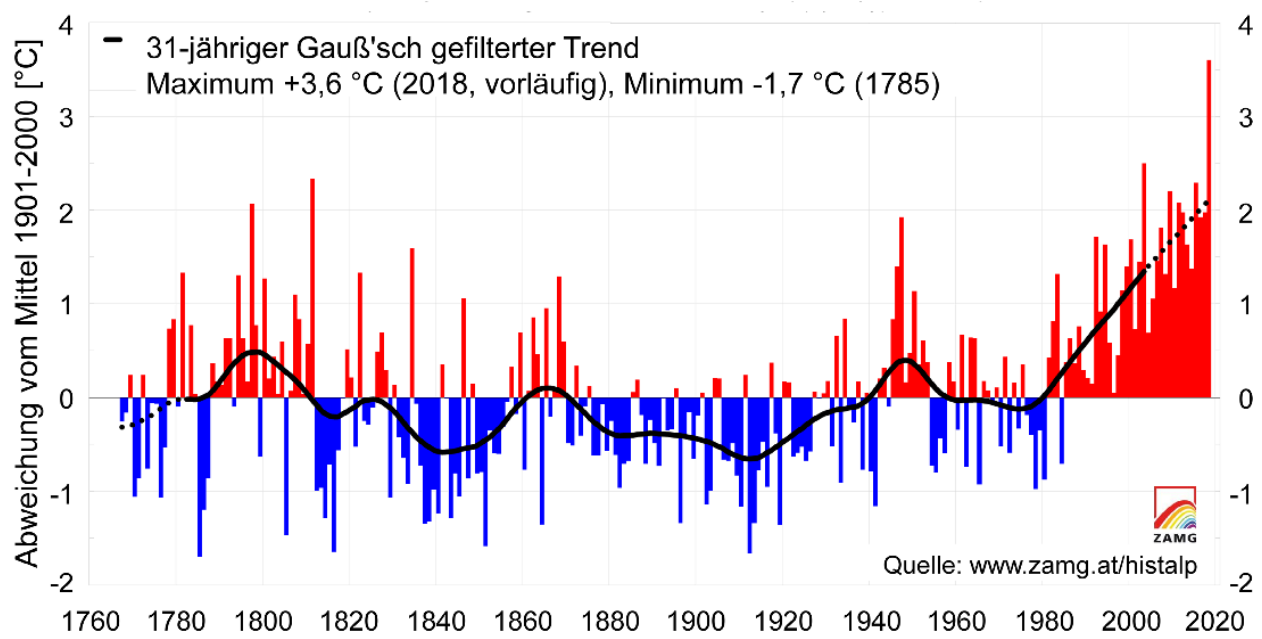

Abbildung 4.2.1: Historische Temperaturentwicklung in den Sommerhalbjahren (April bis September) in Österreich (Datenquelle: HISTALP, ZAMG (Chimani et al. 2013))

Hohe Temperaturen und lang anhaltende Schönwetterperioden wirken sich besonders negativ auf die Massenbilanz von alpinen Gletschern aus. Gletscher brauchen einige Zeit, um sich an ein neues thermisches Gleichgewicht anzupassen. Das heißt, der Rückgang von großen Alpengletschern wird in den nächsten Jahrzehnten weitergehen, selbst wenn es gelingt, die Erwärmung zu stoppen.

Der Rückgang wirkt sich nicht nur ästhetisch auf das Gipfelpanorama des Hochgebirges aus, Gletscher spielen auch eine wichtige ausgleichende Rolle beim Abflussverhalten alpiner Flüsse im Hochsommer und während Hitzewellen. Sie verhindern besonders niedrige Wasserstände in Flüssen und die Überhitzung des Wassers. In Europa hängt die Trinkwasserversorgung von mehr als 100 Millionen Menschen von der Wasserführung der gletscherbeeinflussten Flüsse Rhein, Rhone, Po und Donau ab. Dies macht die Tragweite des alpinen Gletscherrückganges ersichtlich.

Nicht nur der hochalpine Raum ist von der Erwärmung betroffen. In den letzten Jahrzehnten rückte das Thema der Hitzebelastung, v.a. in Städten, auch in Mitteleuropa immer mehr ins Blickfeld der Öffentlichkeit. Der Hitzesommer 2003 zeigte die Ver- 
wundbarkeit Europas durch ausgedehnte Hitzeperioden (bis zu 70.000 Hitzetote) (Robine et al. 2006), wobei der Schwerpunkt der Hitzewelle in Frankreich, Norditalien und der Schweiz lag. In Österreich führt die Agentur für Gesundheit und Ernährungssicherheit die offizielle Berechnung der nationalen Übersterblichkeit durch Hitze mit einer europaweit standardisierten Methodik durch (AGES 2019). In den letzten Jahren schwankte diese zwischen keinem (2016) und mehr als 1.000 Toten (2015).

In Städten ist die Hitzebelastung besonders hoch. Dies liegt weniger an den Temperaturen tagsüber (siehe Abbildung 4.2.2), sondern an der geringen Abkühlung in der Nacht. Die Temperaturunterschiede zwischen Stadtgebiet und Umland betragen am Tag bis zu $1{ }^{\circ} \mathrm{C}$ und in der Nacht $5^{\circ} \mathrm{C}$ und mehr. In der Wiener Innenstadt wurden während einer Hitzewelle in der Nacht Temperaturen bis zu $25^{\circ} \mathrm{C}$ gemessen. Unter solchen Bedingungen erholt sich der menschliche Organismus in der Nacht kaum von der Überhitzung. Nächtliches Lüften kühlt die Wohnräume nicht ausreichend.
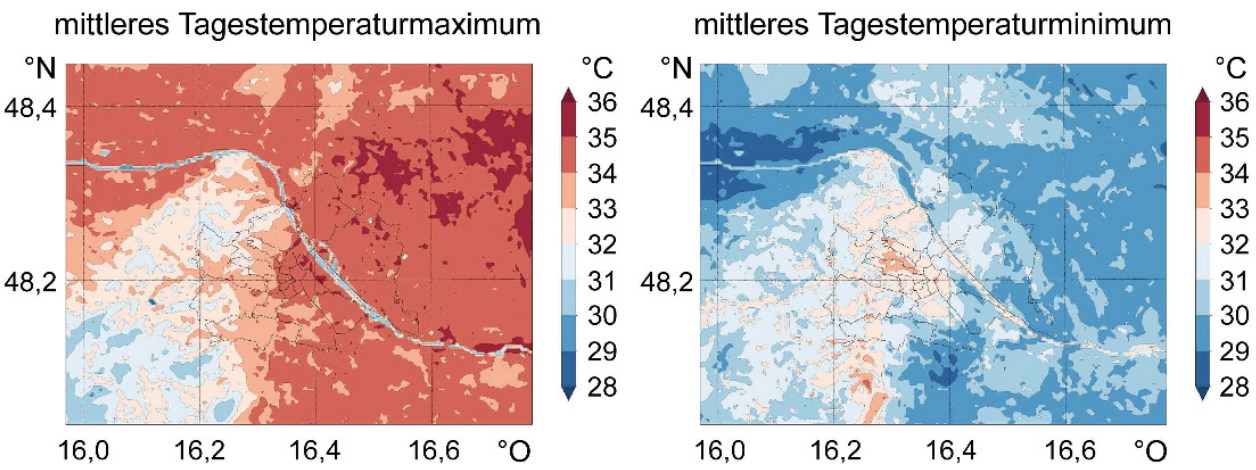

Abbildung 4.2.2: Mittleres Tagesmaximum (links) und Tagesminimum (rechts) der Temperatur im Großraum Wien, während einer fünftägigen Hitzewelle im August 2015 (Weihs et al. 2019)

Modellsimulationen zeigen eine deutliche Zunahme der Hitzebelastung in den nächsten Jahrzehnen (APCC 2014). Auch die zunehmende Urbanisierung führt zu Veränderungen. Der Bevölkerungsanteil in der Stadt nimmt zu, wodurch immer mehr Menschen von städtischen Wärmeinseln betroffen sind. Auch dehnen sich die Städte durch Zuzug weiter aus. Die Bebauung wird verdichtet, was den städtischen Wärmeinseleffekt noch verstärkt. Um die Lebensqualität in Städten in Zukunft auch im Sommer sicherstellen zu können, bedarf es einer konsequenten Raum- und Stadtplanung (welche die Überhitzungsproblematik berücksichtigt) sowie eines wirksamen Klimaschutzes (welcher die Ziele des Pariser Klimaschutzabkommens berücksichtigt).

Das Klima hat auch weitreichende Auswirkungen auf das Zusammenspiel der verschiedenen Ökosystemfunktionen, auf Ökosystemdienstleistungen (siehe dazu auch Beiträge 


\section{4 Ökosysteme, Landnutzung \& Biodiversität}

4.3 und 4.4) und folglich auch auf die landwirtschaftlichen Produktionsbedingungen und -risiken (APCC 2014). Die Veränderung des Klimas hat vielfältige Auswirkungen auf physikalische, biophysikalische und physiologische Prozesse und auf ihr Zusammenspiel im Ökosystem. Erhöht sich die Temperatur unterhalb des jeweiligen Temperaturoptimums eines spezifischen Prozesses, wird dieser beschleunigt (z.B. Photosynthese, Atmung, Phänologie von Pflanzen und Insekten), steigt die Temperatur über das Optimum, verlangsamt sich dieser bis hin zum Stillstand (Absterben). Dies hat direkte Auswirkungen auf die Leistungsfähigkeit, Konkurrenzfähigkeit oder Produktivität von Bodenmikroorganismen, Pflanzen und Tieren und stellt den Pflanzenbau vor die Notwendigkeit von Anpassungsmaßnahmen (Eitzinger et al. 2009).

Aufgrund der ganzjährigen Erwärmung steigt auch das Verdunstungspotenzial. Dies verstärkt, neben Niederschlagsabnahmen im Sommer, den Trend zu mehr Trockenheit. Simulationen von verschiedenen Klimamodellen zeigen jedoch unterschiedliche Veränderungen in den saisonalen Niederschlagsverteilungen. Die Veränderungen können zu temporären Versorgungsdefiziten bei bestimmten Vegetationen oder Pflanzenarten führen. Wärmere Temperaturen verlängern in unseren Breiten die Vegetationsperiode, d.h., die Vegetation benötigt mehr Wasser, und Boden- und Grundwasserreserven werden mehr beansprucht.

Wie viel Wasser eine Pflanze braucht, hängt direkt von der gebildeten Trockenbiomasse pro Flächen- und Zeiteinheit ab. Wassermangel ist direkt ertragslimitierend. Der Transpirationskoeffizient gibt das Verhältnis von Pflanzenverdunstung zu gebildeter Trockenbiomasse an, woraus sich der Wasserbedarf für einen bestimmten Ertrag ableiten lässt. Landwirtschaftliche Nutzpflanzen benötigen pro kg gebildeter Trockenbiomasse ca. 300-600 1 Wasser. Eine gleichmäßige Niederschlagsverteilung während der Wachstumsperiode ist entscheidend, um eine optimale Versorgung zu gewährleisten. Stärkere Verdunstung, mehr Starkniederschläge und Hitzewellen führen bei durchschnittlich abnehmenden oder gleichbleibenden Niederschlagsmitteln zu stärkeren und längeren Trockenperioden. Dies kann den zusätzlichen Wasserbedarf, der durch Bewässerung abgedeckt werden muss, erhöhen. Abbildung 4.2.3 zeigt den erhöhten blauen Wasserfußabdruck (also jenen Wasseranteil, der mittels Bewässerung bereitgestellt werden muss, um einen optimalen Ertrag zu erhalten) verschiedener Nutzpflanzen im Osten Österreichs.

Im agrarischen Bereich gibt es viele Möglichkeiten, sich an Klimaänderungen anzupassen - insbesondere an sich ändernde wetterbedingte abiotische Stressfaktoren für Nutztiere und -pflanzen. Im landwirtschaftlichen Pflanzenbau sind dies neben der Züchtung und Auswahl adaptierter Sorten (die etwa genetische Stresstoleranz, großes Wurzelvolumen oder gute Wassernutzungseffizienz aufweisen) produktionstechnische 


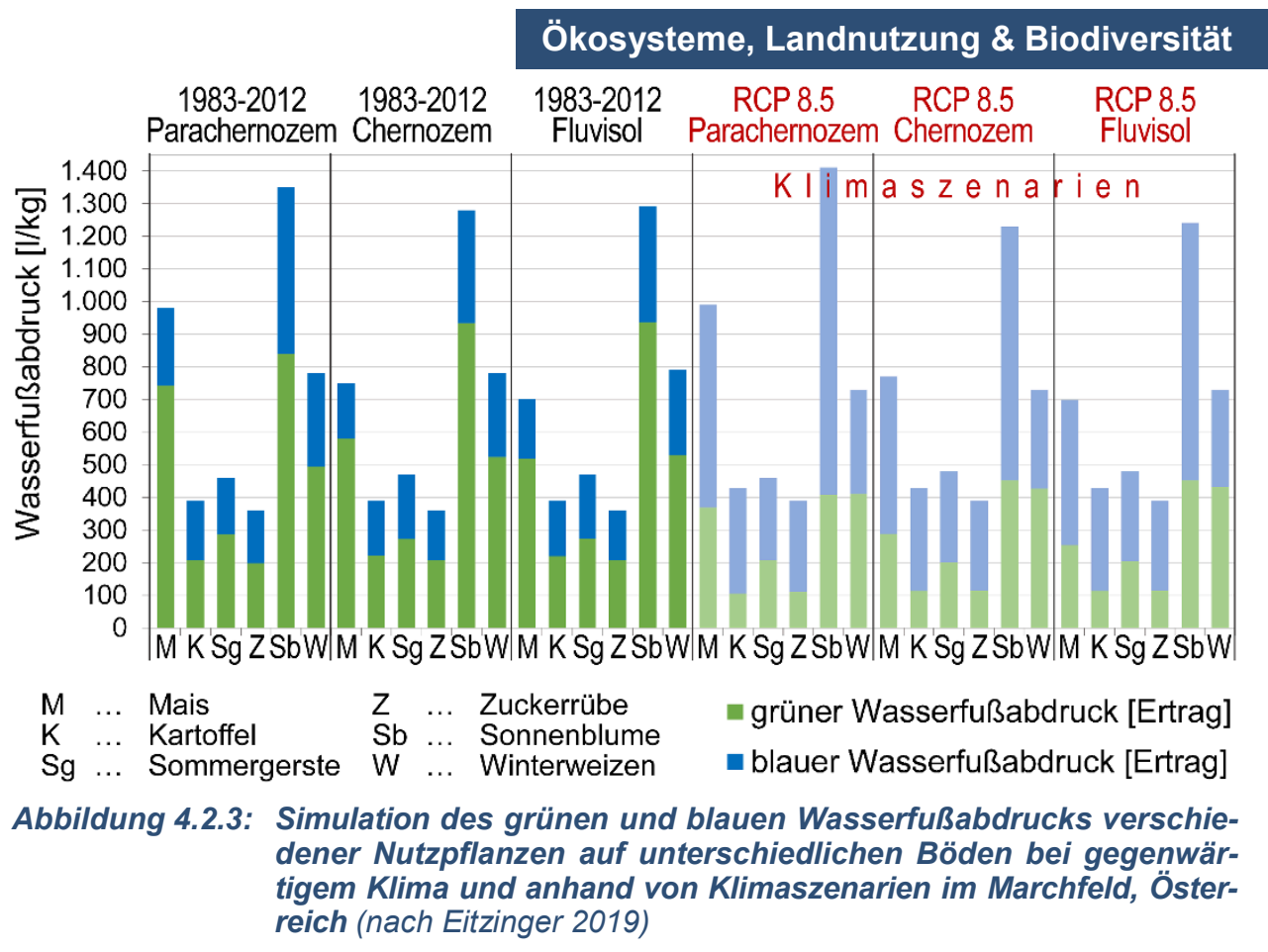

Maßnahmen. Die Bewässerung verschiedener Vegetationsarten bzw. Nutzpflanzenbestände zur Ertragssicherung ist bei fortschreitendem Klimawandel dennoch abzusehen. Hierfür bedarf es zusätzlicher Bewässerungsmöglichkeiten, um natürlich vorkommende Wasserreservoirs zu schützen.

\section{Literatur}

AGES (Österreichische Agentur für Gesundheit und Ernährungssicherheit $\mathrm{GmbH}$ ) (2019): Hitze-Mortalitätsmonitoring. Verfügbar in: https://www.ages.at/themen/umwelt/informationen-zuhitze/hitze-mortalitaetsmonitoring/ [Abfrage am 15.4.1019].

Ahrens, C. D. (2001): Essentials of Meteorology: An Invitation to the Atmosphere. Pacific Grove, CA: Brooks Cole.

APCC (Austrian Panel on Climate Change) (2014): Österreichischer Sachstandsbericht Klimawandel 2014 (AAR14). Wien: Verlag der Österreichischen Akademie der Wissenschaften. Verfügbar in: http://austriaca.at/7699-2 [Abfrage am 16.4.2019].

Chimani, B., Matulla, C., Böhm, R., and Hofstätter, M. (2013): A new high resolution absolute temperature grid for the Greater Alpine Region back to 1780. International Journal of Climatology, 33, 9, 2129-2141. https://doi.org/10.1002/joc.3574.

Chmielewski, F.-M., Hupfer P., Kuttler W. und Pethe, H. (1998): Witterung und Klima: Eine Einführung in die Meteorologie und Klimatologie. Hupfer, P. und Kuttler, W. (Hrsg.), Stuttgart, Leipzig: Teubner.

Crutzen, P. (2002): Geology of mankind. Nature, 415, 23. https://doi.org/10.1038/415023a.

Eitzinger, J. (2019): Wasser. Eine wichtige Ressource der Landwirtschaft. zoll+, Österreichische Schriftenreihe für Landschaft und Freiraum, 34, 1, 24-27. 


\section{4 Ökosysteme, Landnutzung \& Biodiversität}

Eitzinger, J., Kersebaum, K. C. und Formayer, H. (2009): Landwirtschaft im Klimawandel - Auswirkungen und Anpassungsstrategien für die Land- und Forstwirtschaft in Mitteleuropa. Clenze, Deutschland: Agrimedia.

Hiebl, J. and Frei, C. (2016): Daily temperature grids for Austria since 1961 - concept, creation and applicability. Theoretical and Applied Climatology, 124, 1, 161-178. https://doi.org/10.1007/s00704-015-1411-4.

IPCC (Intergovernmental Panel on Climate Change) (2013): Summary for policymakers. In: Stocker, T. F., Qin, D., Plattner, G. K., Tignor, M., Allen, S. K., Boschung, J., Nauels, A., Xia, Y., Bex, V., and Midgley, P. M., eds., Climate Change 2013: The Physical Science Basis. Contribution of Working Group I to the Fifth Assessment Report of the Intergovernmental Panel on Climate Change. Cambridge, UK, New York, NY: Cambridge University Press, 3-29. Available at: https://www.ipcc.ch/report/ar5/wg1/ [accessed 16.4.2019].

IPCC (Intergovernmental Panel on Climate Change) (2018): Global warming of $1.5^{\circ} \mathrm{C}$. An IPCC Special Report on the impacts of global warming of $1.5^{\circ} \mathrm{C}$ above pre-industrial levels and related global greenhouse gas emission pathways, in the context of strengthening the global response to the threat of climate change, sustainable development, and efforts to eradicate poverty [V. Masson-Delmotte, P. Zhai, H. O. Portner, D. Roberts, J. Skea, P.R. Shukla, A. Pirani, W. Moufouma-Okia, C. Pean, R. Pidcock, S. Connors, J. B. R. Matthews, Y. Chen, X. Zhou, M. I. Gomis, E. Lonnoy, T. Maycock, M. Tignor, T. Waterfield (eds.)]. Available at: https://www.ipcc.ch/sr15/ [accessed 16.4.2019].

Kraus, H. (2004): Die Atmosphäre der Erde: Eine Einführung in die Meteorologie. Berlin, Heidelberg: Springer.

Malberg, H. (2007): Meteorologie und Klimatologie: Eine Einführung. Berlin, Heidelberg: Springer.

Milankovitch, M. M. (1941): Kanon der Erdbestrahlung und seine Anwendung auf des Eiszeitenproblem. Royal Serbian Academy special publications, 132, Section of Mathematical and Natural Sciences, 33. Beograd: Königlich Serbische Akademie. Reprinted in English: Canon of Insolation and the Ice-Age Problem. Zavod za udzbenikb i nastavna sredstva, Beograd (1998).

Robine, J. M., Cheung, S. L., Le Roy, S., Van Oyen, H., and Herrmann, F. R. (2006): Report on excess mortality in Europe in Summer 2003. EU Community Action Programme for Public Health, Grant Agreement 2005114.

Weihs, P., Trimmel, H., Oswald, S., Revesz, M., Nadeem, I., Hasel, K., and Formayer, H. (2019): URBANIA - Influence of the development of outlying districts and urban growth on the urban heat island of the city of Vienna in the context of climate change. Final report of the research project within the 8th call of ACRP.

Wild, M., Folini, D., Hakuba, M.Z., Schär, C., Seneviratne, S. I., Kato, S., Rutan, D., Ammann, C., Wood, E. F., and König-Langlo, G. (2015): The energy balance over land and oceans: an assessment based on direct observations and CMIP5 climate models. Climate Dynamics, 44, 11-12, 3393-3429. https://doi.org/10.1007/s00382-014-2430-z. 


\subsection{Landnutzung im globalen Wandel}

Martin Schönhart

Institut für Nachhaltige Wirtschaftsentwicklung,

Department für Wirtschafts- und Sozialwissenschaften (WiSo)

martin.schoenhart@boku.ac.at

\subsubsection{Einführung}

Die günstigen klimatischen Bedingungen zu Beginn des Holozäns vor rund 12.000 Jahren verringerten die Risiken einer ortsgebundenen Lebensweise und landwirtschaftlichen Produktion. Die daraus folgende neolithische Revolution erstreckte sich über Jahrtausende und voneinander unabhängig an verschiedenen Orten der Welt. Mit ihr begann der Mensch, Land systematisch zu nutzen - d.h. die Erdoberfläche zu bewirtschaften. Die technologiebedingt steigende Arbeitsproduktivität der landwirtschaftlichen Landnutzung erlaubte längerfristig die Entwicklung arbeitsteiliger Volkswirtschaften mit komplexen, hoch ausdifferenzierten Gesellschaftsstrukturen, wie wir sie heute kennen.

Solange menschliche Gesellschaften aus Jägern und Sammlern bestanden, waren die „ökosystemaren“ Folgen zwar beträchtlich, blieben aber örtlich beschränkt. Mit der systematischen Landnutzung entwickelte sich der Mensch zu einem globalen Einflussfaktor auf das System Erde. Die Menschheit, ihre Gesellschaft und Wirtschaftssysteme sind Teil dieses Systems Erde, genauso wie die Ökosysteme, das Klimasystem, die interagierenden ökologischen, physikalischen und chemischen Prozesse und die planetaren Kreisläufe (z.B. Wasser, Kohlenstoff, Nährstoffe) (IGBP 2019).

Das System Erde unterliegt permanenten Veränderungen - dem globalen Wandel. Bekannte Beispiele sind der Klimawandel, die Veränderungen der Artenvielfalt oder das Bevölkerungswachstum. Globaler Wandel inkludiert Phänomene, die unmittelbar global wirken, etwa der Klimawandel, und Phänomene auf lokaler Ebene, die durch ihr gleichzeitiges Auftreten an vielen Orten global bedeutsam sind, etwa die Urbanisierung (IGBP 2019). Menschliche Aktivitäten sind zu einem erheblichen Teil für das Ausmaß und die Geschwindigkeit des globalen Wandels verantwortlich, besonders seit Beginn der industriellen Revolution ab ca. 1750. Die sogenannte Great Acceleration beschreibt die Beschleunigung der menschlichen Aktivitäten sowie deren Folgen für den globalen Wandel seit den 1950er-Jahren. Beispiele sind steigende Treibhausgasemissionen, das Bevölkerungswachstum, der Einsatz synthetischer Betriebsmittel in der Landwirtschaft und die Umwandlung vormals unberührter Wälder in Ackerland. In Wissenschaft und Gesellschaft etabliert sich die Zuschreibung, dass diese weitreichenden Aktivitäten zu 


\section{4 Ökosysteme, Landnutzung \& Biodiversität}

einem neuen Erdzeitalter geführt haben, dem Anthropozän (Begriffe und Prozesse siehe Steffen et al. 2004, 2018; Doucet et al. 2019; Future Earth 2019).

\subsubsection{Funktionen von Land}

Landnutzung dient der Befriedigung menschlicher Bedürfnisse (siehe FAO und UNEP 1999). Land ist eine Produktionsgrundlage für erneuerbare Güter (z.B. Nahrungs- und Futtermittel, biogene Rohstoffe und Energieträger) und für Dienstleistungen (z.B. Attraktivität einer landwirtschaftlichen Kulturlandschaft, Schutz vor Naturgefahren) und dient als Lebensraum für Tiere, Pflanzen und Menschen. Letztere nutzen Land als Wohn-, Freizeit-, Industrie- oder Infrastrukturfläche. Selbst die Einrichtung eines Naturschutzgebietes durch die Verhängung eines Bewirtschaftungsverbotes (z.B. in der Kernzone eines Nationalparks) lässt sich als Landnutzung interpretieren.

Der Boden als integraler Bestandteil von Land und die terrestrische Vegetation beeinflussen die globalen Kreisläufe von Wasser, Kohlenstoff und Nährstoffen maßgeblich. Beispielsweise werden Kohlenstoff und Stickstoff zwischen Boden, Vegetation, Gewässern und Luft ausgetauscht. Im Kohlenstoffkreislauf bauen Pflanzen aus Sonnenenergie, Wasser, Nährstoffen und Kohlendioxid $\left(\mathrm{CO}_{2}\right)$, das aus der Luft stammt, Biomasse auf (Prozess der Photosynthese). Biomasse ist Nahrung für Tiere und Menschen, Energieträger und industrieller Rohstoff. Neben der Pflanzenatmung wird auch durch die Nutzung der Biomasse der gebundene Kohlenstoff wieder freigesetzt. Ungenutzte, abgestorbene Pflanzenteile bilden die Streu- und Humusschicht des Bodens, in der große Mengen an organischem Kohlenstoff gespeichert sind. Höhere $\mathrm{CO}_{2}$-Konzentrationen und Temperaturen der Atmosphäre fördern das Biomassewachstum der Vegetation, wodurch mehr $\mathrm{CO}_{2}$ gebunden wird - ein Beispiel für die Fähigkeit zur Selbstregulation des Systems Erde. Damit erfüllt Land mit seiner Vegetation und dem Boden eine Senkenfunktion für Kohlenstoff. Die Vegetation speicherte seit 1750 in etwa $160+/-90$ Pg$^{1}$ zusätzlichen Kohlenstoff, was rund 40\% der Treibhausgasemissionen durch fossile Energieträger und durch die Zementproduktion entspricht (Ciais et al. 2013). Dieser Kreislauf wirkt auch in die entgegengesetzte Richtung: Landnutzung kann die Kohlenstoffgehalte des Bodens und der Vegetation verringern, etwa durch Bodenbearbeitung, die mikrobielle Prozesse beschleunigt und $\mathrm{CO}_{2}$ freisetzt, oder durch die Nutzung bislang ungenutzter Ökosysteme (z.B. Rodung naturbelassener Wälder). Dadurch wurden seit 1750 rund $180+/$ - 80 Pg Kohlenstoff freigesetzt. Seit 1750 kam es zu einem geringen Nettoabfluss an Kohlenstoff aus terrestrischen Ökosystemen in die Atmosphäre von rund $30+/-45 \mathrm{Pg}$ (Ciais et al. 2013), was zum menschlich verursachten Klimawandel beiträgt.

11 Petagramm $(\mathrm{Pg})=1$ Gigatonne $(\mathrm{Gt})=10^{9}$ Tonnen $(\mathrm{t})$ 
Land ist auch eine Quelle für nichterneuerbare Ressourcen. An der Oberfläche oder in tieferen Schichten lagern Sande, Gesteine, Erze oder fossile Energieträger. Die Endlichkeit dieser Ressourcen belegen regelmäßige Medienberichte über lokale Knappheiten an Sand als Industrierohstoff und Baumaterial. Wenngleich flächenmäßig nachrangig, führt der Abbau nichterneuerbarer Ressourcen lokal zu erheblichen Umweltbeeinträchtigungen.

Vor dem Hintergrund der erwarteten zukünftigen gesellschaftlichen Nachfrage nach unterschiedlichen Funktionen dient Land auch als Investitions- und Spekulationsgut. Mark Twain wird die Aussage zugeschrieben: „Kaufen Sie Land. Es wird nicht mehr hergestellt." Land und damit nutzbarer Boden ist nicht nur physisch begrenzt. Eine unsachgemäße Nutzung (z.B. unzureichende Nährstoffversorgung, fehlende Bodenbedeckung), Umweltverschmutzung (z.B. Emissionen der Industrie und des Verkehrs) und natürliche Prozesse (z.B. Extremwetterereignisse) können zu Degradationsprozessen (z.B. Erosion durch Wasser und Wind, Versalzung, Akkumulation von Schadstoffen und Schwermetallen) außerhalb der natürlichen Regenerationsfähigkeit der Böden führen.

Land dient auch als Senke für industrielle Abfälle und Haushaltsmüll. Retentionsflächen sind eine Maßnahme des Hochwasserschutzes zur kurzfristigen Speicherung von Wasser und Ablagerung von Sedimenten. Letztlich ist Land auch eine Informationsgrundlage zur Erforschung der Erd- und Kulturgeschichte. Neue Methoden (z.B. Fernerkundung, Isotopenanalysen) und globale Datenbänke mit langen Zeitreihen erlauben die Rekonstruktion der historischen Landnutzung über Jahrtausende hinweg. Daraus lassen sich Schlussfolgerungen zu ökosystemaren Zusammenhängen ableiten. Historische Landnutzungsdaten sind auch eine unverzichtbare Grundlage der globalen Klimamodellierung.

Eine spezielle Ausprägung der Landnutzung kann gleichzeitig mehrere Funktionen erfüllen. Man spricht in diesem Fall von Synergien bzw. von Multifunktionalität. So können beispielsweise die Produktion von erneuerbaren Gütern und Dienstleistungen, die Speicherung von Kohlenstoff und die Bereitstellung von Retentionsflächen zeitgleich erfolgen. Durch Weidehaltung von Milchkühen auf Grünland in Bergregionen werden Nahrungsmittel erzeugt. Eine Dienstleistung dieser Nutzung ist die auch touristisch verwertbare Attraktivität der Kulturlandschaft. Die Kohlenstoffgehalte der Weideflächen liegen in der Regel über jenen einer ackerbaulichen Nutzung. Zudem können Weideflächen auch als Retentionsflächen bei Hochwässern dienen.

Im Gegensatz zu Synergien liegen bei Nutzungskonflikten Konkurrenzbeziehungen zwischen verschiedenen Funktionen vor. Beispielsweise schließen der Abbau nichterneuerbarer Ressourcen (z.B. Erze und Kohle) oder die Errichtung von Infrastruktur die Produk- 


\section{4 Ökosysteme, Landnutzung \& Biodiversität}

tion von erneuerbaren Gütern aus. Im Folgenden werden die Wechselwirkungen zwischen Landnutzung und ausgewählten Phänomenen des globalen Wandels dargestellt.

\subsubsection{Landnutzung und globaler Wandel}

\subsubsection{Bevölkerungsentwicklung und Ernährung}

Landnutzung und Bevölkerungsentwicklung stehen in einem engen funktionalen $\mathrm{Zu}-$ sammenhang und weisen viele Wechselwirkungen auf. Die Bevölkerung kann - unter der Annahme eines gleichbleibenden Konsumniveaus je Person - nur wachsen, wenn mehr Land genutzt wird (Extensivierung) oder die Produktivität je Flächeneinheit erhöht wird (Intensivierung). Eine Ausdehnung der Landnutzung, sei es für die Produktion erneuerbarer Güter und Dienstleistungen oder den Abbau nicht erneuerbarer Ressourcen, ist möglich, solange bislang ungenutzte Flächenreserven verfügbar sind. Die Möglichkeiten zur Intensivierung bestehender Landnutzungen hängen von der Verfügbarkeit an Betriebsmitteln (z.B. Wasser zur Bewässerung, Pestizide, Düngemittel), Technologien (z.B. Bewässerungsverfahren, Konservierungs- und Lagerungstechnologien) und den Managementfertigkeiten (z.B. Wissen um den zeitgerechten Einsatz von Düngemitteln) der Landnutzerinnen und Landnutzer ab. Ein historisch bedeutsames Beispiel der Intensivierung war die grüne Revolution ab Mitte des 20. Jahrhunderts, vorwiegend in Ländern Asiens. Sie führte zu beachtlichen Ertragssteigerungen ackerbaulicher Kulturen durch den Einsatz von ertragreicheren Sorten, Düngemitteln, Pestiziden und von Bewässerung.

Eine wachsende und wohlhabendere Bevölkerung benötigt nicht nur mehr Güter und Dienstleistungen, sondern stellt auch konkurrierende Landnutzungsansprüche, z.B. an ein attraktives Landschaftsbild, den Schutz der Artenvielfalt, sauberes Trinkwasser oder den Schutz vor Naturgefahren. Diese Ansprüche sind Inhalt gesellschaftlicher Debatten und politischer Ausverhandlungsprozesse auf lokaler, nationaler und internationaler Ebene. Eine wachsende Bevölkerung erhöht aber auch das Angebot an Arbeitskräften und kann die Chancen auf technologische Innovationen steigern, beides mit unmittelbaren Folgen für die Landnutzung.

Zwei konkurrierende Theorien beschreiben die Zusammenhänge zwischen dem Bevölkerungswachstum und dem Bedarf an Gütern der Landnutzung, vorrangig an Nahrungsmitteln. Thomas Malthus, ein englischer Gelehrter des 18. Jahrhunderts, ging aufgrund der Biologie des Menschen von einem exponentiellen Bevölkerungswachstum aus, wohingegen seiner Beobachtung nach die Nahrungsmittelproduktion allenfalls linear wuchs, sofern landwirtschaftlich nutzbare Flächenreserven verfügbar waren. Eine Intensivierung der Landnutzung ist nach Malthus' Theorie nur bedingt 
möglich und würde zur Degradation des Bodens führen. Diese Zusammenhänge hätten längerfristig Konflikte und Hungersnöte auslösen müssen, wodurch sich die Bevölkerungszahl verringern und der Prozess des Wachstums von Neuem beginnen würde.

Ester Boserup, eine dänische Agrarökonomin des 20. Jahrhunderts, entwickelte auf Grundlage ihrer empirischen Forschungsarbeit eine dazu in Gegensatz stehende Theorie. Eine wachsende Bevölkerung erhöht den Druck auf Ressourcen, darunter Land zur Produktion von Nahrungsmitteln. Die sich verschärfende Knappheit stimuliert die Innovationskraft der Menschen und ihren Willen, die Landnutzung zu intensivieren. So können mit denselben Flächenressourcen immer mehr Menschen ernährt werden, was nicht zwangsläufig zur Degradation des Bodens führen muss.

Während Malthus' Theorie zu seiner Zeit plausibel erscheinen musste und auch heute noch vereinzelte Prozesse auf regionaler Ebene zu erklären vermag, kann sie das rasante Bevölkerungswachstum seit der industriellen Revolution, speziell im 20. Jahrhundert, und die massiv steigende landwirtschaftliche Produktion nicht erklären. Malthus unterschätzte die Innovationsfähigkeit der Gesellschaft. Seit 1900 wuchs die Weltbevölkerung von knapp $2 \mathrm{Mrd}$. auf heute rund $7 \mathrm{Mrd}$. Menschen. Die Produktion von Kalorien vervielfachte sich. Real, d.h. inflationsbereinigt, sanken die Preise für Agrargüter im 20. Jahrhundert pro Jahr durchschnittlich um 1\% (Fuglie und Wang 2012). Während der Anteil der Verbrauchsausgaben für Nahrungsmittel österreichischer Konsumentinnen und Konsumenten 1954 noch bei 45\% lag, sank dieser bis 2014 auf 13\% (Statistik Austria 2018). Trotzdem hungern heute weltweit rund 800 Mio. Menschen - nach Jahren sinkender Zahlen wieder mit steigender Tendenz.

\subsubsection{Klimawandel}

Landnutzung und Klimawandel beeinflussen einander. Landnutzung, besonders die land- und forstwirtschaftliche Produktion, ist von klimatischen Rahmenbedingungen abhängig. Der Klimawandel erfordert daher Anpassungsmaßnahmen und eröffnet neue Chancen. Andererseits ist die Landnutzung auch eine Verursacherin des Klimawandels mit Potenzialen zur Verringerung klimaschädlicher Aktivitäten.

Die land- und forstwirtschaftliche Produktion ist von Wetter und Klima (Beitrag 4.2) abhängig. Das regionale Klima erklärt das Vorkommen bestimmter land- und forstwirtschaftlicher Pflanzenarten und Tiere in einer Region (z.B. wärmeliebende Weinstöcke in Südost- und Ostösterreich) und deren unterschiedliche Ertragspotenziale. Das Wetter der jeweiligen Saison erklärt zu einem erheblichen Teil die erzielten Erträge. Die technologischen Möglichkeiten zur Beeinflussung des standörtlichen Mikroklimas 


\section{4 Ökosysteme, Landnutzung \& Biodiversität}

für Kulturpflanzen sind beschränkt und kapitalintensiv (z.B. Folientunnel, Gewächshäuser, Bewässerung), verlängern aber die Vegetationsperiode - bis hin zur ganzjährigen Produktion von Gemüse in Glashäusern -, erhöhen die Ertragspotenziale und verringern das Ertragsrisiko.

Klimawandel beeinflusst die Landwirtschaft in vielfacher Weise. Steigende Temperaturen verlängern die Vegetationsperiode, erhöhen den Hitzestress bei Pflanzen und Tieren sowie die Evapotranspiration, d.h. die Verdunstung von Wasser aus Boden und Pflanzen. Selbst bei gleichbleibenden Niederschlägen erhöhen sich dadurch die Wahrscheinlichkeit für Wasserstress bei Kulturpflanzen sowie der Wasserbedarf in der Tierhaltung. Veränderte Niederschlagsmengen und -verteilungen können diesen Effekt mildern oder verstärken. Häufigere und intensivere Starkniederschlagsereignisse erhöhen das Risiko für Bodenerosion und Nährstoffauswaschung. Der Klimawandel kann die Verbreitungsgebiete und Lebenszyklen von Tier- und Pflanzenkrankheiten verändern. Ein wesentlicher indirekter Vorteil des Klimawandels in der pflanzenbaulichen Produktion ist der Düngungseffekt durch $\mathrm{CO}_{2}$. Pflanzen benötigen $\mathrm{CO}_{2}$ zum Aufbau von Biomasse im Zuge der Photosynthese. Ein höherer atmosphärischer Gehalt an $\mathrm{CO}_{2}$ erhöht bis zu einem gewissen Grad die Produktivität von Kulturpflanzen. In Glashäusern wird deshalb in der Produktion von z.B. Tomaten, Melanzani und Paprika der $\mathrm{CO}_{2}$-Gehalt der Luft künstlich erhöht.

Die Land- und Forstwirtschaft kann mit Anpassungsmaßnahmen auf Klimaveränderungen reagieren, um negative Folgen, etwa Gefahren für die Produktionsgrundlage Boden, zu mildern und vorteilhafte Änderungen, z.B. verlängerte Vegetationsperioden, zu nutzen. Beispiele für Anpassungsmaßnahmen sind veränderte Fruchtfolgen, hitzetolerante Sorten, neue Anbaugebiete für Kulturpflanzen in höheren Lagen und Breitengraden, angepasste Bodenbearbeitungsverfahren zum Schutz vor Erosion, Bewässerungstechnologien, Kühlanlagen in der Tierhaltung oder Versicherungen gegen Ernteausfälle.

Emissionen aus der Landnutzung tragen zum Klimawandel bei. Bedeutende Emissionsquellen insbesondere für Methan $\left(\mathrm{CH}_{4}\right)$ und Lachgas $\left(\mathrm{N}_{2} \mathrm{O}\right)$ sind die Haltung von Wiederkäuern, die Nassreisproduktion und die Lagerung und Ausbringung von Wirtschafts- und Mineraldünger. Der Betrieb landwirtschaftlicher Maschinen und Gebäude (z.B. Glashäuser) verursacht $\mathrm{CO}_{2}$-Emissionen durch die Verbrennung fossiler Energieträger. Die Umwandlung unberührter Ökosysteme (z.B. tropischer Regenwälder) in landwirtschaftliche Nutzflächen setzt einen Teil des in der Biomasse und dem Boden gespeicherten Kohlenstoffs frei (siehe Beschreibung des Kohlenstoffkreislaufs in Abschnitt 4.3.2 und Fallbeispiel 4.3.1). Bis in die 1970er-Jahre waren die kumulierten Emissionen des Landnutzungswandels größer als jene aus der Freisetzung fossiler Energieträger (Ciais et al. 2013). 
Der Effekt der indirekten Landnutzungsänderungen (indirect land use change, ILUC) beschreibt regionale und globale Veränderungen, die durch die Vernetzung über internationale Märkte entstehen (Searchinger et al. 2008). Landnutzungsänderungen sind eine Folge veränderter Rahmenbedingungen (z.B. steigende Marktpreise, Einführung einer Politik zur Förderung von Agrotreibstoffen). Durch die höhere Profitabilität ändern Landwirtinnen und Landwirte ihr Produktionsverhalten. Sie dehnen z.B. die Maisanbauflächen zur Erzeugung von Ethanol aus (direkte Landnutzungsänderung). Großflächig umgesetzt verringert sich die Erntemenge der zuvor auf diesen Flächen angebauten Ackerkulturen (z.B. Getreide für die Tierernährung). Dadurch steigen die Preise mit möglichen Folgen für die Ernährungssicherheit. Die höheren Preise können dazu führen, dass die verdrängte Kultur andernorts angebaut wird, etwa auf bisher ungenutzten bewaldeten Flächen oder vormals degradierten und durch die höhere Profitabilität wieder restaurierten Böden. Auch die Intensivierung der Produktion auf bestehenden Ackerflächen wäre denkbar (indirekte Landnutzungsänderungen).

Hertel et al. (2010) quantifizieren mit einem agrarökonomischen Modell die Landnutzungsfolgen der politisch gelenkten Ausdehnung des Maisanbaus zur Produktion von Ethanol in den USA mit + 50,15 GI (Gigalitern) von 2001 bis 2015. Dies entspräche einem zusätzlichen Landbedarf von rund 15 Mio. ha. Die zusätzliche Nachfrage nach Land erhöht die Preise für agrarische Betriebsmittel, Produktionsfaktoren und agrarische Güter. Die Folgen sind eine verringerte Nachfrage nach Nahrungsmitteln und industriellen Rohstoffen sowie eine Intensivierung der bestehenden Produktion. Die Reststoffe der Ethanolproduktion können als Futtermittel verwendet werden und ersetzen ackerbauliche Kulturen. In Summe reduziert sich der zusätzliche Landbedarf durch die neue Politik von 15 Mio. ha auf rund 3 Mio. ha. Berücksichtigt man, dass die zusätzlich benötigte Fläche eine geringere Produktivität aufweist als die bestehende - das beste Agrarland wird bereits bewirtschaftet, Flächenreserven sind in der Regel von geringerer Qualität -, so ergibt sich ein zusätzlicher Landbedarf von rund 4 Mio. ha mit zahlreichen direkten und indirekten Landnutzungsänderungen.

Indirekte Landnutzungseffekte können nur durch begleitende, vorwiegend politische Maßnahmen auf der Konsum- und Produktionsseite verringert werden. Auf jeden Fall müssen die Maßnahmen den globalen Kontext berücksichtigen und alle Landnutzungssektoren umfassen. Eine so umfangreiche politische Strategie müsste klare Prioritäten in der Nutzung von Land für die Produktion von Lebensmitteln, Futtermitteln, biogenen Roh- und Kraftstoffen und anderen Funktionen setzen.

Das Prinzip der indirekten Landnutzungsänderungen ist anerkannt. Die konkrete Höhe der Effekte ist jedoch schwierig zu ermitteln, einzelfallabhängig und politisch umstritten. Dennoch führen gut gemeinte Politiken zur Förderung alternativer Kraftstoffe mitunter zu höheren Treibhausgasemissionen als fossile Alternativen. Daher fordert die EU für die Beimischung von Agrotreibstoffen (10\% Beimischungsverpflichtung bis 2020) einen Nachweis über die indirekten Landnutzungsänderungen (siehe EU COM 2019).

\subsubsection{Abiotische und biotische Umweltwirkungen}

Stickstoff $(\mathrm{N})$ und Phosphor $(\mathrm{P})$ sind zwei Hauptnährstoffe für Pflanzen. Sie kommen in unterschiedlichen chemischen Formen in den Böden, der Biomasse, der Luft, in Sedimenten und in Gewässern vor. In natürlichen Ökosystemen werden sowohl P als auch N durch Gesteinsverwitterung freigesetzt. Während sich zusätzlicher pflanzen- 


\section{4 Ökosysteme, Landnutzung \& Biodiversität}

verfügbarer $\mathrm{P}$ im Wesentlichen auf die Gesteinsverwitterung beschränkt, ist $\mathrm{N}$ in seiner unreaktiven Form $\mathrm{N}_{2}$ der Hauptbestandteil unserer Luft. Leguminosen, also Pflanzen, die in Symbiose mit Mikroorganismen leben, ausgewählte Mikroorganismen (biologische Fixierung) und Blitze verwandeln atmosphärischen $\mathrm{N}_{2}$ in pflanzenverfügbare Formen. In natürlichen Ökosystemen werden $\mathrm{P}$ und $\mathrm{N}$ durch Bodenerosion ausgetragen und in aquatischen Ökosystemen angereichert. $\mathrm{N}$ wird zusätzlich im Boden und oberflächlich ausgeschwemmt oder in tiefere Schichten bis ins Grundwasser verlagert. Durch den Prozess der Denitrifikation wird reaktiver $\mathrm{N}_{\mathrm{zu} \mathrm{N}}$ (mitunter auch $\mathrm{N}_{2} \mathrm{O}$ ) umgewandelt.

Mit der Landnutzung verändern Menschen die globalen Nährstoffkreisläufe. Sie führen lokal Nährstoffe zu und entziehen diese durch die Abfuhr von Ernteprodukten und die Bodenbearbeitung wieder. Frühe Düngemaßnahmen waren die Nutzung organischer Düngemittel aus Lagerstätten, die gezielte Ausbringung tierischer und menschlicher Exkremente sowie der Anbau von Leguminosen. Letztere binden heute in etwa so viel $\mathrm{N}$ wie die verbleibende biologische Fixierung (Ciais et al. 2013). Die Verbrennung fossiler Energieträger setzt reaktiven $\mathrm{N}$ frei, den Niederschläge (d.h. Deposition) in die Biosphäre einbringen. Die massivsten Auswirkungen auf den N-Kreislauf hat jedoch das im frühen 20. Jahrhundert entwickelte Haber-Bosch-Verfahren. Hierbei wird $\mathrm{N}_{2}$ im industriellen Maßstab gebunden und als mineralischer N-Dünger pflanzenverfügbar gemacht. Die dadurch gebundenen Mengen entsprechen in etwa der Summe der biologischen Fixierung der Land- und Forstwirtschaft und jener natürlicher Ökosysteme. Heute ernährt sich rund die Hälfte der Menschen von Nahrungsmitteln, die mit $\mathrm{N}$ aus dem Haber-Bosch-Verfahren erzeugt werden (Erisman et al. 2008).

Der reichlich verfügbare reaktive $\mathrm{N}$ und punktuell auch die hohen P-Gehalte der Böden durch Düngung verändern terrestrische und aquatische Ökosysteme. $\mathrm{N}_{2} \mathrm{O}$ ist ein potentes Treibhausgas. N-Emissionen, allen voran $\mathrm{NO}_{x}$ aus der Verbrennung fossiler Energieträger und Ammoniak aus der Landwirtschaft beeinträchtigen die menschliche Gesundheit. Die jährlichen gesellschaftlichen Kosten in der EU durch N aus verschiedenen Quellen werden auf 70 bis 320 Mrd. € geschätzt (Sutton et al. 2011).

Global betrachtet ist die landwirtschaftliche Landnutzung mit rund zwei Drittel des Gesamtverbrauchs der größte Wasserverbraucher (OECD 2012) und greift damit in den natürlichen Wasserkreislauf ein. Der überwiegende Anteil entfällt auf die Bewässerung von Ackerkulturen durch die Nutzung erneuerbarer ober- und unterirdischer Quellen, aber auch nichterneuerbarer fossiler Grundwässer. Damit kann die natürliche Funktionsfähigkeit aquatischer Ökosysteme eingeschränkt werden. Es entsteht eine Konkurrenz zu alternativen Nutzungen, etwa zur Energieerzeugung und zum industriellen und privaten Verbrauch. 
Wissenschaftlerinnen und Wissenschaftler sprechen heute vom sechsten globalen Massensterben von Tier- und Pflanzenarten (siehe auch Beitrag 4.4). Eine Ursache dafür ist die Landnutzung, die in vielfacher Weise die Biodiversität beeinflusst. Sie entfernt Arten (z.B. durch Rodung eines Waldes oder Einsatz von Pestiziden) und bringt neue in ein Ökosystem ein (z.B. eine Ackerkultur). Die Landnutzung verändert biogeochemische Prozesse, darunter die Nährstoff- und Wasserkreisläufe. Durch Düngung werden beispielsweise nährstoffbedürftige Arten gefördert, wodurch jene mit geringerem Nährstoffbedarf benachteiligt werden. Eingriffe in Böden und Vegetation, z.B. durch Pflugbewirtschaftung, Mahd von Gras oder das Entfernen von Landschaftselementen (z.B. Streuobst) verändern das Nahrungsangebot und die Habitate für die Reproduktion. Große Infrastruktureinrichtungen zerschneiden Lebensräume und können die Migration von Tieren unterbinden. Über die zahlreichen Verflechtungen der Arten etwa in Nahrungsnetzen können Eingriffe unerwartete Konsequenzen mit sich bringen (siehe Baudron und Giller 2014). Landnutzung kann jedoch auch zur Artenvielfalt beitragen, weil sie neue Lebensräume schafft. Arten wandern oder passen sich im Zuge der Evolution an die Landnutzung an. Dadurch entstanden über Jahrtausende seminatürliche Lebensräume, etwa die extensiven Wiesen der österreichischen Kulturlandschaft. Sie beherbergen eine Vielzahl an spezialisierten Tier- und Pflanzenarten, die an eine offene Kulturlandschaft gebunden sind. Ohne regelmäßige Mahd würden die Standorte verwalden und die Arten verschwinden. Eine Intensivierung, z.B. durch Düngung und häufigere Mahd, würde die Standorte zwar offenhalten, führt in der Regel aber auch zu geringeren Artenzahlen (vgl. Zechmeister et al. 2003; Beispiele für artenreiche Wiesen finden sich im Biosphärenpark Wienerwald 2019; siehe auch Beitrag 4.4).

Mit dem Verlust intakter Ökosysteme durch die Landnutzung können Leistungen verloren gehen, von denen die Gesellschaft profitiert. Diese werden mit dem Konzept der Ökosystemleistungen beschrieben. In der Landwirtschaft sind die Bestäubungsleistung von Insekten und die Kontrolle von Schädlingen durch natürliche Räuber besonders relevant. Ausgewogene Landnutzungsentscheidungen berücksichtigen die Ökosystemleistungen unterschiedlicher Landnutzungssysteme und den gesellschaftlichen Bedarf. Abschnitt 4.3.4 beschäftigt sich mit Mechanismen, diese ausgewogenen Landnutzungsentscheidungen durchzusetzen.

\subsubsection{Steuerungsmöglichkeiten der Landnutzung}

Die Landnutzung resultiert aus individuellen und kollektiven Entscheidungen mit großen Auswirkungen auf das System Erde. Den Entscheidungsprozessen liegen verschiedene biophysikalische und sozioökonomische Faktoren zugrunde. Zu Ersteren zählen u.a. 
das standörtliche Klima, die Hangneigung und Bodenqualität, zu Zweiteren u.a. Marktpreise für Betriebsmittel und Produkte, Gesetze, individuelle und soziale Normen oder die Verfügbarkeit von Technologien, Arbeitskräften und Kapital. Für Entscheidungen relevant sind nicht nur aktuelle Rahmenbedingungen, sondern auch Erwartungen über zukünftige Entwicklungen, besonders wenn es um langfristige Investitionen geht.

Gesellschaftliche Ansprüche an die Landnutzung und daraus resultierende Ökosystemleistungen können über vielfältige Instrumente verwirklicht werden. In funktionierenden Märkten entscheidet neben den Produktionskosten die Zahlungsbereitschaft der Konsumentinnen und Konsumenten über Angebotsmengen und Herstellungsmethoden.

Gesetze legen fest, welche Betriebsmittel in welchen Mengen und Anwendungszeiträumen erlaubt sind (siehe z.B. die Debatte über den Einsatz von Neonicotinoiden und Glyphosat im Pflanzenschutz). Sie bestimmen die Nutzung von Land durch Bebauungspläne, die Ausweisung von Schutzzonen (z.B. Hochwasser) und Naturschutzgebieten. In Österreich ist Wald gesetzlich geschützt und darf nur in Ausnahmefällen gerodet und in andere Formen der Landnutzung umgewandelt werden. Diese normativen Instrumente werden durch ökonomische ergänzt, darunter Steuern auf umweltschädliches Verhalten (z.B. Besteuerung von Grundverbrauch, Mineraldüngern und Pestiziden) oder Subventionen zur Förderung von umweltfreundlichem Verhalten (siehe Fallbeispiel 4.3.2 sowie Beiträge 2.1 und 6.1).

\section{Fallbeispiel 4.3.2: Österreichisches Agrarumweltprogramm (BMNT 2019)}

Das „Österreichische Programm zur Förderung einer umweltgerechten, extensiven und den natürlichen Lebensraum schützenden Landwirtschaft" (ÖPUL) ist Bestandteil der Politik zur Entwicklung ländlicher Räume. Die Ziele des ÖPUL sind u.a.:

- Wiederherstellung, Erhaltung und Verbesserung der biologischen Vielfalt,

- Verbesserung der Wasserwirtschaft,

- Verhinderung der Bodenerosion und Verbesserung der Bodenbewirtschaftung,

- Verringerung der aus der Landwirtschaft stammenden Treibhausgas- und Ammoniakemissionen,

- Förderung der Kohlenstoffspeicherung und -bindung in der Land- und Forstwirtschaft.

Über das ÖPUL erhalten Bäuerinnen und Bauern Prämien, wenn sie sich über einen mehrjährigen Zeitraum zu bestimmten Landnutzungen verpflichten. Typische Maßnahmen sind die Reduktion oder der gänzliche Verzicht auf synthetische Betriebsmittel (z.B. mineralischer N-Dünger, Pestizide), die Beschränkung der Tierproduktion oder die Wahl bestimmter Fruchtfolgen (z.B. Zwischenfrüchte zur Minderung der Bodenerosion). Im Jahr 2017 beliefen sich die ÖPUL-Zahlungen auf rund 440 Mio. $€$. Es nahmen $83 \%$ aller im EU-Fördersystem registrierten Betriebe (INEKOS) teil. Das entspricht $82 \%$ der landwirtschaftlich genutzten Fläche dieser Betriebe (weiterführende Informationen: BMNT 2018).

Längerfristig entscheiden die privaten und öffentlichen Investitionen in Infrastruktur, Bildung und Technologieentwicklung über die Ausprägungen und Auswirkungen der 
Landnutzung. Da Technologien eine lange Vorlaufzeit bis zur Marktreife aufweisen und einmal getätigte Investitionen lange wirksam sind, müssen solche Entscheidungen gut durchdacht sein. Unser auf fossilen Energieträgern beruhendes Wirtschaftssystem zeigt die Pfadabhängigkeit, also die Verstärkung von Effekten eines einmal eingeschlagenen Wegs, deutlich. Investitionen in Straßen beschleunigen beispielsweise die Rodung tropischer Regenwälder (Laurance und Arrea 2017). Der Bau großer Bewässerungsinfrastruktur (z.B. Staudämme) entscheidet über die Möglichkeit und Kosten der Bewässerung landwirtschaftlicher Kulturen. Auch unter dem Gesichtspunkt der Anpassung an den Klimawandel ist die Verfügbarkeit zukünftiger Technologien entscheidend, z.B. angepasste Sorten bei Ackerkulturen, deren Züchtung Jahre in Anspruch nehmen kann (vgl. Abschnitt 4.3.3.2).

\subsubsection{Zusammenfassung und Ausblick}

Landnutzung steht in vielfachen Wechselbeziehungen zu anderen Phänomenen des globalen Wandels. Wissenschaftlerinnen und Wissenschaftler versuchen, über die Definition von globalen Grenzen für Teilaspekte des Systems Erde (Planetary Boundaries) jenen Bereich festzulegen, innerhalb dessen dauerhaftes menschliches Leben auf der Erde möglich ist (Steffen et al. 2015; siehe auch Beitrag 4.1). Teilaspekte davon - nur die für die Thematik Landnutzung wichtigsten konnten in diesem Beitrag diskutiert werden - beinhalten den Klimawandel, die Einführung neuer Arten in fremde Ökosysteme (Neobiota), die Zerstörung des Ozonlochs, den atmosphärischen Gehalt an Aerosolen, die Versauerung der Ozeane, die biochemischen Zyklen für P und N, den Verbrauch an Frischwasser, die Landbedeckung und die Integrität der Biosphäre. Aus den Ausführungen dieses Beitrags wird deutlich, dass die Landnutzung in nahezu alle Teilaspekte hineinwirkt. Die lokalen bis globalen Ausprägungen der Landnutzung entscheiden über den Zustand und die zukünftige Entwicklung des Systems Erde.

Dem Konsumverhalten der Menschen kommt dabei eine entscheidende Rolle zu. Bis zur Mitte des 21. Jahrhunderts könnte die Weltbevölkerung von derzeit rund 7 Mrd. auf über 9 Mrd. Menschen wachsen. Aufgrund des steigenden Wohlstands wird ein Mehrbedarf an Nahrungsmitteln von bis zu 100\% erwartet (Tilman et al. 2011). Da bereits heute planetare Grenzen überschritten werden und sich die globalen Produktionsbedingungen durch den Klimawandel eher verschlechtern dürften, erscheinen nachhaltigere Formen der Landnutzung in Verbindung mit einem veränderten Konsumverhalten unausweichlich. Das betrifft insbesondere den Verbrauch an Flächen für Siedlungen, Infrastruktur und wirtschaftliche Aktivitäten, den Abbau nichterneuerbarer Ressourcen und die Nachfrage nach land- und forstwirtschaftlichen Gütern, darunter tierische Produkte mit ihrem charakteristisch hohen Ressourcenbedarf. 


\section{Literatur}

Baudron, F. and Giller, K. E. (2014): Agriculture and nature: Trouble and strife? Biological Conservation, 170, 232-245. https://doi.org/10.1016/i.biocon.2013.12.009.

BMNT (Bundesministerium für Nachhaltigkeit und Tourismus) (2019): ÖPUL. Das österreichische AgrarUmweltprogramm. Verfügbar in: https://www.bmnt.gv.at/land/laendl entwicklung/oepul.html [Abfrage am 9.4.2019].

Ciais, P., Sabine, C., Bala, G., Bopp, L., Brovkin, V., Canadell, J., Chhabra, A., DeFries, R., Galloway, J., Heimann, M., Jones, C., Le Quéré, C., Myneni, R. B., Piao, S., and Thornton, P. (2013): Carbon and other biogeochemical cycles. In: Stocker, T. F., Qin, D., Plattner, G.-K., Tignor, M., Allen, S.K., Boschung, J., Nauels, A., Xia, Y., Bex, V., and Midgley, P. M., eds., Climate Change 2013: The Physical Science Basis. Contribution of Working Group I to the Fifth Assessment Report of the Intergovernmental Panel on Climate Change. Cambridge, UK, New York, NY, USA: Cambridge University Press, 465-570.

Erisman, J. W., Sutton, M. A., Galloway, J., Klimont, Z., and Winiwarter, W. (2008): How a century of ammonia synthesis changed the world. Nature Geoscience, 1, 636-639. https://doi.org/10.1038/ngeo325.

EU COM (European Commission) (2019): Sustainability criteria. Available at: https://ec.europa.eu/energy/en/topics/renewable-energy/biofuels/sustainability-criteria [accessed 9.4.2019].

FAO and UNEP (Food and Agriculture Organization of the United Nations; United Nations Environment Programme) (1999): The Future of Our Land. Facing the Challenge. Rome.

Fuglie, K. O. and Wang, S. L. (2012): New evidence points to robust but uneven productivity growth in global agriculture. Amber Waves, 10, 1-6. https://doi.org/10.1177/0974910112469266.

Hertel, T. W., Golub, A. A., Jones, A. D., O'Hare, M., Plevin, R. J., and Kammen, D. M. (2010): Effects of US maize ethanol on global land use and greenhouse gas emissions: Estimating marketmediated responses. BioScience, 60, 3, 223-231. https://doi.org/10.1525/bio.2010.60.3.8.

IGBP (International Geosphere-Biosphere Programme) (2019): Earth system definitions. Available at: http://www.igbp.net/globalchange/earthsystemdefinitions.4.d8b4c3c12bf3be638a80001 040.html [accessed 9.4.2019].

Laurance, W. F. and Arrea, I. B. (2017): Roads to riches or ruin? Science, 358, 6362, 442-444. https://doi.org/10.1126/science.aao0312.

OECD (Organisation for Economic Co-operation and Development) (2012): OECD Environmental Outlook to 2050. Paris: OECD Publishing. https://dx.doi.org/10.1787/9789264122246-en.

Searchinger, T., Heimlich, R., Houghton, R. A., Dong, F., Elobeid, A., Fabiosa, J., Tokgoz, S., Hayes, D., and Yu, T.-H. (2008): Use of U.S. croplands for biofuels increases greenhouse gases through emissions from land-use change. Science, 319, 1238-1240. https://doi.org/10.1126/science.1151861.

Statistik Austria (2018): Konsumerhebung 2014/15. Verfügbar in: https://www.statistik.at/web de/statistiken/menschen und gesellschaft/soziales/verbra uchsausgaben/konsumerhebung 2014 2015/index.html [Abfrage am 9.4.2019].

Steffen, W., Sanderson, A., Tyson, P., Jäger, J., Matson, P. A., Moore III, B., Oldfield, F., Richardson, K., Schellnhuber, H. J., Turner II, B. L., and Wasson, R. J. (2004): Global Change and the Earth System. A Planet Under Pressure. Berlin et al.: Springer.

Steffen, W., Richardson, K., Rockström, J., Cornell, S. E., Fetzer, I., Bennett, E. M., Biggs, R., Carpenter, S. R., Vries, W. de, Wit, C. A. de, Folke, C., Gerten, D., Heinke, J., Mace, G. M., Persson, L. M., Ramanathan, V., Reyers, B., and Sörlin, S. (2015): Planetary boundaries: Guiding human development on a changing planet. Science, 347, 1-10. https://doi.org/10.1126/science.1259855.

Steffen, W., Rockström, J., Richardson, K., Lenton, T. M., Folke, C., Liverman, D., Summerhayes, C. P., Barnosky, A. D., Cornell, S. E., Crucifix, M., Donges, J. F., Fetzer, I., Lade, S. J., Scheffer, 
M., Winkelmann, R., and Schellnhuber, H. J. (2018): Trajectories of the earth system in the Anthropocene. Proceedings of the National Academy of Sciences of the United States of America (PNAS), 115, 33, 8252-8259. https://doi.org/10.1073/pnas.1810141115.

Sutton, M. A., Oenema, O., Erisman, J. W., Leip, A., van Grinsven, H., and Winiwarter, W. (2011): Too much of a good thing. Nature, 472, 159-161. https://doi.org/10.1038/472159a.

Tilman, D., Balzer, C., Hill, J., and Befort, B. L. (2011): Global food demand and the sustainable intensification of agriculture. Proceedings of the National Academy of Sciences of the United States of America (PNAS), 108, 50, 20260-20264. https://doi.org/10.1073/pnas.1116437108.

Zechmeister, H. G., Schmitzberger, I., Steurer, B., Peterseil, J., and Wrbka, T. (2003): The influence of land-use practices and economics on plant species richness in meadows. Biological Conservation, 114, 2, 165-177. https://doi.org/10.1016/S0006-3207(03)00020-X.

\section{Weiterführende Literatur}

Biosphärenpark Wienerwald (Biosphärenpark Wienerwald Management GmbH) (2019): Webseite des Biosphärenparks Wienerwald. Verfügbar in: https://www.bpww.at/ [Abfrage am 25.6.2019].

BMNT (Bundesministerium für Nachhaltigkeit und Tourismus) (2018): Grüner Bericht 2018. Bericht über die Situation der österreichischen Land- und Forstwirtschaft. Wien. Verfügbar in: https://gruenerbericht.at/ [Abfrage am 25.6.2019].

Doucet, A.-M., Gaffney, O., Haeggman, M., Moberg, F., Pharand-Deschênes, F., and Simonsen S. (2019): Welcome to the Anthropocene. Website. Available at: http://www.anthropocene.info/ [accessed 25.6.2019].

FAO (Food and Agriculture Organization of the United Nations) (2019): Website of the FAO. Available at: http://www.fao.org/home/en/ [accessed 25.6.2019]

Future Earth (2019): Future Earth Partnership. Website. Available at: http://futureearth.org/ [accessed 25.6.2019].

Pingali, P. L. (2012): Green revolution: impacts, limits, and the path ahead. Proceedings of the National Academy of Sciences of the United States of America (PNAS), 109, 31, 12302-12308. https://doi.org/10.1073/pnas.0912953109. 


\section{4 Ökosysteme, Landnutzung \& Biodiversität}

\subsection{Biodiversitätskrise und Ökosystemdienstleistungen}

Harald Meimberg

Institut für Integrative Naturschutzforschung,

Department für Integrative Biologie und Biodiversitätsforschung (DIBB)

meimberg@boku.ac.at

\subsubsection{Was versteht man unter Biodiversität?}

Die Erde ist der einzige Planet, von dem wir sicher sind, dass er Leben hervorgebracht hat. Er ist in geeigneter Entfernung zur Sonne, um die Existenz von flüssigem Wasser zu erlauben, kann eine Atmosphäre halten und zeigt verschiedene andere Eigenschaften, die wir für die Entwicklung von Leben als notwendig erachten. Auch wenn neuere astronomische Forschungen viele ähnlich geeignete Planten vermuten lassen, ist alles uns bisher bekannte Leben von der Erde. Menschen sind ein Teil davon und zusammen mit allen anderen derzeit existierenden Organismen das Ergebnis einer 2 Mrd. Jahre andauernden Entwicklung. Die Evolution, die biologische Grundlage für diese Entwicklung, führte nach derzeitigem Wissensstand zu einer weiteren Aufspaltung in an unterschiedliche Bedingungen angepasste Formen. Diese Formen bezeichnen wir in der Regel als Arten und sehen sie meist als kleinste ökologische Einheit an.

Das Leben selbst war ein wesentlicher Faktor für die Geologie unseres Planeten. Organismen veränderten die Erde und ihre Lebensbedingungen eingehend. Damit erscheint der derzeitige Zustand der Erde als Ergebnis einer Einheit aus geologischer Entwicklung und biologischer Evolution. Dies ist der Kern der Gaia-Hypothese, die erstmals vor ca. 50 Jahren von J. Lovelock und L. Margulis vorgeschlagen wurde (vgl. Lovelock 1995; Schneider und Boston 1991). Die Hypothese wird häufig als philosophisches Konzept angesehen, welches die Einheit von Natur und Erde unterstreicht. Sie beruht jedoch auf gut gesicherten naturwissenschaftlichen Befunden: Viele durch Organismen geprägte Prozesse verändern über lange Zeiträume die geologischen Gegebenheiten (z.B. bei der Humusbildung). Eines der wichtigsten Beispiele in diesem Zusammenhang ist die Entstehung der Atmosphäre mit ihrem Sauerstoffgehalt. Diese ist heute weitgehend als Ergebnis biogener Prozesse akzeptiert. Der langsame Übergang von einer reduzierenden (sauerstoffarmen) zu einer oxidierenden (sauerstoffreichen) Atmosphäre, zunächst durch den Stoffwechsel von bakteriellen Mikroorganismen und später durch die Photosynthese der Pflanzen, zeigt die Interaktion zwischen Evolution und Geologie besonders deutlich. Die kontinuierliche Sauerstoffzunahme in der Atmosphäre veränderte nicht nur deren Zusammensetzung, sondern führte auch zu einer Oxidation oberflächennaher Mineralien (z.B. zur Entstehung von Eisenerzlagern). Die von Organismen veränderten Bedingungen auf der Erde machten wiederum neue Anpassungen erforderlich. Orga- 
nismen sind also nicht nur als Reaktion auf die Geologie der Erde entstanden, vielmehr beeinflussen sich beide Aspekte wechselseitig. Sie sind daher sehr wahrscheinlich auch für den Erhalt der derzeitigen Lebensbedingungen verantwortlich und unabdingbar.

Grundlage für die biologische Vielfalt (die Biodiversität) ist die Evolution. Sie erlaubt als Prozess die graduelle Anpassung an die jeweiligen Bedingungen und ermöglicht es, vorhandene Energie immer effektiver zu nutzen. Nach dem Prinzip der Ressourcenteilung teilen sich Arten, die miteinander in Konkurrenz stehen, vorhandene Umweltressourcen so auf, dass jede Art eine ökologische Nische besetzt. Dadurch kann ein größeres Spektrum an Ressourcen genutzt werden, was die Zahl der Arten kontinuierlich ansteigen lässt. Unterbrochen wurde diese Entwicklung von verschiedenen, durch Katastrophen ausgelöste Aussterbeereignisse. Dies führte zur heutigen Ausstattung der Erde mit Arten, Populationen und Individuen. Diese bezeichnen wir allgemein als Biodiversität.

In der Regel wird Biodiversität als die Anzahl von Arten und ihre relative Häufigkeit in einem bestimmten Gebiet betrachtet. Noss (1990) entwickelte eine grundlegende Charakterisierung der Biodiversität und definierte drei Aspekte: (1) Zusammensetzung (Wie ist eine Population, eine Art, eine Artengruppe, ein Ökosystem etc. zusammen-

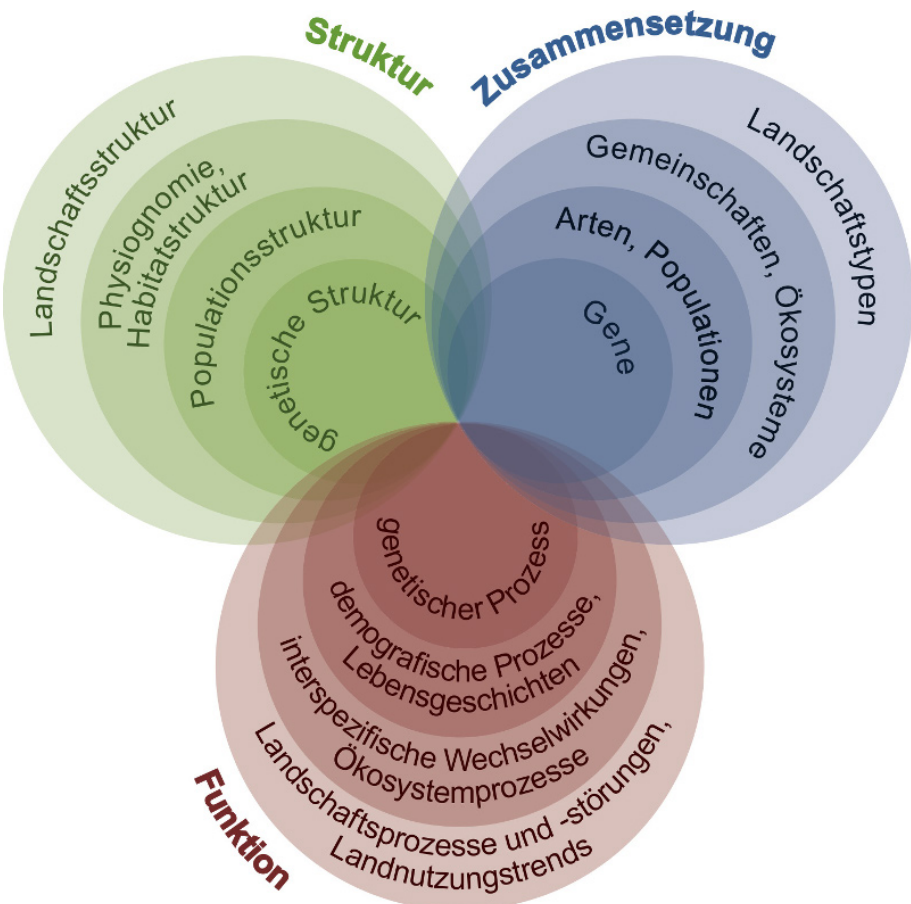

Abbildung 4.4.1: Die drei Aspekte der Biodiversität (Zusammensetzung, Struktur und Funktion) in den verschiedenen Betrachtungsebenen (nach Noss 1990, verändert) 


\section{4 Ökosysteme, Landnutzung \& Biodiversität}

gesetzt?), (2) Funktion (unterschiedliche ökologische Rollen und Prozesse, die Organismen einnehmen bzw. verursachen können) und (3) Struktur (Unterschiede, die nicht innerhalb von Einheiten, sondern zwischen den Einheiten bestehen). Diese drei Aspekte können auf unterschiedlichen Ebenen betrachtet werden: beispielsweise innerhalb einer Art (Diversität der Individuen oder Genotypen) oder innerhalb von Gesellschaften (z.B. Diversität der Arten in einer Artengruppe). Mehrere Gesellschaften bilden wiederum ein Ökosystem, verschiedene Ökosysteme formen Großlebensräume, sogenannte Biome. Abbildung 4.4.1 zeigt die drei Aspekte der Biodiversität in den unterschiedlichen Ebenen.

\subsubsection{Artenzahlen}

Derzeit sind ca. 1,5 Mio. Arten beschrieben, d.h., sie wurden von Expertinnen und Experten als homogene Gruppe erkannt und von anderen, ähnlichen Gruppen abgegrenzt. Eine Art wird meist als Gruppe von Individuen definiert, die sich nur untereinander fortpflanzen können, aber nicht mit Angehörigen anderer Gruppen (biologisches Artkonzept). Regelmäßig werden neue Arten entdeckt, und es stellt sich die Frage, wie viele Arten es tatsächlich gibt. Derzeit gehen wir von ca. 8 Mio. Arten aus, davon ungefähr 1 Mio. Pflanzen und Pilze (Mora et al. 2011; Stork 2018), wovon ca. $18 \%$ beschrieben sind. Die besser bekannten Gruppen wie Säugetiere oder Vögel mit ca. 4.400 bzw. 10.000 Arten sind wahrscheinlich sehr genau erfasst. Andere Artengruppen wie die Zweiflügler (Fliegen und Mücken) sind viel weniger detailliert beschrieben. Nur wenige Expertinnen und Experten befassen sich mit den kleinen, unscheinbaren Arten, die sich morphologisch nur schwer einteilen lassen (Stork 2018).

Da wir die Biodiversität eines Areales meist als die dort vorkommende Anzahl der Arten darstellen, sehen wir eine Änderung der Biodiversität meist als eine veränderte Artenzusammensetzung an. Dies ist allerdings vereinfachend. Wesentliche ökologische Effekte sind auch von der absoluten Individuenanzahl der einzelnen Arten und vom Verhältnis dieser Zahlen zueinander bestimmt. All diese Faktoren führen dazu, dass Systeme mit hoher Biodiversität andere Eigenschaften haben als solche mit geringer Diversität.

\subsubsection{Rückgang der Biodiversität}

Biodiversität wird durch die menschliche Landnutzung maßgeblich beeinträchtigt. Dies kann auf verschiedene Weise erfolgen: durch direkte Nutzung von Organismen oder deren Entnahme aus der Natur, aber auch durch Beeinflussung der Lebensumstände von Lebewesen, beispielswiese weil der Mensch mit anderen Arten um Ressourcen konkurriert oder weil er deren Lebensräume in nutzbare Produktionsflächen 
umwandelt. Hierbei verringert sich nicht nur die für die Organismen verfügbare Fläche, es nimmt auch die Lebensraumqualität $\mathrm{ab}$. Landbewirtschaftung spielt hierbei eine wesentliche Rolle. Regionen, die schon lange intensiv landwirtschaftlich genutzt werden, unterscheiden sich stark von der vom Menschen unbeeinflussten Natur. In diesem Zusammenhang unterscheidet man zwischen natürlicher bzw. primärer Vegetation (ohne menschlichen Einfluss) und potenzieller Vegetation (Entwicklung unter den derzeitigen Bedingungen ohne weiteren Einfluss des Menschen).

Durch lang andauernde, extensive Nutzung sind andererseits viele Ökosysteme entstanden, die besonders wertvoll für die Biodiversität sind. Dazu zählen z.B. Magerrasen, Streuwiesen oder Almwiesen, die durch Nährstoffaustrag aufgrund menschlicher Aktivität entstanden sind und heute hohe Naturschutzpriorität haben. Diese sekundären Lebensräume werden derzeit zunehmend in intensive Produktionsflächen umgewandelt oder gar nicht mehr durch den Menschen genutzt. In beiden Fällen kommt es zu einer Reduktion der Biodiversität in diesen Agroökosystemen. Durch die Bearbeitung des Bodens und durch Düngung sind solche Biotope weitgehend verschwunden. Jene Bereiche der Erde, die nicht im Fokus menschlicher Nutzung stehen, werden immer weniger (Watson et al. 2016). Selbst Flächen, die nicht direkt genutzt werden, sind durch Einflüsse aus der Umgebung zunehmend als natürlicher Lebensraum ungeeignet. Die Abnahme von Individuen- und Artenzahlen lässt sich also durch den Flächenverbrauch sowie die Beeinträchtigung und die direkte Entnahme von Organismen erklären.

\subsubsection{Die Biodiversitätskrise}

Die Abnahme der Individuenzahlen, auch wenn sie noch nicht zum globalen Aussterben einer Art geführt hat, bedeutet eine wesentliche Veränderung in der Zusammensetzung der Artengemeinschaften. Die einzelnen Erdzeitalter sind durch solche Veränderungen charakterisiert, sodass sich eine bestimmte Abfolge dieser Zusammensetzung ergibt. Ein bekanntes Beispiel ist der Übergang von der Kreide zum Tertiär, bei dem 75\% der Arten und ca. 40\% der Gattungen verschwanden. Als Grund dieses Ereignisses, bei dem auch die Dinosaurier ausstarben, wird ein Meteoriteneinschlag angenommen. Ähnliche Katastrophen scheinen bei jedem Wechsel von einem Erdzeitalter zu einem anderen eine Rolle zu spielen (Barnosky et al. 2011). Eine starke Änderung der Artenzahl ist auch gegenwärtig zu erwarten, weshalb 2008 bei der Geological Society of London die Anerkennung des aktuellen Zeitabschnittes als Beginn eines neuen Zeitalters (Anthropozän) beantragt wurde. Dass es zu einer solchen Anerkennung kommt, ist wahrscheinlich, da die derzeitigen menschlichen Aktivitäten eine sehr starke Veränderung in der Artenzusammensetzung erwarten lassen (Steffen et al. 2011). 


\section{Fallbeispiel 4.4.1: Populationsentwicklung der Nashörner}

Derzeit leben auf der Erde fünf Nashornarten (zwei in Afrika und drei in Asien). Während der vergangenen Eis- und Zwischeneiszeiten gab es noch einige andere Nashornarten in den gemäßigten Breiten. Diese sind allerdings mit dem Verschwinden der sogenannten eiszeitlichen Megafauna ausgestorben, eventuell unter Beteiligung des Menschen. Die heutigen Nashornarten haben eine tropische bis subtropische Verbreitung mit Ausläufern in warmgemäßigten Regionen (z.B. Nordafrika). Die Arten sind bis zu einem gewissen Grad ökologisch getrennt. In Afrika ist z.B. das Spitzmaulnashorn ein Selektierer (d.h. seine Nahrung ist arm an Pflanzenfasern, aber reich an leicht verdaulichen Nährstoffen), während das Breitmaulnashorn ein typischer Weidegänger ist.

Nashörner wurden durch die kommerzialisierte Jagd stark dezimiert. Sie waren während des Kolonialismus bevorzugtes Ziel von Großwildjägern. Außerdem wird das Kollagen, aus dem das Horn besteht, als Bestandteil traditioneller Medizin sowie als Rohstoff für verschiedene Artefakte gehandelt. Dieser Handel brach auch nach der Unterschutzstellung der Arten nicht ab und wird heute durch Wilderei und einen illegalen Schwarzmarkt aufrechterhalten. Dies führte zu einer sehr starken Abnahme der Individuenzahlen.

Besonders gut dokumentiert ist die Populationsentwicklung der afrikanischen Arten (Emslie 2012a, b). Ende des 19. Jahrhunderts war das Spitzmaulnashorn in Afrika südlich der Sahara verbreitet (mit geschätzten 1 Mio. Individuen), es wurde jedoch bis in die 1960er-Jahre auf wenige 1.000 Individuen dezimiert (Moodley et al. 2017). Die Abnahme kann nur zum Teil mit der zunehmenden Flächennutzung durch den Menschen erklärt werden. In vielen geschützten oder wenig genutzten Arealen wurden Nashörner ebenfalls zurückgedrängt. Heute existieren ca. 5.000 Individuen hauptsächlich in afrikanischen Nationalparks in voneinander getrennten Gebieten. Durch gezielte Managementmaßnahmen wird derzeit versucht, die Population des Spitzmaulnashorns wieder zu vergrößern (Black Rhino Expansion Program).

Zwischenzeitlich war ein ähnliches Programm bei der anderen afrikanischen Art, dem Breitmaulnashorn, sehr erfolgreich. Das Breitmaulnashorn hat seinen Verbreitungsschwerpunkt im südlichen Afrika. Vor Beginn der systematischen Bejagung betrug die Populationsgröße geschätzte 300.000 Tiere. Anfang des 20. Jahrhunderts lebten nur noch wenige 100 Individuen in einigen geschützten Arealen und in privaten Farmen in Südafrika. Bis zum Jahr 2000 konnte die Population auf ca. 20.000 Individuen erhöht werden. In einem Translokationsprogramm wurden die Tiere nicht nur auf von Nashörnern besiedelte Areale verteilt, sondern auch auf Gebiete, wo die Art in historischen Zeiten vorkam, aber durch Bejagung ausgerottet wurde. Dadurch wurde eine Populationsdynamik wiederhergestellt, welche neben Wachstum auch die Prozesse der Ausbreitung und Kolonisierung umfasst. So konnte eine kontinuierliche Zunahme der Population erreicht werden. Solch ein Vorgehen ist nicht selbstverständlich. Neben der unbestrittenen Schwierigkeit, große Säugetiere in neue Gebiete einzuführen, ohne dabei Konflikte mit der lokalen Bevölkerung zu erzeugen, birgt die Translokation auch das Risiko des Transports für die Tiere. Sie müssen betäubt und teilweise unter dem Hubschrauber hängend transportiert werden. Das Risiko, die Tiere dabei zu verletzen oder zu traumatisieren, ist sehr groß. Eine Managementmaßnahme, die das Einfangen aller oder eines großen Teils der verbliebenen Individuen beinhaltet, birgt daher auch die Gefahr, das Aussterben zu beschleunigen. Auch können Habitate, in welche die Nashörner eingeführt werden, heute ungeeignet sein. Dies zeigen Rückschläge im Expansionsprojekt, das derzeit für Spitzmaulnashörner durchgeführt wird. Hier sind nach der Translokation einige Tiere in den neuen Gebieten verhungert. Ungeachtet solcher Rückschläge waren bei Nashörnern Expansionsprojekte bisher sehr erfolgreich, auch wenn die Populationen heute wieder sinken. Anfang des 21. Jahrhunderts stieg der Jagddruck durch Wilderei v.a. auf das Breitmaulnashorn. Angefacht durch die Nachfrage nach Horn als medizinisches Produkt in Asien werden derzeit jährlich bis zu 1.359 Tiere dieser Art getötet (im Jahr 2015), zwischen 2007 
und 2018 insgesamt 9.150 Tiere (Save the Rhino International 2018). Die Mortalitätsrate (jährlich bis zu 10\%) kann nicht durch mehr Geburten ausgeglichen werden. Diese - als zweite Wildereikrise (second poaching crisis) bezeichnete - Entwicklung verursacht eine kontinuierliche Abnahme der Population. Derzeit leben ca. 20.000 Breitmaulnashörner.

In Asien kommen drei Nashornarten vor. Das Panzernashorn oder Indische Nashorn mit Verbreitungsschwerpunkt auf dem indischen Subkontinent ist heute auf die Ausläufer des Himalayas in Indien, Nepal und Bhutan beschränkt. Das Sumatra-Nashorn und das Java-Nashorn kamen in teilweise überlappenden Arealen in ganz Südostasien vor (vom Norden Vietnams über die Malaiische Halbinsel bis zu den Inseln des Sunda-Schelfs, Sumatra, Java und Borneo). Anfang des 20. Jahrhunderts wurde das Indische Nashorn unter Schutz gestellt, nachdem es durch Jagd auf wenige Individuen dezimiert wurde. Heute beträgt die Population ca. 3.500 Individuen (Talukdar et al. 2008). Diese Zunahme wurde ähnlich wie in den oben genannten Expansionsprogrammen durch Wiederansiedlung in zwischenzeitlich verlorenen Arealen erreicht. Beim Sumatra-Nashorn und beim Java-Nashorn gelang dies nicht. Geschätzte 230 (evtl. auch nur mehr 87) Sumatra-Nashörner (Pusparini et al. 2015) leben verstreut in wenigen Gebieten (van Strien et al. 2008). Vom Java-Nashorn haben im National Park Ujung Kulon an der Westküste Javas nur 62 Tiere überlebt (Setiawan et al. 2017). Historisch war die Art v.a. aus Java bekannt. Im 18. Jahrhundert noch als Schädling für die Plantagenwirtschaft beschrieben, lassen Abschusszahlen von Expeditionsberichten darauf schließen, dass die Art auf Java zu den häufig auftretenden großen Säugetierarten zählte. Der Rückgang an Nashörnern auf Java wurde bereits vor dem Anstieg der menschlichen Population dokumentiert. Ab Mitte des 20. Jahrhunderts kam es nur noch im heutigen Nationalpark vor (Sody 1959). Auf einer Halbinsel gelegen, ist der Park nur schwer zugänglich und dadurch der Jagddruck geringer. Seit der Unterschutzstellung des Gebietes in den 1960er-Jahren ist die Populationsgröße konstant geblieben. Bis 2009 existierte eine zweite, wahrscheinlich schon seit längerer Zeit sehr kleine Restpopulation in Nordvietnam. Das letzte Individuum wurde durch Wilderer mit einem Schuss verletzt. Ein paar Jahre später wurde das Tier mit einem Steckschuss im Oberschenkelknochen gefunden, an dem es kurz nach der Verletzung verendete. Bei diesem Individuum handelte es sich um das letzte bekannte Exemplar außerhalb Javas (Brook et al. 2014). Das Java-Nashorn ist nun mit 62 Individuen akut vom Aussterben bedroht. Ein Expansionsprogramm kann hier nicht durchgeführt werden, da die Population nicht wächst und eine Translokation die wenigen verbliebenen Individuen zu stark gefährden würde.

\subsubsection{Anthropozänkonzept}

Die Nashornarten sind ein typisches Beispiel für die Bestandsentwicklung der Arten und Verwandtschaftsgruppen von Großsäugern. Weitere Beispiele sind der Amerikanische Bison und der Europäische Wisent (auch Europäischer Bison), deren aus wenigen Individuen bestehenden Restpopulationen sich langsam erholen. Große Raubkatzen wurden dezimiert, wie der Tiger, der von ca. 200.000 auf derzeit 3.500 Individuen zurückgegangen ist. Die verschiedenen Arten der Pferdeartigen sind außerhalb Afrikas in der Wildnis zwischenzeitlich ausgestorben und haben nur aufgrund von Zucht- und Wiederansiedlungsprogrammen überlebt. Auch wenn viele der Arten nach unseren Definitionen nicht unmittelbar vom Aussterben bedroht sind, stellen die niedrigen Individuenzahlen der heutigen Populationen einen wesentlichen Unterschied zu einem Zustand ohne den Einfluss des modernen Menschen dar. Je kleiner eine Population, 


\section{4 Ökosysteme, Landnutzung \& Biodiversität}

desto geringer ist die Wahrscheinlichkeit, dass ihre Mitglieder fossile Überreste hinterlassen, die in entfernter Zukunft gefunden werden könnten. Derzeit werden die ursprünglichen Arten im Fossilhorizont durch die Überreste jener Arten, deren Existenz wir erlauben und zu unserem eigenen Nutzen befördern, ersetzt. Die Biomasse von Broilern (für die Fleischproduktion gezüchtete Hühner) ist z.B. größer als jene aller landlebenden, nicht domestizierten Wirbeltiere. Zukünftige Betrachterinnen und Betrachter derzeit entstehender Fossilschichten könnten ein relativ plötzliches Auftreten fossiler Überreste von Hühnern und ein gleichzeitiges Verschwinden der meisten anderen Arten erkennen (Bennett et al. 2018). Diese durch den Artenrückgang gekennzeichnete Veränderung dient der Definition des Anthropozäns, das als neues Zeitalter das bisherige, seit der letzten Eiszeit bestehende Erdzeitalter (das Holozän) ablöst.

Der zu erwartende Artenrückgang, der mit diesem Übergang einhergeht, wird wahrscheinlich ähnlich hoch sein wie jener bei den bisherigen Massenaussterbeereignissen der Erdgeschichte. Bislang fanden fünf solcher Ereignisse mit einer Reduktion der Artenzahlen um mindestens 75\% statt. Mit je 75\% eher klein waren die Ereignisse am Übergang Kreide - Tertiär vor 60 Mio. Jahren und am Übergang Devon - Carbon vor 400 Mio. Jahren, gefolgt von ca. 80\% an der Grenze des Trias - Jura vor 200 Mio. Jahren und $86 \%$ am Übergang Ordovizium - Silur vor 450 Mio. Jahren.

Das größte Ereignis der Erdgeschichte fand vor 300 Mio. Jahren am Ende des Perms im Übergang zum Trias statt, als geschätzt 96\% der Arten verschwanden (Barnosky et al. 2011). Bisherige Aussterbeereignisse waren wahrscheinlich durch einen Rückgang der Artenzahlen im Verlauf von mehreren Hunderttausend oder Millionen Jahren gekennzeichnet. Die derzeitige Entwicklung machte sich bereits nach zwei bis drei Generationen des Menschen bemerkbar. Die hohe Aussterberate im Anthropozän ergibt sich, wenn wir die Anzahl der derzeit bedrohten Arten betrachten und der Mensch weiterhin die Auswirkungen seines Handelns ignoriert. Der Mensch scheint somit eine sehr „effektive Katastrophe“ darzustellen, die geeignet ist, das sechste Massenaussterben der Erdgeschichte zu verursachen. Dies stellt die derzeitige Biodiversitätskrise dar.

Die Biodiversitätskrise besteht also im Rückgang der Artenzahlen auf globaler Ebene, aber auch im Aussterben einzelner Populationen und im Verschwinden ihrer Funktionen auf lokaler Ebene. In den letzten Jahren wurde ein starker Rückgang der Biomasse oder der Individuenzahl ganzer Organismengruppen beschrieben, z.B. bei Insekten (Sánchez-Bayo und Wyckhuys 2019), Vögeln (z.B. Inger et al. 2015) und Säugetieren (Ripple et al. 2019). Besonderes Aufsehen erregte die sogenannte Krefelder Studie (Hallmann et al. 2017), die in unter Schutz gestellten Gebieten in den letzten 30 Jahren einen Rückgang der Insektenbiomasse um 75\% zeigte. Das Wirtschaften des Menschen führt zu einer starken Reduktion natürlicher Populationen auf Flächen, die unter 
Nutzung stehen, aber auch in vom Menschen nur wenig beeinflussten Gegenden. Dies deutet auf einen systematischen Einfluss hin, der bisher noch nicht oder nicht genügend berücksichtigt wurde. So ist nach neueren Ergebnissen in den letzten Jahren auch die Anzahl an Vögeln stark zurückgegangen, allen Naturschutzbemühungen zum Trotz (z.B. EBCC 2018; Newton 2004). Da v.a. Arten des Offenlandes betroffen sind, ist es sehr wahrscheinlich, dass es sich hierbei um einen direkten Effekt der Landwirtschaft handelt.

\subsubsection{Wozu brauchen wir Biodiversität?}

Nun stellt sich die Frage, ob und wozu die Menschheit Biodiversität braucht. Wir sind zwar von anderen Organismen abhängig, aber nicht notwendigerweise von allen. Während wir den Nutzen von Bienen sofort einsehen, da sie als Bestäuber eine Funktion haben, von der wir direkt profitieren, erschließt sich der Nutzen der Wiederbesiedlung Mitteleuropas durch den Wolf nicht so ohne Weiteres. Die Rückkehr des Wolfes erschwert die landwirtschaftliche Produktion, die nach der Ausrottung des Wolfes entwickelt wurde. Diese muss nun an Bedingungen angepasst werden, die zwar schon einmal existierten, uns heute aber als neu erscheinen.

Da der Mensch das Ergebnis der biologischen Evolution ist, könnte auch sein ökologischer Einfluss als natürlich definiert werden. Diese Argumentation wird gerne verwendet, um den Menschen und seine Ökonomie als Teil der Umwelt darzustellen. Damit wäre die derzeitige Biodiversitätskrise, ebenso wie frühere Massenaussterbeereignisse, ein natürlicher Vorgang. Dies ist aber zu stark vereinfachend. So wären andere ökologische Vorgänge wie beispielsweise katastrophale Populationseinbrüche in der menschlichen Bevölkerung auch als natürlich zu akzeptieren, was wir selbstverständlich nicht tun. Nach dieser Argumentation sind auch Maßnahmen, die der Mensch zur Abwendung der Biodiversitätskrise ergreift, Teil der Evolution bzw. Natur. Die Krise ist daher kein notwendiger Aspekt der natürlichen Entwicklung, sondern ein mögliches Ergebnis des menschlichen Verhaltens.

Zwei wesentliche Argumente können den Schutz von Biodiversität begründen. Diese sind zum einen naturphilosophisch charakterisiert, indem das Recht von Organismen auf Existenz anerkannt wird (als Existenzwert oder intrinsischer Wert) (Batavia und Nelson 2017). Zum anderen gibt es einen ökonomisch charakterisierten Wert von Organismen, der durch einen Vorteil für den Menschen entsteht (Nutzwert). Während der intrinsische Wert auf einem Existenzrecht beruht bzw. sich ohne Beurteilung durch den Menschen ergibt, ist der Nutzwert das Ergebnis einer Verwendung des Organismus zur Erstellung eines Produktes einschließlich der Umwandlung des Organismus in ein solches. Eine Organismengruppe, die einen direkten oder potenziellen Nutzwert hat, 


\section{4 Ökosysteme, Landnutzung \& Biodiversität}

wird wahrscheinlich noch eine Weile erhalten werden, sodass die zukünftige Nutzung möglich bleibt. Der Wert einer potenziellen Nutzung durch heute lebende oder zukünftige Generationen wird auch als Optionswert bezeichnet. Darüber hinaus gibt es einen Wert, der sich aus der Vermeidung irreversibler Entscheidungen und Auswirkungen ergibt und v.a. in Hinblick auf das zukünftige Wissen (über eine potenzielle, heute noch nicht bekannte Nutzung) von Bedeutung ist. Dieser sogenannte Quasioptionswert ist für den Biodiversitätsschutz von großer Bedeutung, da wir z.B. für die Herstellung von Medikamenten viele pflanzliche und tierische Substanzen verwenden bzw. synthetisch auf deren Grundlage herstellen. Viele chemische Substanzen und genetische Prozesse in einer Vielzahl von Organismen sind noch nicht bekannt, können aber für die Entwicklung neuer Medikamente wichtig sein. Biodiversitätsschutz hat somit einen hohen Nutzwert für die Menschheit (siehe Beitrag 3.1).

\subsection{7 Ökosystemdienstleistungen}

Der intrinsische Wert der Biodiversität ist schwer zu bemessen, und ein ökonomisch begründeter Nutzwert, der sich ausschließlich auf den Gebrauch einer Ressource und damit auch auf den Verbrauch bezieht, kann für die Beschreibung der Abhängigkeit des Menschen von der belebten Umwelt irreführend sein. Das Konzept der Ökosystemdienstleistung (ÖSD) versucht dies zu verdeutlichen. Es hat sich mittlerweile als Wertesystem zur Beurteilung natürlicher Ressourcen etabliert. Damit ÖSD ihre ökologische Rolle zum Wohle der Menschheit erfüllen können, ist es in der Regel erforderlich, die kontinuierliche Existenz der Biodiversität zu sichern. Dies kann als ökonomischer Faktor berücksichtigt werden.

Das ÖSD-Konzept wurde Anfang der 1980er-Jahre im Zusammenhang mit der Diskussion, wie Biodiversität und ihr Erhalt bewertet werden könnten, vorgeschlagen. Eine der frühen Studien (Ehrlich und Mooney 1983) wird als eine der wichtigsten Arbeiten im Bereich der Naturschutzbiologie angesehen (Bradshaw et al. 2011). Von „ÖSD“ zu sprechen, wurde ursprünglich als Metapher verstanden, um den Nutzen der Natur darzustellen und diesen im Zusammenhang mit dem Naturschutz besser argumentieren zu können. Erst in späteren Arbeiten wurde die tatsächliche monetäre Bewertung der ÖSD vorgeschlagen. Die Arbeit von Constanza et al. (1997) hatte dabei großen Einfluss und wird heute meist mit dem Ursprung des ÖSD-Konzeptes in Verbindung gebracht. Die Autoren kategorisierten die Leistungen der Biosphäre und belegten sie mit einem monetären Wert. Dieser betrug damals weltweit insgesamt 33 Billiarden Dollar pro Jahr.

Die wesentliche Argumentation dieser Arbeiten ist, dass der Nutzen der Natur für den Menschen ökonomisch bewertet werden muss, um die Natur schützen zu können. Dies 
kann beispielsweise durch die Schaffung eines Marktes geschehen (wie z.B. bei $\mathrm{CO}_{2}$ Derivaten). Spätestens mit der Veröffentlichung des Millennium Ecosystem Assessment (MA) (2005) wurde das ÖSD-Konzept das grundlegende Paradigma zur Bewertung von Umweltauswirkungen sowie von Naturschutzmaßnahmen und -zielen. Dies spiegelt sich auch in späteren Berichten wie dem TEEB-Report (TEEB 2009) sowie der CBD, der Convention on Biological Diversity, wider (EASAC 2009; vgl. auch Grunewald und Bastian 2013; Luck et al. 2009). Als besonders ansprechend wird vonseiten des Umweltmanagements die Möglichkeit gesehen, die Belange des Naturschutzes und der Gesellschaft zu vereinigen und gemeinsame Ziele zu formulieren (z.B. Kareiva und Marvier 2012). Da Ökosysteme im Wesentlichen auf den Interaktionen der Organismen und damit der Biodiversität beruhen, wird der Erhalt der Biodiversität als gewährleistet angesehen, wenn die ÖSD erhalten werden (Goldman und Tallis 2009).

Man unterscheidet grundsätzlich zwischen versorgenden, regulierenden und kulturellen ÖSD (Grunewald und Bastian 2013, S. 49), wobei das MA (2005) noch unterstützende ÖSD anführt (nach Constanza et al. 1997) (siehe Abbildung 4.4.2):

- $\mathrm{Zu}$ den versorgenden ÖSD (provisioning ecosystem services, ökonomische Dienstleistungen) zählen Ressourcen, die von Ökosystemen produziert werden (z.B. Nahrungsmittel, Rohstoffe, sonstige erneuerbare Naturressourcen). Man unterscheidet zwischen Produkten, die angebaut bzw. gezüchtet werden, und jenen, die direkt aus der Natur stammen (z.B. Fisch, Wildfrüchte, Wildkräuter).

- Regulierende ÖSD (regulating ecosystem services, ökologische Dienstleistungen) sind Prozesse, die z.B. das Klima steuern, die Wasserqualität positiv beeinflussen oder Schädlinge in Schach halten. Da die Leistungen indirekt erfolgen, werden sie oft zu wenig beachtet - es sei denn, die Dienstleistungen fallen aus. Sie bilden die Grundlage für die Existenz des Menschen. Damit der Mensch diese Leistungen in Anspruch nehmen kann, muss die Erhaltung und Funktionsfähigkeit der Ökosysteme gewährleistet sein.

- Kulturelle ÖSD (cultural ecosystem services) sind nichtmaterielle Leistungen und Beiträge der Ökosysteme, die z.B. ästhetischen Genuss, Erholung oder spirituelle Erfahrungen ermöglichen. Diese ÖSD werden leicht übersehen, da sie monetär nur schwer bewertet werden können.

- Unterstützende ÖSD (supporting services) sind grundlegende ökologische Vorgänge, von denen der Mensch abhängig ist (z.B. der Nahrungskreislauf, die Primärbzw. Sekundärproduktion, die Bereitstellung von Lebensräumen) (MA 2005). Diese Kategorie wird je nach Anwenderin oder Anwender als eigenständige Dienstleistung angeführt oder auch den anderen ÖSD zugeordnet. 
Ökosystemdienst I istungen

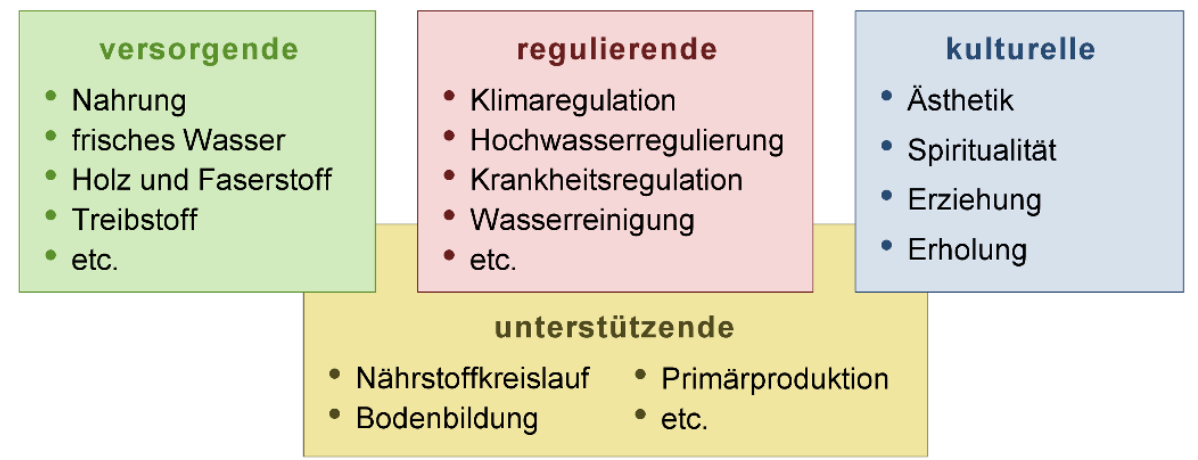

Abbildung 4.4.2: Schematische Darstellung der Kategorien von Ökosystemdienstleistungen (nach MA 2005, verändert)

Ein wesentlicher Punkt des ÖSD-Konzeptes ist, dass verschiedene Aspekte der Leistungen durch sozioökonomische Faktoren (z.B. Bildungsgrad, Beruf, Einkommen) ersetzt werden könnten (MA 2005). Dies veranschaulichen die Vorschläge zum Umgang mit dem Anstieg des $\mathrm{CO}_{2}$-Gehaltes in der Atmosphäre. Durch regulierende ÖSD sorgt die Biosphäre - über den Einbau von Kohlenstoff in Biomasse mittels Photosynthese - für einen stabilen bzw. leicht sinkenden $\mathrm{CO}_{2}$-Gehalt in der Atmosphäre. Das durch Verbrennung fossiler Kohlenstofflagerstätten entstehende $\mathrm{CO}_{2}$ könnte zumindest teilweise in Biomasse gespeichert werden (z.B. durch das Ausweiten von Waldflächen). Alternativ dazu könnte durch technische Lösungen $\mathrm{CO}_{2}$ aus der Atmosphäre abgeschieden und anschließend gelagert werden. Der ökologische Prozess, der den Kohlenstoffgehalt über Einbau in Biomasse senkt, würde so durch einen technologischen Prozess ersetzt.

\subsubsection{Kritik am Ökosystemdienstleistungsparadigma}

Die Annahme, dass ÖSD durch ökonomische und technische Möglichkeiten ersetzbar sind, bildet den Kern der Kritik an diesem Konzept. Die Substituierbarkeit sowie die monetäre Bewertung der ÖSD lässt die ursprüngliche Formulierung des Modells als Metapher zur Veranschaulichung natürlicher Vorgänge eigentlich nicht zu.

Ökologische Leistungen zu bepreisen, kann nach Silvertown (2015) als moralische Entscheidung angesehen werden. Wie in dieser Arbeit ausgeführt, sind wir sehr zufrieden damit, manchen Dingen oder Leistungen keinen Preis zu geben, sondern sie als nichtbewertbar zu akzeptieren. Dies trifft beispielsweise auf menschliche Organe sowie auf andere grundlegende Bedürfnisse des Menschen zu. Solche Faktoren monetär zu bewerten, würde eine ethische Entwertung darstellen, da der monetäre Wert einer unveräußerlichen Leistung nicht bezifferbar ist. 
ÖSD werden häufig auf die ökologische Rolle der einzelnen Mitglieder eines Ökosystems bezogen und nicht auf die Gesamtheit des Systems. So können verschiedene Arten von Organismen ähnliche Funktionen haben und dann innerhalb des Systems funktionell oder ökologisch redundant erscheinen. Diese Redundanz ist positiv, da eine Leistung dann von verschiedenen Elementen unterstützt wird und damit gegenüber Einflüssen stabiler ist. Darauf beruht das Konzept der Resilienz von Ökosystemen (siehe Beitrag 4.1). Die Annahme von Redundanz erweckt jedoch den Anschein, dass manche Elemente in einem Ökosystem nicht nötig wären. Tatsächlich wird in einer auf ÖSD beruhenden Risikoabschätzung das Verschwinden einer Art, die eine einzigartige ökologische Rolle innehat, schwerwiegender beurteilt als das Verschwinden einer Art, die funktionell redundant erscheint. Dies mag kurzfristig plausibel erscheinen, ist aber Ausdruck eines eher naiven Verständnisses von Ökologie. In einem Ökosystem finden Arten aufgrund von aktuell herrschenden Bedingungen zusammen. Mit sich ändernden Bedingungen kann auch die ökologische Redundanz variieren. Es ist daher schwierig abzuschätzen, welche Elemente notwendig sind, um eine Leistung langfristig erhalten zu können.

Die Reduktion eines ökologischen Mechanismus auf eine ÖSD für den Menschen stellt immer eine Vereinfachung dar. Der Wert einer ökologischen Leistung kann nur verstanden werden, wenn alle möglichen Leistungen und deren zukünftige Entwicklungen bekannt sind. Wenn die ökologischen Zusammenhänge nicht bekannt sind, wird auch die Leistung nicht unbedingt als solche erkannt. Der ökologische Mechanismus wäre dann in seiner Wichtigkeit für den Menschen unterbewertet. So werden erst in neuerer Zeit stabilisierende Effekte von Großsäugern auf den Nährstoffhaushalt des Bodens diskutiert (z.B. Doughty et al. 2016) oder die ökologische Rolle der großen Bartenwale untersucht (Roman et al. 2014). Diese neuen Entwicklungen zeigen, dass die Beurteilung, welche ökologischen Dienstleistungen wir erwarten, noch nicht abgeschlossen ist. Dadurch entsteht eine sehr hohe Unsicherheit bei der Bewertung und Anwendung der ÖSD.

\section{Literatur}

Barnosky, A. D., Matzke, N., Tomiya, S., Wogan, G. O. U., Swartz, B., Quental, T. B., Marshall, C., McGuire, J. L., Lindsey, E. L., Maguire, K. C., Mersey, B., and Ferrer, E. A. (2011): Has the earth's sixth mass extinction already arrived? Nature, 471, 51-57. https://doi.org/10.1038/nature09678.

Batavia, C. and Nelson, M. P. (2017): For goodness sake! What is intrinsic value and why should we care? Biological Conservation, 209, 366-376. https://doi.org/10.1016/j.biocon.2017.03.003.

Bennett, C. E., Thomas, R., Williams, M., Zalasiewicz, J., Edgeworth, M., Miller, H., Coles, B., Foster, A., Burton, E. J., and Marume, U. (2018): The broiler chicken as a signal of a human reconfigured biosphere. Royal Society Open Science, 5. https://doi.org/10.1098/rsos.180325.

Bradshaw C. J. A., Sodhi N. S., Laurance W. F., and Brook B. W. (2011): Twenty landmark papers in biodiversity conservation. In: Pavlinov, I., ed., Research in Biodiversity - Models and Applications. Rijeka, Shanghai: Intech, 97-112. https://doi.org/10.5772/23984. 
Brook, S. M., Dudley, N., Mahood, S. P., Polet, G., Williams, A. C., Duckworth, J. W., Van Ngoca, T., and Long B. (2014): Lessons learned from the loss of a flagship: the extinction of the Javan rhinoceros Rhinoceros sondaicus annamiticus from Vietnam. Biological Conservation, 174, 21-29. https://doi.org/10.1016/i.biocon.2014.03.014.

Constanza, R., d'Arge, R., de Groot, R., Farber, S., Grasso, M., Hannon, B., Limburg, K., Naeem, S., O'Neill, R. V., Paruelo, J., Raskin, R. G., Sutton, P., and van den Belt, M. (1997): The value of the world's ecosystem services and natural capital. Nature, 387, 253-260. https://doi.org/10.1038/387253a0.

Doughty, C. E., Roman, J., Faurby, S., Wolf, A., Haque, A., Bakker, E. S., Malhi, Y., Dunning, J. B., and Svenning, J. C. (2016): Global nutrient transport in a world of giants. Proceedings of the National Academy of Sciences of the United States of America, 113, 4, 868-873. https://doi.org/10.1073/pnas.1502549112.

EASAC (European Academies Science Advisory Council) (2009): Ecosystem services and biodiversity in Europe. EASAC policy report 09. London: The Royal Society. Available at: https://easac.eu/publications/details/ecosystems-services-and-biodiversity-in-europe/ [accessed 15.5.2019].

EBCC (European Bird Census Council) (2018): Website of the European Bird Census Council. Available at: https://www.ebcc.info [accessed 15.5.2019].

Ehrlich, P. R. and Mooney, H. A. (1983): Extinction, substitution, and ecosystem services. BioScience, 33, 4, 248-254. https://doi.org/10.2307/1309037.

Emslie, R. (2012a): Ceratotherium simum. The IUCN Red List of Threatened Species. e.T4185A16980466. http://dx.doi.org/10.2305/IUCN.UK.2012.RLTS.T4185A16980466.en.

Emslie, R. (2012b): Diceros bicornis. The IUCN Red List of Threatened Species. e.T6557A16980917. http://dx.doi.org/10.2305/IUCN.UK.2012.RLTS.T6557A16980917.en.

Goldman, R. and Tallis, H. (2009): A critical analysis of ecosystem services as a tool in conservation projects. Annals of the New York Academy of Sciences, 1162, 63-78. https://doi.org/10.1111/j.1749-6632.2009.04151.x.

Grunewald, K. und Bastian, O. (Hrsg.) (2013): Ökosystemdienstleistungen. Konzept, Methoden und Fallbeispiele. Berlin, Heidelberg: Springer. https://doi.org/10.1007/978-3-8274-2987-2.

Hallmann, C. A., Sorg, M., Jongejans, E., Siepel, H., Hofland, N., Schwan, H., Stenman, W., Müller, A., Sumser, H., Hörren, T., Goulson, D., and de Kroon, H. (2017): More than 75 percent decline over 27 years in total flying insect biomass in protected areas. PLOS ONE, 12, 10, e0185809. https://doi.org/10.1371/journal.pone.0185809.

Inger, R., Gregory, R., Duffy, J. P., Stott, I., Voříšek, P., and Gaston, K. J. (2015): Common European birds are declining rapidly while less abundant species' numbers are rising. Ecology Letters, 18, 28-36. https://doi.org/10.1111/ele.12387.

Kareiva, P. and Marvier, M. (2012): What is conservation science? BioScience, 62, 962-969. https://doi.org/10.1525/bio.2012.62.11.5.

Lovelock, J. (1995): The Ages of Gaia. A Biography of Our Living Earth. Second edition. New York, London: Oxford University Press.

Luck, G. W., Harrington, R., Harrison, P. A., Kremen, C., Berry, P. M., Bugter, R., Dawson T. P., de Bello, F., Diaz, S., Feld, C. K., Haslett, J. R., Hering, D., Kontogianni, A., Lavorel, S., Rounsevell, M., Samways, M. J., Sandin, L., Settele, J., Sykes, M. T., van den Hove, S., Vandewalle, M., and Zobel, M. (2009): Quantifying the contribution of organisms to the provision of ecosystem services. BioScience, 59, 3, 223-235. https://doi.org/10.1525/bio.2009.59.3.7.

MA (Millennium Ecosystem Assessment) (2005): Ecosystems and Human Well-Being: Synthesis. Washington, DC, USA: Island Press. Available at: http://www.millenniumassessment.org/ [accessed 20.7.2019].

Moodley, Y., Russo, I. R. M., Dalton, D. L., Kotzé, A., Muya, S., Haubensak, P., Bálint, B., Munimanda, G. K., Deimel, C., Setzer, A., Dicks, K., Herzig-Straschil, B., Kalthoff, D. C., Siegismund, H. R., Robovský, J., O'Donoghue, P., and Bruford, M. W. (2017): Extinctions, genetic erosion and conservation options for the black rhinoceros (Diceros bicornis). Scientific Reports, 7, 41417. https://doi.org/10.1038/srep41417. 
Mora, C., Tittensor, D. P., Adl, S., Simpson, A. G. B., and Worm, B. (2011): How many species are there on earth and in the ocean? PLOS Biology, 9, 8, e1001127.

https://doi.org/10.1371/journal.pbio.1001127.

Newton, I. (2004): The recent declines of farmland bird populations in Britain: an appraisal of causal factors and conservation actions. IBIS, 146, 579-600. https://doi.org/10.1111/j.1474919X.2004.00375.x.

Noss, R. F. (1990): Indicators for monitoring biodiversity: A hierarchical approach. Conservation Biology, 4, 4, 355-364. https://doi.org/10.1111/j.1523-1739.1990.tb00309.x.

Pusparini, W., Sievert, P. R., Fuller, T. K., Randhir, T. O., and Andayani, N. (2015): Rhinos in the parks: An island-wide survey of the last wild population of the Sumatran Rhinoceros. PLOS ONE, 10, 9, e0139982. https://doi.org/10.1371/journal.pone.0136643.

Ripple, W. J., Wolf, C., Newsome, T. M., Betts, M. G., Ceballos, G., Courchamp, F., Hayward, M. W., Van Valkenburgh, B., Wallach, A. D., and Worm, B. (2019): Are we eating the world's megafauna to extinction? Conservation Letters, 12, 3, e12627. https://doi.org/10.1111/conl.12627.

Roman, J., Estes, J. A., Morissette, L., Smith, C., Costa, D., McCarthy, J., Nation, J. B. Nicol, S., Pershing, A., and Smetacek, V. (2014): Whales as marine ecosystem engineers. Frontiers in Ecology and the Environment, 12, 7, 377-385. https://doi.org/10.1890/130220.

Sánchez-Bayo, F. and Wyckhuys, K. A. G. (2019): Worldwide decline of the entomofauna: A review of its drivers. Biological Conservation, 232, 8-27. https://doi.org/10.1016/j.biocon.2019.01.020.

Save the Rhino International (2018): Rhino info. Poaching statistics. Available at: https://www.savetherhino.org/rhino-info/poaching-stats/ [accessed 11.4.2019].

Schneider, S. H. and Boston, P. J. (eds.) (1991): Scientists on Gaia. London: MIT Press.

Setiawan, R., Gerber, B. D., Rahmat, U. M., Daryan, D., Firdaus, A. Y., Haryono, M., Khairani, K. O., Kurniawan, Y., Long, B., Lyet, A., Muhiban, M., Mahmud, R., Muhtarom, A., Purastuti, E., Ramono, W. S., Subrata, D., and Sunarto, S. (2017): Preventing global extinction of the Javan rhino. Tsunami risk and future conservation direction. Conservation Letters, 11, e12366. https://doi.org/10.1111/conl.12366.

Silvertown, J. (2015): Have ecosystem services been oversold ? Trends in Ecology \& Evolution, 30, 11, 641-648. https://doi.org/10.1016/j.tree.2015.08.007.

Sody, H. J. V. (1959): Das javanische Nashorn Rhinoceros sondaicus. Zeitschrift für Säugetierkunde, 24, 3-4.

Steffen, W., Grinevald, J., Crutzen, P., and McNeill, J. (2011): The Anthropocene: conceptual and historical perspectives. Philosophical Transactions of the Royal Society A. Mathematical, Physical and Engineering Sciences, 369, 842-867. https://doi.org/10.1098/rsta.2010.0327.

Stork, N. E. (2018): How many species of insects and other terrestrial arthropods are there on earth? Annual Reviews of Entomology, 63, 31-45. https://doi.org/10.1146/annurev-ento-020117043348.

Talukdar, B. K., Emslie, R., Bist, S. S., Choudhury, A., Ellis, S., Bonal, B. S., Malakar, M. C., Talukdar, B. N., and Barua, M. (2008): Rhinoceros unicornis. The IUCN Red List of Threatened Species. e.T19496A8928657. http://dx.doi.org/10.2305/IUCN.UK.2008.RLTS.T19496A8928657.en [accessed 20 May 2019].

TEEB (2009): The Economics of Ecosystems and Biodiversity (TEEB). Climate Issues Update. Available at: http://www.teebweb.org/publication/climate-issues-update/ [accessed 15.5.2019].

van Strien, N. J., Manullang, B., Sectionov Isnan, W., Khan, M. K. M., Sumardja, E., Ellis, S., Han, K. H., Boeadi Payne, J., and Bradley Martin, E. (2008): Dicerorhinus sumatrensis. The IUCN Red List of Threatened Species. e.T6553A12787457. http://dx.doi.org/10.2305/IUCN.UK.2008.RLTS.T6553A12787457.en [accessed 20 May 2019].

Watson, J. E. M., Shanahan, D. F., Di Marco, M., Allan, J., Laurance, W. F., Sanderson, E. W., Mackey, B., and Venter, O. (2016): Catastrophic declines in wilderness areas undermine global environment targets. Current Biology, 26, 2929-2934. https://doi.org/10.1016/j.cub.2016.08.049. 


\subsection{Raumplanung für eine nachhaltige Entwicklung}

Gernot Stöglehner

Institut für Raumplanung, Umweltplanung und Bodenordnung,

Department für Raum, Landschaft und Infrastruktur (RALI)

gernot.stoeglehner@boku.ac.at

\subsubsection{Aufgaben und Funktionen der Raumplanung}

Raumplanung wird seit der Sesshaftwerdung der Menschen betrieben, um den Raum und seine Ressourcen nutzbar zu machen. Anfänge von Raumplanung können z.B. in der Gestaltung von Siedlungen (Reicher 2014) oder in der Nutzbarmachung landwirtschaftlicher Flächen z.B. durch die Dreifelderwirtschaft (Krausmann 1998; Schwackhöfer 1988) erkannt werden. Dabei wurden in jeder Epoche planerische Erwägungen angestellt, z.B. die planmäßige Gestaltung römischer Legionslager nach bestimmten Gestaltungsprinzipien (Schirmacher 1988) oder die Planung mittelalterlicher Städte um einen Marktplatz und von der Umgebung durch Stadtmauern klar getrennt, um militärischen Schutz zu gewährleisten. Auch Feuersicherheit und Hygiene spielten eine wichtige Rolle in der Planung (vgl. z.B. Hägermann 2005; Reicher 2014).

Der zunehmende gesellschaftliche Fortschritt macht auch die Aufgaben komplexer. Dabei gilt es, eine Vielzahl von Nutzungsansprüchen an den Raum zu berücksichtigen, wie z.B. Wohnen, betriebliche Nutzungen im produzierenden Gewerbe, in der Industrie, im Handel und den Dienstleistungen, öffentliche Einrichtungen, Freizeitund Erholungsnutzungen, die landwirtschaftliche Nutzung, aber auch den Schutz von Lebensräumen für wildlebende Tiere und Pflanzen. Zeitgemäße Raumplanung, wie sie heute betrieben wird, hat sich ab der zweiten Hälfte der 1960er-Jahre entwickelt. Bis in die Mitte der 1970er-Jahre haben alle Bundesländer die Erstfassungen ihrer Raumplanungs- bzw. Raumordnungsgesetze ${ }^{1}$ erlassen, auf deren Basis Raumplanung heute betrieben wird. Das Oberösterreichische Raumordnungsgesetz, das hier als Beispiel dienen soll, umreißt die Aufgaben so: „Raumordnung im Sinne dieses Landesgesetzes bedeutet, den Gesamtraum und seine Teilräume vorausschauend planmäßig zu gestalten und die bestmögliche Nutzung und Sicherung des Lebensraumes im Interesse des Gemeinwohles zu gewährleisten; dabei sind die abschätzbaren wirtschaftlichen, sozialen und kulturellen Bedürfnisse der Bevölkerung, die freie Entfaltung der Persönlichkeit in der Gemeinschaft sowie der Schutz der natürlichen Umwelt als Lebensgrundlage des Menschen zu beachten“" $\$ 1$ Abs. 2 Oö. ROG 1994).

1 Während im wissenschaftlichen Diskurs verschiedene definitorische Abgrenzungen von Raumplanung und Raumordnung anzutreffen sind, werden die Begriffe in der Planungspraxis üblicherweise synonym verwendet. In diesem Beitrag wird der Einfachheit halber im Folgenden nur noch der Begriff Raumplanung verwendet, wobei Raumordnung im Sinne der Synonymität mit gemeint ist. 
Raumplanung übt sowohl Ordnungs- als auch Entwicklungsfunktionen aus (Mäding 2009). In der Ordnungsfunktion werden wesentliche Schutzansprüche zum Ausdruck gebracht, um sensible und störende Landnutzungen voneinander zu trennen. Die Ordnungsfunktion kann z.B. dadurch umgesetzt werden, dass Wohnnutzungen nicht direkt neben Industrieanlagen angesiedelt werden oder dass Landschaftsräume, die für den Erhalt der Biodiversität, für die Agrarproduktion oder die landschaftsgebundene Erholungsnutzung bedeutend sind, von Bebauung und Infrastruktureinrichtungen ${ }^{2}$ freigehalten werden. Bei der Entwicklungsfunktion geht es darum, Optionen für zukünftige Raumnutzungen zu eröffnen: So wird z.B. Raum für wirtschaftliche Entwicklung geschaffen, wenn Bauland für Industrie und Gewerbe ausgewiesen und durch technische Infrastruktur erschlossen wird. Durch verschiedene Maßnahmen können Flächen für die Nutzbarmachung von Umweltressourcen freigehalten werden, seien dies z.B. Vorrangzonen für die Windenergienutzung oder für die landwirtschaftliche Nutzung.

Im Folgenden wird gezeigt, welchen Herausforderungen Raumplanung gegenübersteht, mit welchen Planungsprinzipien nachhaltige Raumentwicklung unterstützt werden kann, welche Raumplanungsinstrumente zur Verfügung stehen und welche Bedeutung Raumplanung für die Gestaltung der Energie- und Ressourcenwende sowie für die Bioökonomie entfalten kann.

Dabei ist zu berücksichtigen, dass Raumplanung selbst ein komplexes Geflecht aus rechtlichen Rahmenbedingungen - den Raumplanungs- bzw. Raumordnungsgesetzen und den darin verankerten Planungsinstrumenten ist. Sie koordiniert verschiedene öffentliche und private Interessen im Raum. Entscheidungen werden von Planerinnen und Planern auf Basis fachlicher Grundlagen und entsprechender Planungsmethoden vorbereitet, in demokratisch legitimierten Gremien getroffen und von verschiedenen Akteurinnen und Akteuren bzw. Planungsbetroffenen beeinflusst. Daher ist Raumplanung eine Querschnittsmaterie, die naturräumliche, soziale, kulturelle und ökonomische Aspekte der Raumnutzung zu berücksichtigen hat. ${ }^{3}$ Planungsprozesse werden so gestaltet, dass ein Mindestmaß an Öffentlichkeitsbeteiligung im Sinne von Informations- und Stellungnahmerechten gewährleistet ist. Vielfach werden aber auch Entscheidungen, die Einfluss auf die Raumentwicklung haben, außerhalb des Raumplanungssystems getroffen, z.B. im Förderwesen, in der Agrar-, Wirtschaftsund Energiepolitik. Aber auch Lebensstile und Wirtschaftsweisen beeinflussen die

2 Infrastruktur umfasst die Einrichtungen des Raumes, die dessen Nutzung ermöglichen. Es wird zwischen technischer Infrastruktur (z.B. Straßen, Eisenbahnen, Flughäfen, Häfen, Wasserversorgung, Abwasserentsorgung, Energieversorgung, Kommunikationsreinrichtungen) und sozialer Infrastruktur (z.B. Schulen, Kinderbetreuungseinrichtungen, Universitäten, medizinische Versorgung, Alten- und Pflegeheime, Polizei, Rettung und Feuerwehr) unterschieden (vgl. z.B. Zapf 2005).

3 Vergleiche dazu die Darstellung der Aufgaben der Raumordnung im Oberösterreichischen Raumordnungsgesetz. 


\section{4 Ökosysteme, Landnutzung \& Biodiversität}

räumliche Entwicklung und die damit verbundene Aneignung von Ressourcen (Stöglehner et al. 2014).

\subsubsection{Herausforderungen für eine nachhaltige räumliche Entwicklung}

Österreich steht in Bezug auf das Bruttoinlandsprodukt (BIP) pro Kopf weltweit an 14. Stelle (Stand 2018, IMF 2019). Bevölkerung und Wirtschaft wachsen weiter, wobei eine Entkopplung von Wirtschaftswachstum, Energie- und Ressourcenverbrauch bis dato über längere Zeiträume nicht stattgefunden hat (Lutter und Giljum 2009). Seit 1990 ist die Bevölkerung in Österreich von ca. 7,64 Mio. auf fast 8,86 Mio. Menschen (2019) angestiegen (Statistik Austria 2019a), das BIP pro Kopf ist von ca. 17.700 Euro auf ca. 42.000 Euro (2018) gewachsen (WKO 2019). Die Zahl der Privat-Pkw hat sich im gleichen Zeitraum von ca. 3 Mio. auf ca. 5 Mio. erhöht (Statistik Austria 2019b). Die Anzahl der Hauptwohnsitzwohnungen ist seit 1990 um ca. 1 Mio. gestiegen, was einem Wachstum von ca. 34\% entspricht (Statistik Austria 2019a). Seit 1995 hat ein Boom bei der Errichtung von Einkaufszentren eingesetzt, der dazu führt, dass die Verkaufsflächenausstattung mit $1,66 \mathrm{~m}^{2}$ pro Kopf (Stand 2017) einen der höchsten Werte in Europa erreicht hat (GfK 2018). Nicht zuletzt ist dieser Bauboom mit einem erheblichen Infrastrukturaufwand verbunden. Die Straßenlänge pro Kopf (Stand 2016) ist in Österreich mit rund 16,2 m um mehr als 50\% höher als jene in Deutschland (ca. 10,7 $\mathrm{m}$ pro Kopf) und fast doppelt so hoch wie in der Schweiz (ca. 8,6 m pro Kopf) (BMVI 2018, S. 101; Eurostat 2019a, b).

Viele dieser Entwicklungen sind aus Sicht von Wachstum und Wohlstandsmehrung gewünscht. Es entstehen jedoch auch zahlreiche Probleme und Herausforderungen im Rahmen einer nachhaltigen räumlichen Entwicklung in Bezug auf die Umwelt. So steigt die Flächeninanspruchnahme von Boden für Bauland und Infrastruktur kontinuierlich an, auch wenn in den letzten Jahren die Zuwächse zurückgegangen sind. Laut Umweltbundesamt (2019a) sind in Österreich derzeit $266 \mathrm{~m}^{2}$ Fläche pro Person versiegelt, d.h. durch Gebäude, Straßen etc. fest verschlossen, sodass der Wasserhaushalt unterbrochen und die biologisch produktive Bodenfunktion zerstört ist. Im Vergleich dazu stehen jeder Österreicherin/jedem Österreicher ca. $45 \mathrm{~m}^{2}$ Wohnraum zur Verfügung, also ein Sechstel der versiegelten Fläche pro Person (Statistik Austria 2019c).

Damit verbunden ist nicht nur ein Verlust an biologisch produktiver Fläche durch Versiegelung. Durch die Standortwahl für Bauland und Infrastruktur kommt es auch zu einer Zerschneidung von Landschaftsräumen. Darunter leidet zunächst die Biodiversität (Essl et al. 2018). Das Landschaftsbild wird überprägt und vielfach negativ beeinflusst. Nicht zuletzt werden Optionen für die Umsetzung der Energie- 
und Ressourcenwende im Sinne einer Bioökonomie sowie in Bezug auf Klimaschutz und Klimawandelanpassung eingeschränkt. So sind z.B. im Verkehr (nationaler Flugverkehr eingeschlossen) die Treibhausgasemissionen zwischen 1990 und 2017 um 71,8\% gestiegen (Umweltbundesamt 2019b). Dies liegt nicht nur daran, dass auf den Straßen mehr und größere Autos unterwegs sind. Ungünstige Siedlungsstrukturen, die durch die Trennung von Wohnen, Arbeiten, Erholen, Einkaufen etc. weite Wege verursachen, tragen ebenso zu mehr Verkehr und Emissionen bei. Gleichzeitig konnten die Treibhausgasemissionen bei Gebäuden trotz starker Neubautätigkeit um 35,1\% reduziert werden (Umweltbundesamt 2019b).

In den derzeitigen Raumstrukturen sind wesentliche Raumfunktionen wie Wohnen, Arbeiten, Einkaufen, Bilden, Erholen durch zunehmend größer werdende Distanzen voneinander getrennt. Dies führt zu mehr Mobilität, aber auch zu einem schwieriger zu bewältigenden Alltag, in dem Arbeiten, die Betreuung von Kindern oder älteren Familienangehörigen sowie das Versorgen miteinander vereinbart werden müssen. Die Lebensqualität sinkt, und öffentliche Investitionen in neue Infrastruktur steigen. So sind z.B. die öffentlichen Investitionen in die Erschließung für Straßen, Kanal, Wasser etc. bei Einfamilienhäusern ca. zehnmal so hoch wie bei drei- bis fünfgeschossigen Mehrfamilienhäusern (Dallhammer 2016). Vielfach kann z.B. in dispersen Raumund Siedlungsstrukturen mit geringer Dichte an Bevölkerung und Arbeitsplätzen kein effizienter öffentlicher Verkehr angeboten werden.

Diese Schlaglichter auf die räumliche Entwicklung, die keinen Anspruch auf Vollständigkeit erheben, zeigen, dass aus einer umfassenden Nachhaltigkeitsperspektive zurzeit viel Fehlsteuerung stattfindet. Gerade die derzeit drängenden Umweltprobleme wie Klimawandel, Flächeninanspruchnahme und Biodiversitätsverluste, aber auch Perspektiven der Energie- und Ressourcenwende können wesentliche Anreize bieten, die in Abschnitt 4.5.3 dargestellten Planungsprinzipien für eine nachhaltige Raumentwicklung umzusetzen.

\subsubsection{Planungsprinzipien für eine nachhaltige Raumentwicklung}

Die oben skizzierten räumlichen Entwicklungen sind nicht nur in Österreich, sondern weltweit sichtbar, wenngleich sie hierzulande zum Teil besonders stark ausgeprägt sind. Das Problembewusstsein dafür hat sich sowohl in der Fachwelt als auch in der interessierten Öffentlichkeit bereits seit dem ersten Bericht des Club of Rome „Die Grenzen des Wachstums“ (Meadows et al. 1972) in den 1970er-Jahren gebildet. Speziell ab den 1980er- und 1990er-Jahren wurden Leitbilder für eine nachhaltige Raumplanung entwickelt. Leitbilder werden in der Planung dazu verwendet, Zielvorstellungen auszudrücken (Fürst und Scholles 2008). Leitbilder mit starkem Nachhaltigkeitsbezug weisen viele Gemeinsamkeiten auf, sodass nur relativ wenige Gestaltungs- 


\section{4 Ökosysteme, Landnutzung \& Biodiversität}

prinzipien für eine nachhaltige räumliche Entwicklung umzusetzen wären (Jabareen 2006): kompakte Siedlungsentwicklung, die sich an Funktionsmischung ${ }^{4}$, Dichte ${ }^{5}$, Nähe und kurzen Wegen für eine nachhaltige Mobilität (Zufußgehen, Radfahren, öffentlicher Verkehr), Durchgrünung der Städte und Siedlungen sowie passiver Solarenergienutzung orientieren. Dazu kommen die regionale Organisation von Zentren und Orten unterschiedlicher Ausstattung mit Gütern und Dienstleistungen entlang von Entwicklungsachsen mit leistungsfähigem öffentlichem Verkehr.

Darüber hinaus besteht - ausgehend von der Agenda 21 (UN 1992) - in den Planungstheorien Konsens darüber, dass Planungsprozesse auf eine Art und Weise zu organisieren sind, die es möglichst vielen Bevölkerungsgruppen erlaubt, ihre Ideen und Interessen einzubringen. Gemäß „kommunikativer Planung“ (Healey 1992), die eng mit dem Nachhaltigkeitsdiskurs (Lawrence 2000) verknüpft ist, soll die Prozessgestaltung auf Kommunikation, Konsens und Kooperation basieren und soziale Lernprozesse zwischen Planerinnen und Planern, Entscheidungsträgerinnen und -trägern sowie der beteiligten Öffentlichkeit in Gang setzen. In den Planungsprozessen soll die Wertebene, also die zu verfolgenden Planungsziele, verhandelt und ein gemeinsames Verständnis der Planungsaufgabe auf Sachebene erzielt werden. Eine Folgenabschätzung von angestrebten Planungsmaßnahmen soll zeigen, ob die angedachten Ziele und Maßnahmen zum Erfolg führen oder ungewollte negative Wirkungen zeitigen, die ein Überdenken und Adaptieren der Planungsziele und -maßnahmen notwendig machen (vgl. Stöglehner 2010).

\subsubsection{Planungsinstrumente der Raumplanung in Österreich}

Der Raumplanung stehen auf Basis der Raumplanungsgesetze eine Reihe von Planungsinstrumenten zur Verfügung, die auf Landesebene, regionaler Ebene (als Teilraum eines Landes) oder auf Gemeindeebene wirken. Die Landes- und Regionalebene werden als überörtliche Raumplanung bezeichnet, die Gemeindeebene als örtliche Raumplanung. Die Raumplanung ist über die in den Raumplanungsgesetzen formulierten Planungsziele bestimmt, d.h., alle Maßnahmen müssen in den verschiedenen Planungsebenen räumlich konkretisiert werden und in den Begründungsketten auf die Planungsziele rückführbar sein. Die Pläne und Programme stehen in einer Hierarchie zueinander, die der Reihenfolge der Nennung im Text entspricht. Das heißt, Pläne einer niedrigeren Hierarchieebene dürfen Plänen einer höheren Ebenen nicht widersprechen. Die Festlegungen werden entlang der Hierarchie von oben nach unten konkreter.

${ }^{4}$ Das ist eine Mischung der Nutzungen Wohnen, Arbeiten, Versorgen, Einkaufen, Bilden, Erholen etc. in engem räumlichem Kontext.

5 Das ist eine dem jeweiligen räumlichen Kontext angemessene Dichte an Einwohnerinnen und Einwohnern, Arbeitsplätzen, Versorgungseinrichtungen etc. 
In der überörtlichen Raumplanung stehen im Wesentlichen drei Arten von Plänen - die vielfach auch als Programme bezeichnet werden ${ }^{6}$ - zur Verfügung:

- Landesraumordnungs- oder -entwicklungsprogramme präzisieren die Planungsziele für das gesamte Landesgebiet auf einer allgemeinen Ebene (z.B. Festlegung zentraler Orte und räumlicher Entwicklungsachsen für Wohnen, Betriebe etc.).

- Überörtliche Sachprogramme werden für das gesamte Landesgebiet oder für Regionen erstellt und behandeln einen konkreten Sachbereich, der in der Verantwortung der Planungsbehörden liegt (z.B. Ausweisung von Vorrangzonen, die für die Energiewende von Bedeutung sind, etwa Eignungs- und/oder Ausschlussflächen für die Windenergienutzung in mehreren Bundesländern).

- Regionale Raumordnungsprogramme treffen räumliche Festlegungen für Gebiete, die mehrere Gemeinden umfassen. Diese schließen die gesamte Bandbreite planerischen Handelns ein, wobei die hier bestehenden Möglichkeiten insbesondere für das UBRM bedeutend sein können (z.B. Ausweisung von Grünräumen mit überörtlicher Bedeutung für den Kulturlandschafts- und Biodiversitätsschutz, den Schutz landwirtschaftlicher Flächen sowie für Erholung und Tourismus).

Die überörtliche Raumplanung hat in den Bundesländern unterschiedliche Bedeutung. Nicht alle Bundesländer verfügen über ein Landesraumordnungsprogramm. Die Regionalplanung ist nicht überall gleich stark ausgeprägt. Sie ist flächendeckend in der Steiermark bzw. beinahe flächendeckend in Salzburg vorhanden (StLREG 2018; LEP SBG 2003).

Die örtliche Raumplanung ist von den Gemeinden umzusetzen. Dafür stehen ihnen in den Bundesländern im Allgemeinen - wie in der überörtlichen Raumplanung drei Arten von Plänen zur Verfügung (allerdings in wesentlich größerer Detailschärfe):

- Das örtliche Entwicklungskonzept behandelt die längerfristigen räumlichen Entwicklungsperspektiven der Gemeinden jenseits von 10 Jahren. Es werden die Bedarfsfragen für Bauland geklärt, die wesentlichen Entwicklungsmöglichkeiten festgelegt und diese mit dem Infrastrukturausbau koordiniert. Auf örtlicher Ebene werden die wesentlichen Festlegungen dafür getroffen, welche Flächen als Grünraum dienen und daher von Bauland und Infrastrukturmaßnahmen freigehalten werden sollen. Dies betrifft einerseits Flächen mit Vorrang für die landwirtschaftliche Nutzung oder Bereiche, die für das Landschaftsbild wichtig sind bzw. wertvolle Lebensräume für wildlebende Tiere und Pflanzen bieten, aber auch Freizeit- und Erholungsflächen (z.B. Spielplätze, Parks).

- Im Flächenwidmungsplan wird jeder Parzelle in den Kategorien Bauland, Verkehrsflächen und Grünland (in zahlreichen Unterkategorien) eine Flächenwidmung zu-

6 Die Raumplanung wird in Landesgesetzen geregelt. Daher werden einzelne Plantypen in verschiedenen Bundesländern eventuell unterschiedlich bezeichnet. 


\section{4 Ökosysteme, Landnutzung \& Biodiversität}

gewiesen. Diese Widmungen bestimmen, welche Nutzungen in weiterer Folge zulässig sind. Wesentliche Aspekte sind einerseits spezifische Entwicklungsmöglichkeiten auf Standorten, die für die jeweilige Nutzung günstig sind, und andererseits der Schutz von sensiblen Nutzungen (z.B. der Wohn- und Erholungsnutzung vor Beeinträchtigung im Rahmen der Ordnungsfunktion).

- Im Bebauungsplan wird die dritte Dimension mitbedacht (z.B. Höhe bzw. Größe und Lage von Gebäuden, Lage und Größe von Freiräumen) sowie der Verlauf der Infrastruktureinrichtungen im Detail festgelegt. Die Bestimmungen können sehr detailliert sein, was z.B. für die Klimawandelanpassung notwendig ist, um Grünelemente wie Gründächer, Baumpflanzungen etc. in den Baulandflächen vorsehen zu können.

In Österreich ist von den Plänen auf örtlicher Ebene der Flächenwidmungsplan am bedeutendsten, da er für die Eigentümerinnen und Eigentümer bzw. Nutzerinnen und Nutzer von Grundstücken direkt verbindlich ist und für ganz Österreich flächendeckend vorhanden ist. Die Bundesländer handhaben örtliche Entwicklungskonzepte unterschiedlich. Nicht alle Gemeinden verfügen über ein örtliches Entwicklungskonzept, auch die Bebauungsplanung wird unterschiedlich intensiv angewendet.

In Bezug auf das UBRM können die Planungsinstrumente dazu verwendet werden, Flächen für die Gewinnung von Nahrungsmitteln, von erneuerbarer Energie und Rohstoffen zu sichern. Außerdem können Festlegungen getroffen werden, die eine reibungslose Nutzung dieser Flächen erlauben. So stellt z.B. die Ausweisung einer Vorrangzone für Windenergienutzung nicht nur ein Entwicklungspotenzial dar, damit ist de facto auch ein Bauverbot für Wohngebäude verbunden. Werden die genannten Gestaltungsprinzipien für eine nachhaltige Raumentwicklung umgesetzt, können Ortschaften kompakter gehalten werden. Auch lassen sich größere und zusammenhängende Flächen außerhalb der Orte erzielen, die als Rohstoffgewinnungsflächen für die Umsetzung der Energie- und Ressourcenwende im Sinne einer Bioökonomie zur Verfügung stehen.

\subsubsection{Raumplanung und ihre Bedeutung für den Klimaschutz und die Energiewende}

Die Energieraumplanung, welche sich in den letzten Jahren entwickelt hat, macht die räumlichen Aspekte von Klimaschutz und Energiewende für die Raumplanung sichtbar und bearbeitbar. Sie ist ,jener integrale Bestandteil der Raumplanung, der sich mit den räumlichen Dimensionen von Energieverbrauch und Energieversorgung umfassend beschäftigt" (Stöglehner et al. 2014, S. 26).

Die räumliche Dimension des Energieverbrauchs besteht darin, Raum- und Siedlungsstrukturen energieeffizient zu gestalten (Stöglehner et al. 2014, 2016). Dadurch kann 
Mobilität vermieden und der Raumwärmebedarf durch die günstigeren OberflächenVolumen-Verhältnisse maßvoll verdichteter Gebäude (z.B. Reihenhäuser oder Mehrfamilienhäuser) verringert werden. Energieeffiziente Raum- und Siedlungsstrukturen sind besser mit leitungsgebundenen Energiesystemen versorgbar, was unmittelbar zur räumlichen Dimension der Energieversorgung überleitet. Diese Eigenschaft ist für die Energiewende vorteilhaft, weil damit die sogenannte Sektorkopplung, d.h. die Verschaltung verschiedener Energiesubsysteme und Infrastruktursysteme, unterstützt werden kann (BMNT und BMVIT 2018). Dies dient der Integration volatiler erneuerbarer Energie (z.B. Strom aus Wind und Photovoltaik) in das Energiesystem und erhöht dessen Effizienz, weil die Nutzung von Energie über längere Zeiträume optimiert werden kann. Die Raumplanung leistet mit der Entwicklung energieeffizienter Raum- und Siedlungsstrukturen einen wesentlichen Beitrag zur Energiewende (siehe Fallbeispiel 4.5.1).

Für eine Energiewende bedarf es zusätzlicher Anlagen für die Gewinnung, Speicherung und Verteilung von erneuerbarer Energie, deren Standorte gesichert werden müssen (z.B. Freihaltung von Korridoren für Hochspannungsnetze, Ausweisung von Flächen

\section{Fallbeispiel 4.5.1: Energieraumplanung in der Steiermark}

(Abart-Heriszt und Stöglehner 2019)

Das Steiermärkische Raumordnungsgesetz ermöglicht es, im Zuge des Örtlichen Entwicklungskonzepts ein sogenanntes "Sachbereichskonzept Energie" zu erstellen. Datenbasis und Planungsmethodik dafür wurden im Rahmen der Forschungstätigkeiten des Instituts für Raumplanung, Umweltplanung und Bodenordnung (IRUB, BOKU) aufbereitet. Es umfasst eine steiermarkweite Datenbasis im 250m-Raster auf Gemeindeebene (1) mit Aussagen zum Energieverbrauch und zu den Treibhausgasemissionen für Wohnen, Land- und Forstwirtschaft, Industrie und Gewerbe, Dienstleistungen und Mobilität, (2) mit einer Differenzierung nach Verwendungszwecken (Raumwärme, Warmwasser, Prozessenergie, Wirtschaftsverkehr und Mobilität), (3) unter Berücksichtigung verschiedener Energieträger, (4) einschließlich der Darstellung von Einspar- und Substitutionspotenzialen von fossiler durch erneuerbare Energie sowie (5) die Abgrenzung von Standorträumen für die Fernwärmeversorgung und für klimafreundliche Mobilität. Die Daten stehen allen Gemeinden der Steiermark (u.a. im Digitalen Atlas Steiermark, siehe Land Steiermark 2019) zur Verfügung.

Wie die Daten in der örtlichen Raumplanung eingesetzt werden können, wurde in einem Leitfaden für das Sachbereichskonzept Energie und dessen Berücksichtigung im Örtlichen Entwicklungskonzept aufbereitet (Abart-Heriszt und Stöglehner 2019). Darüber hinaus wurden Ortsplanerinnen und Ortsplaner sowie Gemeindevertreterinnen und Gemeindevertreter geschult. Mithilfe weniger Veranstaltungen konnten alle in der Steiermark tätigen Raumplanungsbüros erreicht werden. Die Möglichkeiten und Handlungsnotwendigkeiten, die sich aus den Energie- und Treibhausgasbilanzen ergeben, sollen von den Gemeinden in Ziele und Maßnahmen der örtlichen Raumplanung übergeführt werden. Die Standorträume geben Hinweise darauf, wo die räumliche Entwicklung in Zukunft vorangetrieben werden soll. Sie sind mit weiteren Belangen der örtlichen Raumplanung abzustimmen. Die Ergebnisse dieser planerischen Abwägungen sollen in das Örtliche Entwicklungskonzept aufgenommen werden. Zur Unterstützung der Umsetzung wurde vom Land Steiermark ein Förderprogramm für Gemeinden aufgelegt, die Sachbereichskonzepte Energie gemäß IRUB-Leitfaden erstellen und rechtsverbindlich in das Örtliche Entwicklungskonzept integrieren. 


\section{4 Ökosysteme, Landnutzung \& Biodiversität}

für Kraftwerksstandorte wie Biomasseheizwerke oder Windkraftanlagen, die einen reibungslosen Betrieb der Anlagen gewährleisten). Des Weiteren können auch ausreichend Flächen für die Primärproduktion gesichert werden (z.B. die oben angesprochenen Vorrangflächen für landwirtschaftliche Produktion oder für die Windkraftnutzung).

\subsubsection{Raumplanung und ihre Bedeutung für die Ressourcen- wende und die Bioökonomie}

Jeder Mensch verfügt über einen gewissen Ressourcengarten, das ist jene biologisch produktive Landfläche, die die Lebensgrundlage pro Kopf darstellt. Wie zahlreiche Berechnungen des ökologischen Fußabdrucks belegen, ist dieser Ressourcengarten bereits massiv überbeansprucht (Stöglehner et al. 2016). Die Energie- und Ressourcenwende im Sinne einer Bioökonomie wird diesen Druck noch weiter verschärfen (Stöglehner 2018). Bedeutende Funktionen der Raumplanung für die Bioökonomie sind daher die Sicherung agrarischer Produktionsflächen und die Orientierung des Managements von Ressourcenketten an den räumlichen Bedingungen.

Stöglehner (2018) argumentiert, dass speziell bei der Nutzung von Biomasse das Schließen von Nährstoffkreisläufen von Bedeutung ist. Biomasse weist vielfach einen hohen Wassergehalt und geringere Haltbarkeit auf. Für die stoffliche Nutzung werden Zwischenprodukte, z.B. in „grünen Bioraffinerien“ (Gwehenberger et al. 2007) hergestellt, die aufgrund höherer Transportierbarkeit und Haltbarkeit zu den verarbeitenden Betrieben gebracht werden können. Die Reststoffe aus den Bioraffinerien werden noch für die Energienutzung verwendet, z.B. in Biogasanlagen. Letztlich müssen Reststoffe, üblicherweise Schlämme, als Dünger auf die Felder zurückgeführt werden. Transportdistanzen sind also ein wesentlicher Faktor und ab einer gewissen Entfernung der bestimmende Faktor für die Umweltfolgen im Lebenszyklus (Stöglehner und Narodoslawsky 2009).

Für jede technische Anlage gilt - auch in der Biomasseverarbeitung: Je größer eine Anlage ist, desto ökonomisch effizienter kann sie normalerweise betrieben werden (Skaleneffekte, „economies of scale"). Wird nun das Problem der Transportdistanzen berücksichtigt, sind geringere Entfernungen, d.h. mittlere Anlagen mit kleineren Einzugsgebieten, von Vorteil. Es ist also eine „ecology of scale“ mitzuberücksichtigen. Um diese Aspekte zu verknüpfen, sind Anlagen mit mittleren Produktionskapazitäten und geringeren Einzugsradien von Vorteil (Gwehenberger et al. 2007).

Dieses Beispiel zeigt, dass für eine nachhaltige Entwicklung das Konzept einer regionalisierten Bioökonomie zu bevorzugen ist. Dabei werden Ressourcenströme durch gestreute Schwerpunktbildungen organisiert, wie sie die Raumplanung z.B. im Leitbild der dezentralen Konzentration kennt. Bei der Planung solcher Schwerpunkte 
sind nicht nur Transportdistanzen zwischen Feld und Weiterverarbeitung und weiter zu Zentren der industriellen Produktion zu berücksichtigen, sondern auch Standortfaktoren wie die Einspeisung von Biogas in Gasnetze, die Weiterleitung von Überschusswärme in Fernwärmenetze, der Bezug und die Abgabe von Elektrizität, die Gewinnung von Energie in Kraft-Wärme-Kopplungen etc. (vgl. Stöglehner et al. 2011). All diese Faktoren machen die Ansiedlung von Weiterverarbeitungsanlagen (z.B. Bioraffinerien) in der Nähe von Infrastrukturknoten sinnvoll, wo sie in funktionsgemischte, kompakte räumliche Strukturen mit einer gewissen Mindestdichte eingebettet werden können. Daher argumentieren Stöglehner et al. (2011, 2016), dass Kleinstädte zu Energie- und Ressourcenknoten in einer dezentralen Industriegesellschaft entwickelt werden können, von denen Impulse für den ländlichen Raum ausgehen. Sie übernehmen so wesentliche Aufgaben in der räumlichen Organisation der Energie- und Ressourcenwende.

\subsubsection{Schlussbemerkung}

Die Organisation des Raumes bestimmt die Möglichkeiten, die Energie- und Ressourcenwende im Sinne einer Bioökonomie zu gestalten. Durch die Raum- und Siedlungsstrukturen werden Energie- und Ressourcenverbrauch beeinflusst, gleichzeitig aber auch räumliche Voraussetzungen für die Gewinnung erneuerbarer Energieträger und Ressourcen geschaffen. Raumplanung eröffnet auch Optionen, die Maßnahmen für die Energie- und Ressourcenwende zu steuern, um Nutzungskonflikte im Raum zu vermeiden bzw. zu verringern, die bei einer Maßnahmenumsetzung hinderlich sein können. Dies betrifft sowohl die Sicherung von Ressourcenbereitstellungsflächen als auch die Positionierung von Anlagen der Ressourcenverarbeitung. In diesem Sinne lohnt es sich, die Energie- und Ressourcenwende im Kontext der Bioökonomie auch aus der raumplanerischen Perspektive zu betrachten.

\section{Literatur}

Abart-Heriszt, L. und Stöglehner, G. (2019): Das Sachbereichskonzept Energie. Ein Beitrag zum Örtlichen Entwicklungskonzept. Leitfaden. Version 2.0. Graz: Amt der Steiermärkischen Landesregierung, Abteilung 13, 15 und 17. Verfügbar in:

https://www.verwaltung.steiermark.at/cms/beitrag/12663031/144381826/ [Abfrage am 27.5.2019].

BMNT und BMVIT (Bundesministerium für Nachhaltigkeit und Tourismus; Bundesministerium für Verkehr, Innovation und Technologie) (Hrsg.) (2018): \#mission2030: Die österreichische Klima- und Energiestrategie. Wien. Verfügbar in: https://mission2030.info/ [Abfrage am 27.5.2019].

BMVI (Bundesministerium für Verkehr und digitale Infrastruktur) (Hrsg.) (2018): Verkehr in Zahlen 2018/2019. 47. Jahrgang. Verfügbar in: https://www.bmvi.de/SharedDocs/DE/Publikationen/G/verkehr-in-zahlen 2018pdf.html?nn=13190 [Abfrage am 23.5.2019].

Dallhammer, E. (2016): Flächen- und kostenintensive Siedlungsentwicklung: Folgen und Lösungsansätze. In: Köck, P., Hrsg., Baulandmobilisierung und Flächenmanagement. SIR-Mitteilungen und Berichte, Band 36/2016. Salzburg: Salzburger Institut für Raumordnung \& Wohnen (SIR), 19- 
28. Verfügbar in: https://www.salzburg.gv.at/bauenwohnen/Seiten/sir-pub-start mb.aspx [Abfrage am 27.5.2019].

Essl, F., Moser, D., Mildren, A., Gattringer, I., Banko, G. und Stejskal-Tiefenbach, M. (2018): Naturschutzfachlich wertvolle Lebensräume und Baulandwidmung in Österreich: Analyse des Konfliktpotenzials. Wien: Umweltbundesamt. Verfügbar in: https://www.umweltbundesamt.at/aktuell/publikationen/publikationssuche/publikations detail/?pub id=2275 [Abfrage am 27.5.2019].

Eurostat (2019a): Bevölkerung am 1. Januar. https://ec.europa.eu/eurostat/tgm/table.do?tab=table\&init=1\&plugin=1\&language=de\& pcode=tps00001 [Abfrage am 23.5.2019].

Eurostat (2019b): Länge der übrigen Straßen nach Straßenkategorien [road_if_roadsc]. http://appsso.eurostat.ec.europa.eu/nui/show.do?dataset=road if ${ }^{-}$roadsc\&lang=de [Abfrage am 23.5.2019].

Fürst, D. und Scholles, F. (Hrsg.) (2008): Handbuch Theorien und Methoden der Raum- und Umweltplanung. Dortmund: Rohn.

GfK (GfK Geomarketing GmbH) (ed.) (2018): European retail in 2018: GfK study on key retail indicators: 2017 review and 2018 forecast. Bruchsal. Available at: https://geodaten.gfk.com/en/landingpages/download-european-retail-study/ [accessed 27.5.2019].

Gwehenberger, G., Narodoslawsky, M., Liebmann, B., and Friedl, A. (2007): Ecology of scale versus economy of scale of bioethanol production. Biofuels, Bioproducts \& Biorefining, 1, 4, 264269. https://doi.org/10.1002/bbb.35.

Hägermann, D. (Hrsg.) (2005): Das Mittelalter: Die Welt der Bauern, Bürger, Ritter und Mönche. Wien: Tosa-Verlag.

Healey, P. (1992): Planning through debate: The communicative turn in planning theory. The Town Planning Review, 63, 2, 143-162. https://www.jstor.org/stable/40113141.

IMF (2019): International Monetary Fund. World Economic Outlook (April 2019) - GDP per capita, current prices.

https://www.imf.org/external/datamapper/NGDPDPC@WEO/OEMDC/ADVEC/WEOWORLD [Abfrage am 27.5.2019].

Jabareen, Y. R. (2006): Sustainable urban forms: Their typologies, models and concepts. Journal of Planning Education and Research, 26, 1, 38-52. https://doi.org/10.1177/0739456X05285119.

Krausmann, F. (1998): Von der Erhaltung der Bodenfruchtbarkeit zur Steigerung der Erträge. In: Dirlinger, H., Fliegenschnee, M., Krausmann, F., Liska, G. und Schmidt, M. A. (Hrsg.): Bodenfruchtbarkeit und Schädlinge im Kontext von Agrargesellschaften. Social Ecology Working Paper 51. Wien: IFF, Abteilung Soziale Ökologie. 5-26. Verfügbar in:

https://boku.ac.at/wiso/sec/publikationen/social-ecology-working-papers [Abfrage am 27.5.2019].

Land Steiermark (Amt der Steiermärkischen Landesregierung) (2019): Digitaler Atlas der Steiermark. Verfügbar in: http://www.landesentwicklung.steiermark.at/cms/ziel/141979637/DE/ [Abfrage am 20.7.2019].

Lawrence, D. P. (2000): Planning theories and environmental impact assessment. Environmental Impact Assessment Review, 20, 6, 607-625. https://doi.org/10.1016/S0195-9255(00)00036-6.

LEP SBG (2003): Verordnung der Salzburger Landesregierung vom 30. September 2003 zur Verbindlicherklärung des Landesentwicklungsprogramms. LGBI. Nr. 94/2003.

Lutter, S. und Giljum, S. (2009): Ökologische Wachstumsgrenzen: Die Notwendigkeit eines Systemwechsels im Umgang mit natürlichen Ressourcen. Wissenschaft \& Umwelt Interdisziplinär, $13,12-21$.

Mäding, H. (2009): Raumplanung in der sozialen Marktwirtschaft. Freiburger Diskussionspapiere zur Ordnungsökonomik No. 09/7. Freiburg i.Br.: Albert-Ludwigs-Universität, Freiburg, Institut für Allgemeine Wirtschaftsforschung, Abteilung für Wirtschaftspolitik. Verfügbar in: http://hdl.handle.net/10419/36469 [Abfrage am 27.5.2019].

Meadows, D. H., Zahn, E., Milling, P. und Heck, H.-D. (1972): Die Grenzen des Wachstums: Bericht des Club of Rome zur Lage der Menschheit. Stuttgart: Deutsche Verlagsanstalt.

Oö. ROG (1994): Landesgesetz vom 6. Oktober 1993 über die Raumordnung im Land Oberösterreich (Ö̈. Raumordnungsgesetz 1994). LGBI. Nr. 114/1993 i.d.F. LGBI. Nr. 69/2015. 
Reicher, C. (2014): Städtebauliches Entwerfen. Wiesbaden: Springer Fachmedien Wiesbaden.

Schirmacher, E. (1988): Stadtvorstellungen: Die Gestalt der mittelalterlichen Städte - Erhaltung und planendes Handeln. Zürich, München: Artemis-Verlag.

Schwackhöfer, W. (1988): Raumordnung und Landwirtschaft in Österreich: Regional coordination and agriculture in Austria. Wien: Österreichischer Agrarverlag.

Statistik Austria (Hrsg.) (2019a): Abfrage der Wohnungen mit Hauptwohnsitzangabe. STATcube. Statistische Datenbank. Verfügbar in: http://statcube.at/statistik.at/ext/statcube/jsf/tableView/tableView.xhtml [Abfrage am 24.5.2019].

Statistik Austria (Hrsg.) (2019b): Pkw, Lkw und Zweiräder - Bestand 1960 bis 2018: Absolut und Anteile. Verfügbar in:

https://www.statistik.at/web de/statistiken/energie umwelt innovation mobilitaet/verkehr/ strasse/kraftfahrzeuge - bestand/index.html [Abfrage am 24.5.2019].

Statistik Austria (Hrsg.) (2019c): Wohnungsgröße von Hauptwohnsitzwohnungen nach Bundesland (Zeitreihe). Verfügbar in:

https://www.statistik.at/web de/statistiken/menschen und gesellschaft/wohnen/wohn situation/index.html [Abfrage am 24.5.2019].

StLREG (2018): Gesetz vom 14. November 2017, mit dem das Gesetz zur Landes- und Regionalentwicklung in der Steiermark (Steiermärkisches Landes- und Regionalentwicklungsgesetz 2018) erlassen wird. LGBI. Nr. 117/2017.

Stoeglehner, G. (2010): Enhancing SEA effectiveness: lessons learnt from Austrian experiences in spatial planning. Impact Assessment and Project Appraisal, 28, 3, 217-231. https://doi.org/10.3152/146155110X12772982841168.

Stoeglehner, G. (2018): Spatial dimensions of a regionalized bioeconomy. Influence of the bioeconomy on spatial development of territories, Kiew, Sept 14-15, 2018. In: Ministry of Education and Science of Ukraine, National University of Life and Environmental Sciences of Ukraine, eds., Influence of the Bioeconomy on Spatial Development of Territories. 18-19.

Stoeglehner, G and Narodoslawsky, M. (2009): How sustainable are biofuels? Answers and further questions arising from an ecological footprint perspective. Bioressource Technology, 100, 3825-3830. https://doi.org/10.1016/j.biortech.2009.01.059.

Stöglehner, G., Niemetz, N., and Kettl, K.-H. (2011): Spatial dimensions of sustainable energy systems: new visions for integrated spatial and energy planning. Energy, Sustainability and Society, 1, 1-9. https://doi.org/10.1186/2192-0567-1-2.

Stöglehner, G., Erker, S. und Neugebauer, G. (2014): Energieraumplanung. Materialienband. In Zusammenarbeit mit der ÖREK-Partnerschaft "Energieraumplanung". Schriftenreihe der Österreichischen Raumordnungskonferenz (ÖROK), Band 192, Wien: ÖROK.

Stoeglehner, G., Neugebauer, G., Erker, S., and Narodoslawsky, M. (2016): Integrated Spatial and Energy Planning: Supporting Climate Protection and the Energy Turn with Means of Spatial Planning. Springer.

Umweltbundesamt (Hrsg.) (2019a): Flächeninanspruchnahme in Österreich 2018. Wien. Verfügbar in: https://www.umweltbundesamt.at/umweltsituation/raumordnung/rp flaecheninanspruch nahme/ [Abfrage am 24.5.2019].

Umweltbundesamt (Hrsg.) (2019b): Treibhausgas-Bilanz 2017: Daten, Trends \& Ausblick. Wien. Verfügbar in: https://www.umweltbundesamt.at/news 190129/ [Abfrage am 24.5.2019].

UN (United Nations) (Hrsg.) (1992): Agenda 21: Konferenz der Vereinten Nationen für Umwelt und Entwicklung. Rio de Janeiro. Verfügbar in:

https://www.un.org/Depts/german/conf/agenda21/agenda 21.pdf [Abfrage am 24.5.2019].

WKO (Wirtschaftskammer Österreich) (2019): WKO Statistik, BIP pro Kopf. Verfügbar in: https://www.wko.at/service/zahlen-daten-fakten/BIP.html [Abfrage am 16.5.2019].

Zapf, K. (2005): Soziale Infrastruktur. In: Akademie für Raumforschung und Landesplanung (ARL), Hrsg., Handwörterbuch der Raumordnung. Ritter, Ernst-Hasso (Red.L.), Hannover. 1025-1031. 
Open Access Dieses Kapitel wird unter der Creative Commons Namensnennung - Nicht kommerziell 4.0 International Lizenz (http://creativecommons.org/licenses/by-nc/4.0/deed.de)veröffentlicht, welche die nicht-kommerzielle Nutzung, Vervielfältigung, Bearbeitung, Verbreitung und Wiedergabe in jeglichem Medium und Format erlaubt, sofern Sie den/die ursprünglichen Autor(en) und die Quelle ordnungsgemäß nennen, einen Link zur Creative Commons Lizenz beifügen und angeben, ob Änderungen vorgenommen wurden.

Die in diesem Kapitel enthaltenen Bilder und sonstiges Drittmaterial unterliegen ebenfalls der genannten Creative Commons Lizenz, sofern sich aus der Abbildungslegende nichts anderes ergibt. Sofern das betreffende Material nicht unter der genannten Creative Commons Lizenz steht und die betreffende Handlung nicht nach gesetzlichen Vorschriften erlaubt ist, ist auch für die oben aufgeführten nicht-kommerziellen Weiterverwendungen des Materials die Einwilligung des jeweiligen Rechteinhabers einzuholen.

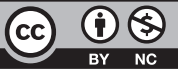

